NBER WORKING PAPER SERIES

MORAL HAZARD, WILDFIRES, AND THE ECONOMIC INCIDENCE OF NATURAL
DISASTERS
Patrick Baylis
Judson Boomhower
Working Paper 26550
http://www.nber.org/papers/w26550

\author{
NATIONAL BUREAU OF ECONOMIC RESEARCH \\ 1050 Massachusetts Avenue \\ Cambridge, MA 02138 \\ December 2019
}

The authors gratefully acknowledge research support from the Stanford Institute for Economic Policy Research (Boomhower), the Stanford Center on Food Security and the Environment (Baylis), and the Giannini Foundation. We are grateful to seminar participants at the NBER Summer Institute, the AERE Summer Conference, the UC Santa Barbara Occasional Workshop, WEAI, ASSA, Arizona State University, University of British Columbia, UC Berkeley, UC San Diego, University of Illinois, Indiana University, Nova School of Business and Economics, University of Ottawa, University of Pennsylvania (Wharton), University of Southern California, Stanford University, and University of Victoria. We also extend our thanks to Laura Bakkensen, Severin Borenstein, Marshall Burke, Richard Carson, Brian Copeland, Marc Conte, Lucas Davis, Joshua Gottlieb, Larry Goulder, Mark Jacobsen, Lee Lockwood, Jim Stock, and Matthew Wibbenmeyer. The views expressed herein are those of the authors and do not necessarily reflect the views of the National Bureau of Economic Research.

NBER working papers are circulated for discussion and comment purposes. They have not been peer-reviewed or been subject to the review by the NBER Board of Directors that accompanies official NBER publications.

(C) 2019 by Patrick Baylis and Judson Boomhower. All rights reserved. Short sections of text, not to exceed two paragraphs, may be quoted without explicit permission provided that full credit, including $\odot$ notice, is given to the source. 
Moral Hazard, Wildfires, and the Economic Incidence of Natural Disasters

Patrick Baylis and Judson Boomhower

NBER Working Paper No. 26550

December 2019

JEL No. H22,H23,Q54,Q58

\begin{abstract}
$\underline{\text { ABSTRACT }}$
This study measures the degree to which large public expenditures on wildfire protection subsidize development in harm's way. Using administrative firefighting data, we calculate geographically-differentiated implicit subsidies to homeowners throughout the western USA. We first examine how the presence of homes affects firefighting expenditures. These results are used to reconstruct the implied historical cost of protecting each home and to perform an actuarial calculation of expected future protection cost. The expected net present value of this subsidy can exceed $20 \%$ of a home's value. It increases with fire risk and decreases surprisingly steeply with development density. A simple model is used to explore effects on expansion of developed areas, density, and private risk-reducing investments. These results demonstrate how policy and institutions influence the costs imposed by a changing climate.
\end{abstract}

\author{
Patrick Baylis \\ 6000 Iona Dr \\ Vancouver School of Economics \\ Vancouver, BC V6T 2E8 \\ Canada \\ pbaylis@mail.ubc.ca \\ Judson Boomhower \\ Department of Economics \\ University of California at San Diego \\ 9500 Gilman Drive \#0508 \\ La Jolla, CA 92093 \\ and NBER \\ jboomhower@ucsd.edu
}


Driven by climate change, land use decisions, and other factors, annual wildland firefighting costs for the US federal government have more than doubled in real terms over the past 30 years and are expected to keep growing. ${ }^{1}$ During the fire season, tens of thousands of firefighters and many millions of dollars worth of equipment are continuously dispatched throughout the United States, often with the goal of preventing damage to private homes. As we show, these costly efforts to avoid property damage represent a large share of the total cost imposed by wildfires. While much of the cost of defending threatened homes is borne by the federal and state governments, decisions about where and how to build these homes are largely made by localities and individual homeowners.

This apparent misalignment of incentives has historical roots. Fire protection in US cities has long been provided by local governments, but fire management for the forests and grasslands that cover the rest of the western US is the job of federal or state land management agencies, especially the US Forest Service (USFS). In recent decades, rapid development outside cities has added many homes near these wildland areas, in the so-called "wildland-urban interface" (WUI) (Radeloff et al. 2018). Compared to cities, fire risk in the WUI is higher on average and more spatially differentiated. Predictably high-risk portions of this landscape - based on topography, vegetation, and climate - experience repeated, costly fires.

The combination of public fire protection and spatially heterogeneous risk has two important implications. First, because the federal government bears much of the cost, wildland firefighting represents a transfer of wealth to homeowners in highrisk locations. Second, the guarantee of federal protection generates moral hazard. Homeowners do not internalize the expected costs of future fire protection when choosing where to live or how to design and maintain their homes. Perhaps just as importantly, local governments do not internalize these costs in zoning, land use, and building code decisions.

Firefighting costs represent a major component of the total social cost imposed by wildfires. Wildfires are unusual among natural hazards in that it is feasible to prevent property damage during an incident through large investments of manpower and equipment. Unlike cyclones or earthquakes, for example, wildfires can often be stopped in place to protect homes and other valuable assets. During 1985-2017,

1. National Interagency Fire Center, "Federal Firefighting Costs (Suppression Only)", 2017. 
total wildfire property damages in the United States were $\$ 51$ billion, while direct firefighting costs for federal agencies alone totaled $\$ 43$ billion. ${ }^{2}$ Public spending on floods, cyclones, and other disasters comes largely in the form of rebuilding grants or insurance subsidies to individual households. Identifying the beneficiaries of such spending is comparatively straightforward. Because wildfire spending comes instead through firefighting expenditures, understanding the beneficiaries of that spending requires a more involved analysis that has not previously been undertaken.

In this paper, we consider the interaction between local development decisions and federal and state protection spending. We provide the first estimates of the geographicallydifferentiated implicit transfer to homeowners due to fire protection at the individual parcel level for homes throughout the western United States. To do so, we combine parcel-level data on the universe of homes in the West with administrative data on historical firefighting expenditures to estimate federal government expenditures dedicated to protecting each home from wildfires. We assemble the firefighting cost data from the administrative records of six different federal and state agencies, which we obtained through multiple Freedom of Information Act and public records requests. This yields the most comprehensive dataset on wildland firefighting expenditures in existence. Our empirical approach takes advantage of variation in ignition locations to measure how incident-level firefighting expenditures increase when homes are built in harm's way. We then use these estimates to construct an actuarial measure of the expected additional future cost to the government to protect each home from wildfires. Using a simple theoretical framework, we show how these per capita protection costs can be interpreted as the minimum amount by which residents' average willingness to pay to live in a WUI location must exceed housing costs and insurance premiums in order for new development in a given location to be welfare-improving.

We find that residential development dramatically increases firefighting costs. Efforts to protect private homes appear to account for the majority of wildland firefighting expenditures. Perhaps more surprisingly, once development reaches a relatively

2. The five most damaging fires during this time period accounted for $55 \%$ of all property losses (including the 2017 "Wine Country" fires in Northern California that caused $\$ 13$ billion in losses). Unofficial estimates for the 2018 Camp Fire in Northern California project damages of about $\$ 16$ billion. Damage data are from Munich RE NatCatService and are overall losses (insured and uninsured) for wildfires and heat waves in the United States. Firefighting costs are from National Interagency Fire Center (2017), "Federal Firefighting Costs (Suppression Only)". All dollar amounts in the paper are in 2017 dollars. 
low density threshold, further increases in the number or total value of threatened homes have little effect on firefighting costs. The difference in response costs between a fire threatening dozens of homes and a fire threatening several hundred or even several thousand homes is strikingly small. This non-rival aspect of fire protection means that development density is an important determinant of per-home protection cost. Overall, we find that firefighting represents a large transfer to a few landowners in high-risk, low-density places. In our highest risk categories, the net present value (NPV) of fire protection costs exceeds $20 \%$ of the transaction value of the property.

These implicit subsidies imply potentially significant efficiency costs. We discuss possible distortions along three margins. The first is the location of new residential development. Because new development is relatively price-elastic in regions with high fire protection costs, there may be substantial excess development in high-cost areas. We provide back-of-the-envelope estimates for this expansion of the WUI footprint. Second, providing fire protection for free reduces incentives to capitalize on the economies of density that we measure, effectively subsidizing large lot sizes and low-density development. To the extent that sprawl also results from other preexisting market failures, this subsidy exacerbates those inefficiencies. Finally, freely provided fire protection could affect the design and maintenance of WUI homes. The promise of aggressive firefighting at no cost may reduce private incentives to choose fire-proof building materials and clear brush around homes, actions that can decrease the threat to homes during a wildfire. Similarly, federally financed firefighting limits incentives for cities and states to create and enforce wildland building codes and defensible space regulations.

The significance of these distortions is likely to increase as the climate changes and new development proceeds in wildland areas. Foresters predict considerable new construction over the next several decades in fire-prone locations throughout the West that currently have no or very little development (Gude, Rasker, and Noort 2008). Mann et al. (2014) forecasts that land use changes in California through 2050 will be dominated by the conversion of undeveloped or sparsely developed areas to low- and medium-density housing use. Much of this new development is predicted to occur in areas that the state has designated as "very high" wildfire risk zones. At the same time, climate change is predicted to make wildfires more frequent and more 
severe.

One way to mitigate these distortions is to adopt policies that lead individuals and localities to internalize a larger share of the firefighting costs imposed by new construction in currently undeveloped areas. We discuss how the empirical approach that we develop can be used to calculate a differentiated fire protection fee for this purpose.

From a fiscal perspective, our results imply that wildland firefighting is a previously unappreciated mechanism for redistribution to particular geographic areas. For example, we find that the annual implicit subsidies to homeowners in Montana and Idaho via firefighting are larger than federal transfers to those states under the Temporary Assistance to Needy Families program (TANF). ${ }^{3}$ Contrary to conventional wisdom (e.g., Davis 1995), we do not find that federal fire protection spending is regressive. This is because fire protection costs are highest in rural and ex-urban parts of the West where incomes and land values are generally low.

More broadly, this study underscores the importance of institutions in responding to the impacts of climate change. The growing literature on climate adaptation has tended to emphasize private responses (e.g., Barreca et al. 2016; Burke and Emerick 2016; Auffhammer 2018). But many important adaptive responses to climate change are likely to occur through government investments in public goods like infrastructure, national security, scientific research, public health, and emergency response. This study's results are a reminder that these large public investments will confront pressing economic questions about moral hazard, distributional impacts, and allocative efficiency.

Our setting has some particular parallels to flood risk. Economists have studied behavioral responses to subsidized federal flood insurance and ex post rebuilding assistance (Kousky, Luttmer, and Zeckhauser 2006; Smith et al. 2006; Boustan, Kahn, and Rhode 2012; Deryugina 2017; Gregory 2017). Several of these studies find that such policies encourage rebuilding in high-risk areas after losses, which is also an issue for fires. However, development in high fire risk areas includes substantial new construction, including in undeveloped areas (Radeloff et al. 2005). Construction in

3. Federal TANF expenditures in FY2016 were $\$ 32$ million for Montana and $\$ 26$ million for Idaho. US Department of Health and Human Services, Office of Family Assistance, "TANF Financial Data - FY 2016", published February 2018. See sheet C.1. 
new areas is likely to be more price-elastic than rebuilding in an existing location, implying potentially larger responses to subsidies. In addition, one home's expected losses in a flood (and thus, the value of insurance subsidies) do not usually depend on the number of nearby homes, while we show that the per capita costs of protecting a home from wildfire depend strongly on density.

This paper makes several contributions. Introducing administrative data on firefighting expenditures allows us to provide the first quantitative estimates of the spatially differentiated implicit subsidy, and thus the optimal "fire protection fee" for every home in the western United States. Researchers and policymakers have long suspected that federal firefighting affects local incentives, but ours is the first study to measure these subsidies. ${ }^{4}$ We also present novel evidence of a non-linear response of firefighting costs to the number of threatened homes, with important implications for the effect of freely provided firefighting on development density. From a methodological perspective, the introduction of parcel-level data on 18 million western homes allows us to be geographically precise about risks and costs relative to existing work on wildfires that relies on spatially coarse aggregate data. This specificity represents a valuable advance since fire and other disaster risks can vary substantially over small distances. Finally, we embed our empirical results in a simple economic model that demonstrates the economic and policy implications of the subsidies that we measure.

The paper is organized as follows: Section 1 provides an overview of wildland fire institutions and explains how they motivate our empirical approach. Section 2 establishes the economic context for our empirical analysis through a simple conceptual framework, and Section 3 discusses the data. Section 4 measures the cost of saving homes during wildfires, Section 5 calculates implicit subsidies to homeowners, Section 6 considers efficiency costs along with policies to internalize fire protection costs, and Section 7 concludes.

4. Examples of many academic studies that speculate about the importance of moral hazard in this setting include Davis (1995), Loomis (2004), Stetler, Venn, and Calkin (2010), Lueck and Yoder (2016), Simon (2017), and Wibbenmeyer (2017). Policy examples include US Department of Interior and Department of Agriculture. 1995. "Federal Wildland Fire Management Policy \& Program Review"; California Legislative Analyst's Office. 2005. "A Primer: California's Wildland Fire Protection System"; and USDA (2006). 


\section{Wildland Firefighting in the United States}

Wildland firefighting in the United States is provided by a patchwork of federal, state, and local government agencies. Broadly speaking, financial and operational responsibility for a wildfire is determined by its ignition location and the area affected (Hoover and Lindsay 2017). For fires on national forest land, for example, primary responsibility rests with the USFS. A handful of federal government agencies manage large amounts of public land and thus oversee significant firefighting activity. These include USFS, the Bureau of Land Management, the National Park Service, the Bureau of Indian Affairs, and the Fish and Wildlife Service. States are responsible for incidents on state lands and private unincorporated areas. The largest state fire service is the California Department of Forestry and Fire Protection (Cal Fire), which is responsible for large areas of mostly private land in California. Incidents within cities are initially the responsibility of local fire departments. When fires affect multiple jurisdictions, responsibility is apportioned by law and by cooperative agreements. ${ }^{5}$ Regardless of the managing agency, large incidents feature aid and cooperation across many different jurisdictions.

Many large wildfires begin on lands where federal or sometimes state agencies bear financial responsibility for firefighting. The federal government also bears a portion of costs incurred by state and local governments through the FEMA Fire Management Assistance Grant (FMAG) program. This program reimburses $75 \%$ of state and local firefighting costs for qualifying large fires. Thus, both through direct expenditures and indirect support, the federal government absorbs a large share of wildland firefighting expenses.

Existing case studies indicate that firefighting costs are disproportionately driven by structures, as opposed to other goals like saving lives or protecting natural resources. It requires significantly more manpower and equipment (e.g., air support, bulldozers) to stop a fire in place before it reaches homes, as opposed to letting it burn to a road, ridge, or other barrier. Interviews with Forest Service managers suggest that 50 to 95 percent of federal firefighting costs come from efforts to prevent damage to homes (USDA 2006). Case studies of small samples of fires have found statistical results in line with these estimates (Gebert, Calkin, and Yoder 2007; Liang et al. 2008; Gude et

5. An example is the California Master Cooperative Wildland Fire Management and Stafford Act Response Agreement, which includes California and 5 federal agencies. 
al. 2013). Wibbenmeyer (2017) shows that fire perimeters coincide closely with areas of changing population and housing density, implying that fire managers frequently stop fires just before they reach more developed areas. ${ }^{6}$

The overall increase in wildland firefighting costs over the past several decades has been attributed to three factors: increased human habitation, climate change, and the buildup of increasingly dangerous fuel loads. Numerous descriptive studies in forestry and urban planning document widespread, ongoing housing construction in high risk areas (Radeloff et al. 2005; Hammer, Stewart, and Radeloff 2009; Martinuzzi et al. 2015; Radeloff et al. 2018). At the same time, changes in climate have affected the amount and combustibility of fuel available for fires (Abatzoglou and Williams 2016). Past fire suppression has also altered the type and extent of fuels in the western United States (Stephens et al. 2016). Many scientists argue that more prescribed and managed fires would reduce the risk of dangerous wildfires and lower overall expenditures on fire management. Efforts to implement these recommendations have proven politically unpopular and have met with limited success. Prescribed fire is particularly difficult to use in areas with private homes because of concerns about threats to structures.

\subsection{Potential Market Failures}

The complexity of the wildfire problem introduces a number of potential inefficiencies. There may be spillovers in protection benefits between adjacent landowners, dynamic tradeoffs of firefighting today with fuel loads tomorrow, and political economy considerations in fire management. ${ }^{7}$ Home prices in wildland areas decrease after nearby fires or wildfire information campaigns, suggesting this risk is imperfectly salient (Loomis 2004; Donovan, Champ, and Butry 2007; McCoy and Walsh 2018). Such inattentiveness to private wildfire costs may affect individuals' location and maintenance decisions by reducing perceived private costs in high-risk areas.

Our study addresses the external costs of individuals' decisions. The effects of this externality do not depend on whether homeowners accurately perceive protection costs.

6. This last study also reports that firefighting costs sometimes exceed the value of structures that would have burned according to a simulation model. This could imply inefficient firefighting dispatch, or it could mean that managers also consider values like natural resources, contents of homes, and catastrophic losses if the fire exceeds the forecast area.

7. See Lueck and Yoder (2016) for a review of economic issues in wildland fire. 
Beliefs about fire protection costs do not enter individual decisions when protection is not priced. ${ }^{8}$ Moreover, if wildfire protection were to be priced via an up-front corrective tax on new construction (as we discuss in Section 6.2), the cost would presumably be highly salient.

Economists and policymakers have long believed that the particular market failure we study is important (see citations in Footnote 4). The USDA Inspector General wrote in 2006 that, "Assigning the financial responsibility for WUI wildfire protection to state and local government is critical because federal agencies do not have the power to regulate WUI development" and "Homeowner reliance on the federal government to provide wildfire suppression services... removes incentives for landowners moving into the WUI to take responsibility for their own protection and ensure their homes are constructed and landscaped in ways that reduce wildfire risks" (USDA 2006).

\subsection{Implications for Measurement}

The empirical portion of this paper uses administrative expenditure data along with plausibly-exogenous variation in ignition locations to estimate the amount of money that is spent to protect homes from wildfires. This approach quantifies the spatiallyvarying implicit subsidy to homeowners, a parameter that is directly useful for economic and policy analysis. Combined with existing estimates of supply and demand for new construction, our estimates can be used to calculate expected quantity changes relative to optimal pricing of fire protection, and the resulting deadweight loss. Our estimates also directly reveal the fiscal and distributional consequences of federal firefighting policy.

An alternative empirical approach would be to directly measure changes in construction and home prices in response to policy differences over time or space. Our approach has several advantages over this alternative. First, existing firefighting policies provide little credible identifying variation. We are not aware of any part of the US where no effort is made to protect homes during a wildfire. Existing policies generate only small, difficult-to-interpret differences in perceived protection. ${ }^{9}$ Given the

8. Similarly, a polluting firm's output does not depend on whether the firm knows the external costs of pollution, since it only considers private costs.

9. Even in the few remote areas with no local fire service ("no man's land"), neighboring jurisdictions may help when wildfires threaten homes. Furthermore, firefighting responsibility depends on the ignition location (frequently federal lands), not just the home's location. 
evidence that wildfire risk is imperfectly salient, it seems unlikely that home buyers correctly perceive small differences in the risk of property damage when firefighting rules shift. Moreover, responses to these policy differences have limited applicability to our research question. Since our focus is on the effects of providing fire protection for free, the welfare-relevant counterfactual is a scenario where homeowners or local governments internalize this cost (for example, through a tax at the time of construction that equals expected future protection costs). The response to a transparent up-front tax would presumably be different than responses to the opaque subtleties of firefighting dispatch rules. One final advantage of our approach is that the resulting estimates are calculated for the entire Western US, as opposed to a particular policy change or boundary. ${ }^{10}$

\section{Conceptual framework}

This section develops the stylized economic model that guides the empirical analysis. Sections 2.1 and 2.2 introduce the model. Section 2.3 shows how behavioral responses depend on average protection costs and marginal protection costs, yielding a plan for the empirical analysis.

\subsection{Setup}

There are $N$ households indexed by $i$ that choose one of two locations: "safe" or "risky". Each household weighs its (household-specific) benefit from each location against the location-specific cost of living, which includes the expected cost of a stochastic natural hazard (e.g., wildfire) and the price of housing (a locally-produced non-tradable good). We impose several stylized assumptions commonly used in the literature to simplify exposition and focus on our research question. Households supply a single unit of labor inelastically at a fixed wage and consume a single unit of housing at the local price. Housing is supplied in a competitive market. The risky and safe locations also vary in other (exogenous) amenities valued by households (e.g., outdoor recreation). Each household's willingness to pay (WTP) to live in the risky place instead of the safe reservation location (not including disaster costs) is $\theta_{i}$. We adopt a static framework in which development in the risky place happens all at

10. We see research that leverages variation in protection policy in special instances where it exists as a potential complement to our approach. The one relevant paper that we are aware of is a 2012 working paper that studies construction near public lands after the 1988 Yellowstone fires changed federal firefighting policies (Kousky and Olmstead 2012). 
once.

The probabilities of a natural disaster in the risky and safe locations are $\phi$ and 0 , respectively. During a disaster, the central government chooses an amount of defensive expenditures, $f$ (e.g. firefighting effort in our empirical application). These expenditures affect the expected property damages to each individual risky place resident, $H(f)$. Defensive expenditures reduce expected damages and do so with diminishing returns: $H^{\prime}(f)<0$ and $H^{\prime \prime}(f)>0$. The optimal response $f^{*}$ minimizes the sum of defensive expenditures and total property damage, $f+n_{r} H(f)$, where $n_{r}$ is population in the risky place. ${ }^{11}$ Thus, the function $f^{*}\left(n_{r}\right)$ defines the optimal response for a given population in the risky place. Henceforth we drop the ${ }^{*}$ and write $f\left(n_{r}\right)$.

\subsection{The Market for Housing in the Risky Place}

First, consider how the financing of defensive expenditures affects population in the risky place. One intuitive benchmark is a policy that requires households to reimburse the central government for their per capita share of defensive expenditures after a disaster. ${ }^{12}$ In the absence of a disaster, realized household benefit from living in the risky place is $\theta_{i}$. If a disaster occurs, realized household benefit in the risky place is $\theta_{i}-\frac{f\left(n_{r}\right)}{n_{r}}-H\left(f\left(n_{r}\right)\right)$. The last two terms represent per capita disaster-related cost. This per capita disaster-related cost shrinks as local population increases. ${ }^{13}$ Assuming risk-averse households and perfectly competitive insurance markets, households in the risky place will purchase full insurance covering property losses and defensive expenditures. Premiums will equal expected losses, $\phi\left[\frac{f\left(n_{r}\right)}{n_{r}}+H\left(f\left(n_{r}\right)\right)\right]$. Thus, the expected benefit of choosing to live in the risky location is $\theta_{i}-\phi\left[\frac{f\left(n_{r}\right)}{n_{r}}+H\left(f\left(n_{r}\right)\right)\right]$.

Compare this to an alternative policy where the central government does not require reimbursement for defensive expenditures. The expected disaster costs borne by households (and thus the households' insurance premiums) include only expected property damages, $\phi H\left(f\left(n_{r}\right)\right)$. Accordingly, private net benefits from locating in

11. This rule mimics the principle of "least cost plus net value change" in the natural resources literature on fire suppression.

12. An alternative assumption would be that local governments reimburse the central government (or even self-supply defensive expenditures) and recover these costs through local taxes. These local taxes would reduce private utility from choosing the risky place.

13. This result comes from the envelope theorem, noting that $f\left(n_{r}\right)$ is chosen to minimize disaster costs. The proof is in Appendix Section A.3. 
the risky place are higher. The externalized costs of defensive expenditures are assumed to be borne equally by all households regardless of location through a constant budget-balancing tax equal to $\frac{1}{N} f\left(n_{r}\right)$.

Figure 1 depicts the market for housing in the risky location under each policy. The black downward sloping line indicates demand for non-disaster amenities, $\theta_{i}$. This line slopes downward due to heterogeneity in households' WTP to live in the risky location. The solid gray line shows demand net of expected per capita disaster costs $\phi\left[\frac{f\left(n_{r}\right)}{n_{r}}+H\left(f\left(n_{r}\right)\right)\right]$. As discussed above, the vertical distance between these two lines is larger at lower population levels because per capita disaster costs decrease with population. The dashed gray line shows demand net only of expected property damages, $\phi H\left(f\left(n_{r}\right)\right)$, corresponding to the case where households are not required to pay for defensive expenditures. The black line labeled $s$ shows the marginal cost of housing in the risky place. This example is drawn to reflect elastic housing supply up to a capacity constraint (perhaps due to land availability or land use regulations). The supply elasticity of housing has important implications that we revisit in Section 6.

When households pay for defensive expenditures, the equilibrium population $n_{r}^{0}$ equates demand and supply in the risky place. If the government pays for defensive expenditures, housing demand is higher and population is $n_{r}^{\prime}$.

\subsection{Potential Distortions Due to Moral Hazard}

Having shown how the financing of defensive expenditures affects individual decisions, we now consider the optimal amount of development in the risky place. This section explores three potential distortions due to moral hazard and shows how they relate to empirically observable quantities.

The total net benefit of development in the risky place is,

$$
\int_{0}^{n_{r}} \theta_{i} d n-\int_{0}^{n_{r}} s(n) d n-\phi f\left(n_{r}\right)-\phi H\left(f\left(n_{r}\right)\right) n_{r}
$$

The first term is total WTP of risky place residents; the second is the total cost of supplying housing; the third is expected defensive expenditures; and the fourth is total expected property damage to all risky place residents. 


\section{Expansion into undeveloped high-risk areas}

The first potential distortion concerns whether any development occurs in the risky place. For development in the risky place to be welfare-improving, there must be some non-zero population for which Expression 1 is positive. This condition can be re-written in terms of average net benefits as,

$$
\frac{\phi}{n_{r}} f\left(n_{r}\right) \leq \frac{1}{n_{r}} \int_{0}^{n_{r}}\left[\theta_{i}-s(n)\right] d n-\phi H\left(f\left(n_{r}\right)\right)
$$

The right-hand side of Equation 2 is average private net benefit among risky place residents: WTP for the risky place minus housing costs and expected private property damage. In order for development in the risky place to be welfare-improving, average private net benefit must at least equal the quantity on the left-hand side, which is the expected per-resident cost of defending homes during a disaster. ${ }^{14}$ This condition may not hold when the central government pays for defensive expenditures. When private net benefits are greater than zero but less than expected protection costs, development occurs and yields negative net social benefits.

In our empirical analysis, we directly calculate the expected protection cost $\frac{\phi}{n_{r}} f\left(n_{r}\right)$ on the left-hand side of Equation 2 in a spatially disaggregated way for homes throughout the western United States. Thus, our expected protection cost estimates can be interpreted as a lower bound on the private net benefits required for new development in a given risky area to be efficient.

\section{The number of homes in developed high-risk areas}

Conditional on development occurring, the financing of defensive expenditures may also have an intensive margin effect on the number of homes in the risky place. This intensive margin effect depends on the marginal increase in defensive expenditures with population, $f^{\prime}\left(n_{r}\right)$, which in this model depends on the shape of $H(f)$. When the central government provides defensive expenditures for free, the marginal private cost of development in the risky place is lower than under full accountability. Appendix

14. The cost of defensive expenditures does not have to be divided equally among risky place residents. In fact, welfare may be higher when costs are allocated in proportion to residents' WTP for the risky place. Such differentiation makes it possible to balance the marginal resident's WTP against marginal (instead of average) defensive expenditures. Absent contracting frictions, households could in principle reproduce this efficient allocation of protection costs through private contracts regardless of the statutory assignment of costs. 
Section A.3 discusses the derivation and welfare implications of marginal protection costs in more detail.

In our empirical application we observe response costs for a large number of fires with varying numbers of threatened homes, allowing us to measure $f^{\prime}\left(n_{r}\right)$ directly. These marginal protection cost estimates are useful for considering the effects of new development in high-risk areas where substantial development has already occurred.

\section{Private risk-reducing investments}

To explore one more effect of publicly-financed property protection, we extend the model to allow for durable private investments that reduce vulnerability to disasters (full details are in Appendix Section A.3). For wildfires, examples are investments in fire-resistant construction or vegetation maintenance to create "defensible space." Let $g$ represent these investments, so that per-capita property damage during a disaster is now $H(f, g)$. As happens in the case of wildfires and other disasters, assume that the government takes $g$ as given when choosing $f$ during a disaster. If private investments reduce vulnerability to the disaster, then $f$ and $g$ may be substitutes (that is, $\frac{\partial^{2} H}{\partial f \partial g}>0$; investment in $g$ reduces the rate at which damages decrease with $f$ ). When choosing $g$, households that are fully accountable for disaster-related costs consider both the direct effect on expected property damage and the indirect effect of $g$ on emergency defensive expenditures $f$. When households are not accountable for emergency defensive expenditures, their investments in $g$ are below the sociallyoptimal level.

The importance of this distortion in practice depends on expected emergency defensive expenditures $f$ and the derivative $\frac{\partial f}{\partial g}$. Our empirical setting allows us to observe the former but not the latter, since we do not observe individual risk-reducing investments. As we discuss in Section 6, the large expected defensive expenditures that we measure make measuring $\frac{\partial f}{\partial g}$ an important goal for future empirical work.

\section{Data}

We construct a dataset that combines administrative data on firefighting expenditures from federal and state agencies with assessor data for nearly all homes in the 11 western states (Arizona, California, Colorado, Idaho, Montana, New Mexico, Nevada, Oregon, Utah, Washington, and Wyoming). Our dataset also includes topographical 
information, wildfire risk assessments, and weather conditions from the time and location of the fire ignition. This section provides an overview of the dataset, while a comprehensive account of dataset construction can be found in Section B in the appendix.

We collect fire suppression and fire preparedness data from five federal agencies and one state agency. Fire suppression refers to expenditures made in the act of fighting a fire, while preparedness expenditures are costs incurred in order to reduce or mitigate damage from future fires. The federal agencies are the US Forest Service (USFS), the National Park Service (NPS), the Bureau of Land Management (BLM), the Bureau of Indian Affairs (BIA), and the Federal Emergency Management Agency (FEMA). The state agency is California's Department of Forestry and Fire Protection (Cal Fire), which is unique among state agencies in the magnitude of its firefighting spending. Incident-level expenditures for each agency come from a combination of Freedom of Information Act requests (Public Records Act requests for California) and publicly available sources. Because fire costs are only reported consistently for large fires and because large fires comprise the bulk of fire suppression expenditures, we focus our analysis on fires that are 300 acres or larger. The regression analysis in Section 4 focuses on the USFS fire suppression data, which cover 1995 to 2014. Appendix Section C validates the accuracy of these USFS cost data. The calculation of implicit subsidies in Section 5 uses expenditures from all agencies in the dataset. For each fire, we obtain the topographical conditions (elevation, slope, aspect, and vegetation characteristics) at the ignition point and weather conditions (temperature, precipitation, wind speed, and humidity) at the time of ignition. We also estimate the distance between the ignition point of each fire and valuable nearby resources, including homes and state and federal highways.

The real estate dataset we use is a proprietary compilation of county assessor data. It includes location, transaction values, year of construction, and other relevant information for 18.5 million parcels, or nearly all of the homes in the western United States. We limit this sample to 9.1 million homes in areas with significant wildland vegetation, as defined by Radeloff et al. (2018). For each home, our data includes a measure of its actual location, which is an improvement over previous studies of wildfires that rely on aggregate housing counts by Census block. Census blocks are often quite large in the rural and ex-urban areas where fire risk is high. 
Our final dataset includes 4,581 fires that account for $\$ 10.5$ billion of suppression costs and links those fires to 9.1 million western US homes in the WUI. Detailed descriptive statistics are given in Appendix Table 7.

\section{The Cost of Saving Homes During Wildfires}

\subsection{Empirical strategy}

The first step in our empirical analysis is to establish what share of firefighting expenditures are incurred to protect private homes. Even with zero threatened homes, some effort would likely be devoted to a fire. Our objective is to understand how fire managers change this effort when homes are located in harm's way. We recover this difference empirically by estimating the casual impact of home presence and density on firefighting costs.

Our empirical strategy takes advantage of variation in ignition locations within national forests. Each of the national forests in our dataset experienced multiple large fires during our study period. We compare suppression costs for fires within the same national forest that happened to start at different distances from homes. Some fires start far from private homes, for example deep inside the national forest. Other fires start nearer to homes because the ignition point is closer to the boundary or to a privately-owned "inholding", or because new homes have been built near the boundary. Figure 2 illustrates this variation for two national forests. The national forest area is shown in green. Fires are shown as stars and are colored by the distance from the ignition point to the nearest home (top-coded at 30 kilometers).

We take advantage of this variation in ignition locations using a fixed-effects estimation strategy. We model the effect of homes on firefighting costs as,

$$
\ln \left(\operatorname{Cost}_{i f t}\right)=g\left(\text { Homes }_{i t}\right)+X_{i f t} \rho+\delta_{f}+\omega_{s t}+\eta_{i f t}
$$

Cost $_{\text {ift }}$ is the suppression cost for fire $i$ in national forest $f$ in month-of-sample $t$. We are primarily interested in how this cost depends on the potential threat to private homes, Homes $_{i t}$. We begin in Section 4.2 by parameterizing $g\left(\right.$ Homes $\left._{i t}\right)$ as the distance from the ignition point of the fire to the nearest home. In Section 4.3, we use the total number of homes near the ignition point. In either case, our preferred model approximates $g(\cdot)$ with a binned step function to allow a flexible response of costs to 
threatened homes.

This panel data approach addresses a number of omitted variables concerns. The national forest fixed effects $\delta_{f}$ control for unobservable determinants of firefighting cost that are constant at the national forest level. We also include time fixed effects $\omega_{s t}$ that control flexibly for unobserved changes in firefighting costs over time. Our preferred specification includes state by month-of-year fixed effects and state by year fixed effects. Intuitively, this identification strategy amounts to comparing fires in the same national forest during the same time of year and the same year of the sample.

We include additional control variables $X_{i f t}$ to address the fact that locations of private homes are not randomly assigned. Even within a given national forest, areas near homes may differ systematically from areas far from homes in ways that affect firefighting cost. The control variables $X_{i f t}$ include the terrain slope, geographic aspect, and vegetation type (fuel model) at the ignition point, and weather conditions at the ignition point on the ignition day. ${ }^{15}$ We also estimate a specification where we limit the sample to fires caused by lightning, which ensures that the location and timing of fires is not driven by the presence of people. The identifying assumption in this analysis is that unobserved determinants of fire cost, $\eta_{i f t}$, are independent of Homes $_{i t}$, conditional on national forest fixed effects and our other controls.

This empirical strategy based on national forests requires us to restrict the analysis to fires managed by USFS, since lands managed by other agencies are not similarly arranged into large contiguous units. ${ }^{16}$ Moreover, Forest Service expenditures account for over $80 \%$ of expenditures in our dataset, due both to the disproportionate role of USFS in fire management and the longer temporal coverage of the USFS data. Appendix Section A.1.2 explores this relationship for other agencies. When adding up historical expenditures associated with each home in Section 5, we use data from all agencies.

15. The weather variables vary over time while the topographic variables are constant.

16. For example, Cal Fire incidents occur on diffuse private and state lands, while BLM owned lands often consist of smaller patches of land managed by district offices. 


\subsection{Proximity to homes}

We begin by considering a version of Equation (3) where the threat to private homes, Homes $_{i t}$, is proxied by the distance from the ignition point to the nearest home that existed at the time of the fire. Figure 3 shows estimates from three flexible regression specifications. Each regression includes national forest fixed effects, state by month-of-year fixed effects, and state by year fixed effects. The solid black line shows the estimated marginal effect of distance from a regression of log costs on a cubic polynomial of distance to homes. The shaded gray area is the $95 \%$ confidence interval. The dashed black line shows a linear spline in distance to homes, with knots placed every 10 kilometers. Finally, the black dots report coefficients from a binned step function specification. These coefficients correspond to indicator variables for 5-kilometer bins of distance to homes. The omitted category is fires that start less than five kilometers away from homes. Regardless of the functional form that we choose, there is a clear gradient in firefighting costs with distance from nearest home. The relationship is steep, monotonic and close to linear. Relative to a fire that starts $40+$ kilometers from any home, the log cost of a fire less than five kilometers from homes is higher by about 2.25. Taken literally, these estimates imply that a fire that starts less than $5 \mathrm{~km}$ from homes would cost about $70 \%$ less if there were no homes within $25 \mathrm{~km}$, and $90 \%$ less if there were no homes within $40 \mathrm{~km} .{ }^{17}$

Table 1 estimates alternative models using a binned specification. Column (1) follows Figure 3. Column (2) adds additional controls for pre-determined fire characteristics. As we show in the appendix, the signs and magnitudes of the included covariates match expectations. For example, firefighting costs are higher where the terrain slopes more steeply, reflecting difficulty of access. Costs also increase with wind speed on the ignition day, consistent with the importance of wind in fire spread, and with vapor pressure deficit (VPD), a measure of atmospheric dryness. Costs are also higher for fires on south- or southwest-facing slopes, which receive additional sun exposure and thus tend to be more readily combustible. Appendix Table 1 shows detailed regression results for all covariates. While we find that many of these covariates have meaningful effects on firefighting costs, including them in the regression has little effect on our estimated distance gradient.

17. These percentage changes are calculated using the binned specification. Halvorsen and Palmquist (1980) and Kennedy (1981) show that the percentage effect of an indicator variable in a semi-log regression can be approximated as $e^{\beta-0.5 V(\beta)}-1$, where $\beta$ is the regression coefficient. 
The remaining columns show three robustness checks. Column (3) replaces the time fixed effects with more granular month-of-sample by state fixed effects, which allow for arbitrary shocks to firefighting costs in each month of the dataset in each state. These temporally more precise controls absorb higher frequency local cost fluctuations that might be caused by weather patterns or other factors. This alternative specification produces a similar distance gradient. Column (4) restricts the sample to fires started by lightning. Some types of human-caused fires are more likely to occur near populated areas, introducing a potential identification concern if fires due to arson or campfires or other causes vary systematically in their difficulty to extinguish. The locations of lightning strikes are plausibly random and thus purged of this potential bias. If anything, the estimated distance gradient is steeper when this restriction is applied, though the estimates are not different in a statistical sense. Column (5) restricts to fires occurring in "timber" vegetation, since developed areas are also less likely to be heavily wooded than remote areas. As before, the estimated distance gradient steepens slightly with this restriction. The online appendix shows that these results are robust to further controlling for the distance from the ignition point to the nearest major road.

The large effects of threatened homes on firefighting costs are likely explained by the high cost of stopping fires in place by digging firelines, dropping retardant from aircraft, and taking other costly measures. An anecdote from Arno and AllisonBunnell (2002) provides some context: "Consider the campaign against the 217,000acre Clear Creek Fire on the Salmon-Challis National Forest in central Idaho during the summer of 2000. Although the fire burned mostly in undeveloped mountainous terrain, it was near enough to populated valleys, including the town of Salmon, to inspire frenzied efforts to stop the advancing flames with heavy equipment... [and] the monumental expenditure of $\$ 71$ million... In contrast, the 182,000-acre Wilderness Complex fire farther west in similar terrain was monitored and allowed to burn with very little suppression effort at a cost of about half a million dollars."

\subsection{Total Number of Homes}

The results so far show that the presence of nearby private homes strongly affects firefighting costs. We now consider how this effect varies with the number of homes at risk, i.e., the density of development. We fix a radius around each ignition point and estimate a version of Equation (3) that parameterizes $g\left(\right.$ Homes $\left._{i t}\right)$ as the number 
of homes within that radius. Our baseline specification uses 30 kilometers; the online appendix shows results for other radii.

Figure 4 shows results from a binned step function specification. The reference bin is fires with zero homes within $30 \mathrm{~km}$, and the other bins evenly divide the remaining fires into deciles. The presence of just one to 31 homes almost doubles expenditures on a fire. Costs are further increasing over the first few deciles, up to about 100-300 homes. Beyond that costs change very little. The regression coefficients imply that a fire threatening 300 homes costs about 5 times as much as a fire with no nearby homes, while a fire threatening over ten thousand homes costs about 6.5 times as much as a fire with no nearby homes. ${ }^{18}$ This strongly nonlinear relationship implies that the benefits of wildland firefighting are essentially non-rival, so that marginal protection costs are decreasing in population density.

One way to contextualize these results is to convert the numbers of homes in Figure 4 into conventional measures of residential density such as the number of homes per unit area. Land use planners typically work with net density, which measures land consumption per housing unit after subtracting out open space, parks, pasture, roads, and other land uses. To compare to this standard measure, we calculate the average of the reported lot sizes for homes within $30 \mathrm{~km}$ of the fire. The median net density across fires in the fourth non-zero bin, where costs level off, is 0.16 homes per acre. ${ }^{19}$ Mann et al. (2014) define 5 tiers of housing density: sparse, low, medium, high, and very high. A value of 0.16 homes per acre is between the cutoffs for "low" and "medium".

\subsection{Additional Results and Robustness Checks}

In addition to the checks described above, we include a more detailed set of additional results and robustness checks in the online appendix, which we describe here in brief. First, we show that the estimated density effects in Figure 4 are robust to the same

18. Regression details are in the appendix. The relevant coefficients are 1.61 and 1.87 , implying approximate cost ratios of $e^{1.61}=5.00$ and $e^{1.87}=6.49$.

19. This calculation is meant to provide broad context as opposed to a highly accurate measure of net density. We calculate the mean lot size within $30 \mathrm{~km}$ of each fire, and then calculate the median average lot size in each decile bin in the figure. These range from 0.11 homes per acre in the left-most non-zero bin to 0.91 homes per acre in the right-most bin. The average lot size within $30 \mathrm{~km}$ of each fire is sensitive to some very large reported parcels. Lot size is also missing for some homes, which we necessarily omit from this calculation. 
checks shown in Table 1, such as limiting to lightning-caused fires or including temporally more precise fixed effects. We also show that using the total transaction value of homes instead of the number of nearby homes yields similar results. Furthermore, we show that the effect of development density on firefighting costs is robust to using different radii around the ignition point.

Our measure of valuable structures threatened by a fire does not include public infrastructure such as school buildings and municipal parks that would also be considered by incident commanders when choosing response levels. This means that our approach assigns the cost of protecting those public goods to nearby homeowners. For local public goods such as schools and parks, this makes intuitive sense, since construction of such local public goods follows as a direct result of housing construction (Brueckner 1997). It should also be noted that built structures in the WUI areas where we are focused are disproportionately residential, with residents who travel by car to more-developed commercial areas for shopping, work, and school.

Since firefighting costs are only consistently reported for incidents larger than 300 acres, a potential concern is bias due to sample selection. Our analysis could be affected if the subset of ignitions that reach this size differs with distance from homes in a way that is correlated with suppression costs. For example, one might worry that concentrated initial attack efforts near homes make ignitions near homes unlikely to grow large unless conditions are difficult (e.g., high winds). This selection would result in an upward bias in a naive regression of firefighting costs on distance to homes. We address this concern in several ways. Importantly, we are able to control directly for the most significant potential confounders. Wind, weather conditions, and topography are primary determinants of suppression difficulty and cost (Gebert, Calkin, and Yoder 2007). Table 1 and Appendix Table 1 show that controlling flexibly for these variables improves the model fit while introducing only small changes in the coefficients of interest. Appendix A.1.1 also formalizes this sensitivity analysis using the bounding exercise of Oster (2019). Finally, finer-grained time fixed effects reduce the scope for selection due to unobservables that vary over time but are locally constant in space, like fuel dryness or weather patterns. The state by month of sample fixed effects in Column (3) of Table 1 restrict the comparison to fires in a single state that all occurred in the same month. The results are similarly robust to even finergrained time fixed effects (e.g., state by week-of-sample), but the number of relevant 
fire observations begins to decrease since not all state by week cells contain multiple fires.

We also compare our regression-based method to a different empirical approach. Auditors from the USDA Office of the Inspector General have studied federal firefighting expenditures using interview methods. USFS managers reported that in their experience, 50 to $95 \%$ of USFS firefighting expenditures are devoted to protecting private structures (USDA 2006). Appendix Table 5 reports implicit subsidy estimates that ignore the regression results in this section and instead use these interviews to identify the share of firefighting expenditures devoted to protecting homes. Specifically, we assume that protecting homes accounts for $72.5 \%$ of each fire's costs (the midpoint of the reported range). The resulting distribution of homeowner-level implicit subsidies is similar to the main estimates that we calculate in Section 5. This similarity across methods is reassuring.

Finally, because our baseline estimates are not suitable to consider the impact of homes on the frequency of fires in an area, we conduct a separate analysis to investigate how this might impact our findings. As some wildland fires are ignited by humans, increased human population may lead to more ignitions. On the other hand, new homes could be accompanied by greater fire prevention efforts. We explore this relationship using panel variation in new home construction near each of the national forests in our sample. We find weak evidence of a small positive effect of new home construction on the number of large fires each year in places that start from a low level of development. Adding an additional 1,000 homes in a relatively undeveloped area is associated with about a $4.3 \%$ increase in the number of large fires each year, or about 0.06 additional large fires per year. The finding that human presence increases fire frequency is consistent with work by ecologists and geographers (Syphard et al. 2007; Massada et al. 2012; Faivre et al. 2014; Balch et al. 2017). This implies that our estimates may slightly undercount the additional firefighting cost created by new homes.

\section{The Implicit Subsidy To Homeowners}

Federally-funded fire protection is an implicit subsidy to the homeowners whose property is protected. This section combines the estimates from Equation (3) with individual home data to calculate geographically-differentiated subsidy amounts for every 
home in the western US. For each home, we calculate an actuarial ("ex ante") measure of the expected net present value of federal and state costs to protect the home during wildfires. Section 5.1 describes the methods that we use to estimate historical ("ex post") and expected ("ex ante") protection costs for each home. Section 5.2 summarizes the estimated costs and demonstrates the relationship between observable risk predictors and historical cost experience. Sections 5.3 and 5.4 describe the incidence of these implicit subsidies according to geography and income.

\subsection{Methods}

\subsubsection{Historical Protection Cost}

To estimate the historical protection costs attributable to each home, we calculate expenditures to defend homes during each historical fire, allocate those costs across individual homes, and then sum up each home's historical cost over all observed fires. For each fire, we use the estimates from Equation (3) to predict the firefighting cost if there had been no homes within 40 kilometers of the ignition point. This counterfactual cost calculation is described in detail in Appendix Section B.3. For each fire $i$ we calculate the difference $\Delta_{i}$ between the observed firefighting cost and the predicted cost with no nearby homes. We then allocate the home protection costs $\Delta_{i}$ over potentially threatened homes. We include homes as potentially threatened if they are located within $40 \mathrm{~km}$ of the ignition point and are in areas with wildland vegetation following Radeloff et al. (2005) (see Appendix Section B.2 for details). We assign a larger share of $\Delta_{i}$ to potentially threatened homes closer to the ignition point using weights derived from the regression coefficients from Equation (3). ${ }^{20}$ This exercise divides $\Delta_{i}$ across $j$ potentially threatened homes, yielding costs $\delta_{i j}$ for each home, where $\sum_{j=1}^{J} \delta_{i j}=\Delta_{i}$.

Finally, each home's costs are summed across all observed fires in the dataset. For home $j$, this is $\rho_{j}=\sum_{i=1}^{I} \delta_{i j}$. We call this quantity the realized protection cost

20. The incident-specific weight $w_{i j}$ assigned to each threatened home $j$ corresponds to the expected increase in costs if home $j$ were the nearest home to the fire, relative to a fire threatening no homes. Protection cost $\Delta_{i}$ is then allocated proportionally using the normalized weights $\bar{w}_{i j}=w_{i j} / \sum_{j} w_{i j}$. Compared to the common alternative of inverse distance weighting (IDW), our approach is conservative in that it allocates costs more evenly. Under IDW, a home $1 \mathrm{~km}$ from the ignition point would receive more than 15 times the cost allocation of a home $15 \mathrm{~km}$ from the ignition point. Using the regression coefficients as weights, the $1 \mathrm{~km}$ home receives 2 times the cost allocation of the $15 \mathrm{~km}$ home. 
because it represents the total firefighting costs attributable to the home during the study period. While the dataset in Section 4 was limited to USFS fires in order to take advantage of variation in ignition locations within national forests, the calculation of historical firefighting costs described in this section also includes expenditures by BLM, NPS, and BIA to more fully capture federal expenditures. ${ }^{21}$

\subsubsection{Actuarial Estimates of Future Protection Cost}

The model in Section 2.3 shows that behavioral responses to publicly-provided fire protection depend not on realized costs but on ex ante expected costs. To estimate expected firefighting costs, we group regions with similar ecological and fire risk characteristics into actuarial groups (as an insurance company might do). We calculate expected cost for homes in each group as $\mathbb{E}_{h, d, m}\left[\rho_{j}\right]$. This calculation takes expectations over bins of wildfire hazard $h$, development density $d$, and geographic region $m$. Wildfire hazard is defined at the parcel level using the spatially explicit wildfire hazard potential (WHP) scores provided by Dillon (2015), which are a physical measure of wildfire risk based on ecological and topographical factors. The WHP score is a categorical variable with six levels. ${ }^{22}$ Development density (in population per square meter) comes from Gridded Population of the World (GPW), which reports population within $1 \mathrm{~km}$ grid cells. We define 5 bins based on the quintiles of the distribution of GPW grid cells. Geographic regions are based on the seven Geographic Area Coordinating Center (GACC) regions within which firefighting operations are coordinated. This binning process results in 210 actuarial groups. We calculate the net present value of the expected annual firefighting cost in each group using a $5 \%$ discount rate. We call this quantity the expected parcel protection cost. It represents the expected present value of future government expenditures to protect a home from fire.

Appendix Section A.2 shows the geographic distribution of the variables used to define actuarial groups. Appendix Section A.2.4 discusses another approach to calculating expected protection costs using machine learning methods. A regression tree can be used to define actuarial groups that minimize the prediction error for historical costs

21. These additional data sources add a total of $\$ 93$ million per year (in 2017 dollars), compared to $\$ 486$ million per year for USFS.

22. A continuous measure of WHP is also reported, which we use in some specifications to more finely segment fire risk. 
in each group. This approach yields similar results for expected protection costs.

\subsubsection{Incorporating Additional Expenditure Categories}

Governments incur additional fire expenses beyond direct firefighting expenditures by federal agencies. To reflect this, we calculate several measures that incorporate successively broader categories of costs. Each measure represents a tradeoff between completeness and strength of required assumptions. A "suppression only" measure includes direct firefighting costs by USFS, BLM, NPS, and BIA. This measure requires the fewest assumptions beyond those in Section 4.1, but omits potentially important categories of expenditures. A "suppression plus" measure also accounts for the annual fixed costs of maintaining response capabilities ("preparedness" expenditures), and federal reimbursements to state and local firefighting agencies through the Fire Management Assistance Grant (FMAG) program. Finally, our third measure is specific to California, the largest state in the West and a state where we observe detailed state-level expenditures. By design, none of these measures include (non-reimbursed) local government costs because our focus is on external costs.

The "suppression plus" measure includes federal preparedness spending. Allocating preparedness spending to individual fires presents a conceptual challenge and a computational challenge. Conceptually, annual preparedness spending must be allocated across individual incidents. We choose to divide preparedness costs equally across ignitions. ${ }^{23}$ After this even division, we then calculate the share of preparedness costs due to homes using the same model as for suppression expenditures. ${ }^{24}$ The computational challenge is that actually allocating costs to every ignition would require us to calculate distances to homes and other detailed spatial analyses for 100,000+ ignitions. As a feasible alternative, we impose the assumption that the geographic distribution of ignitions is similar to the geographic distribution of fires exceeding 300 acres. Under this assumption, we can achieve the same spatial allocation of preparedness costs by allocating preparedness spending across large fires only. Finally, we allocate these per-fire preparedness costs attributable to homes across nearby

23. For USFS, we divide each region-year of preparedness spending across fires in that region-year. The DOI agencies only report preparedness spending at the annual level, so we divide annual costs by annual number of fires.

24. This assumes that homes increase preparedness costs by the same factor as firefighting costs. This is a strong assumption but it is conservative compared to the obvious alternative, which is to assume that all preparedness costs are incurred to protect homes. 
homes using the same distance weights as in Section 5.1.1.

The "suppression plus" measure also includes FEMA FMAG reimbursements to states and cities as a proxy for state and local firefighting costs. We aggregate FMAG reimbursements to the state-year level. We then assign state-year FMAG reimbursements to parcels using the same method as for preparedness spending. ${ }^{25}$

The final measure is specific to California, the largest western state. This measure excludes FEMA reimbursements and instead uses Cal Fire incident-level expenditure data. The incident-level Cal Fire data include geographic coordinates and costs, allowing us to directly allocate these costs as we did in the "suppression only" measure.

\subsection{Results: Expected Protection Costs}

Figure 5 plots conditional means of historical protection costs. The figure shows average fire protection costs for homes in 400 bins, using the "suppression plus" cost metric. The sample of homes in this figure includes all 8.6 million homes in the western US located near areas of wildland vegetation (44\% of all western US residential homes, condos, and apartments). The color scale indicates average costs in each cell (on a log scale). The range of historical protection costs is large. The average net present value ranges from a few hundred dollars per home for the lowest-cost cells to almost $\$ 100,000$ per home in the highest-cost cells.

Moreover, while there is some noise due to the granularity of the bins, there is a clear graphical relationship between realized protection costs and observable predictors of risk. The vertical axis is defined by 20 bins of landscape fire risk based on wildfire hazard potential (WHP). Average protection costs are clearly increasing with WHP. This relationship is intuitive, but the cost difference between homes in low- and high-WHP areas is striking. Along the horizontal axis, protection costs strongly decrease with development density. This somewhat more surprising result reflects the nonlinear relationship between firefighting costs and number of nearby homes that we measured in Section 4.3. Instead of being driven purely by idiosyncratic risk, the costs of protecting homes from fires vary in a highly predictable way. Homes in low density, high fire risk areas are extremely expensive to protect.

25. This reflects an additional assumption that the spatial distribution of fires for which FEMA makes reimbursements is similar to the overall distribution of fires in the data. 
We compute our final measures of expected protection cost using the 210 actuarial groups described in Section 5.1.2. These coarser bins reduce noise relative to Figure 5 while also allowing for regional variation. Table 2 describes the distribution of the resulting expected protection costs for the 8.6 million homes in our sampling area in the 11 western states. The first three columns describe the upper half of the distribution of the expected present value of firefighting costs attributable to each home using different cost measures. Using the "suppression only" measure, $50 \%$ of WUI homes have expected protection costs under $\$ 500$, while the highest-risk homes have costs that are much larger. Five percent of homes have expected costs exceeding $\$ 3,800$. One percent of homes have expected protection costs exceeding $\$ 12,700$. Using the "suppression plus" measure results in higher costs. The 95th and 99th percentiles of this distribution are about twice as high as for the "suppression only" measure. When we restrict the sample to California homes, where we have higher quality data on state-level expenditures, we find that the 95th and 99th percentile costs are roughly similar to the previous column.

Column (4) of Table 2 reports the "suppression plus" measure as a share of the property's transaction value. ${ }^{26}$ For the $5 \%$ of homes with the highest relative costs, the present value of expected future firefighting costs is over $5.5 \%$ of property value. For the highest $1 \%$ of homes, it exceeds $19.6 \%$.

The expected costs in Table 2 are calculated by averaging historical costs in different locations with similar risk characteristics. Thus, they do not simply reflect an unlucky or exceptional fire history in one location. Instead, they capture the aggregate cost history of homes in a given actuarial category. Homes at or above the 95th percentile represent 78 actuarial groups, while homes at or above the 99th percentile represent 23 actuarial groups.

\subsection{Results: Geographic Incidence}

Figures 6 and 7 show regional and local variation in expected protection costs. Both maps plot the ex ante expected protection cost estimates from Section 5.2. Figure 6 shows averages of these expected costs in 15-kilometer hexagonal cells covering the western US, using the "suppression plus" cost measure (results for the other cost

26. Average share of home value for each actuarial group is calculated as
$\frac{1}{N} \sum\left(\frac{N P V \text { Realized Protection Cost }}{\text { Home Value }}\right)$. We exclude missing or unusable transaction values from
this calculation as described in the online appendix (Appendix Section B.2).


measures are in Appendix Section A.2). The color scale indicates costs and is topcoded so that the darkest red corresponds to per-home expected protection costs of $\$ 30,000$ or more. Expected protection costs are highest in Northern California, central Oregon and Washington, and Idaho and western Montana. These are sparsely populated areas with many areas of high fire risk.

Protection from wildfires is a surprisingly large part of the bundle of federal benefits to households in these areas. To contextualize our findings, the annual implicit subsidies to homeowners in Montana and Idaho via firefighting are larger than federal transfers to those states under the Temporary Assistance to Needy Families (TANF) program (see citation in Footnote 3). Notably, Southern California, which also experiences frequent wildfires, has somewhat lower expected protection cost. Greater development density in fire-prone parts of Southern California likely reduces per-home firefighting costs.

Figure 7 shows the substantial local variation in expected protection costs using smaller 5-kilometer cells. The top panel shows Shasta County in Northern California. Expected protection costs are several hundred dollars per home or less in the more densely developed areas of central Redding and Anderson. Outside of these urban areas, wildfire hazard increases and density decreases rapidly, resulting in much higher expected protection costs. In more remote areas bordering national forests and other public wildlands, costs are tens of thousands of dollars per home. These areas have a high underlying physical risk of fire, meaning that homes built here are likely to repeatedly require costly firefighting efforts to avoid destruction. In addition, these areas include fewer total homes, raising the per-home cost of firefighting. The bottom panel shows San Diego County. Again, expected protection costs are low in the densely developed urban area and higher in the high fire-risk, low-density areas near federal- and state-owned lands in the eastern part of the county.

\subsection{Results: Incidence across Income Groups}

A frequent claim about wildland firefighting is that it mostly benefits the rich (for example, "The Case for Letting Malibu Burn" (Davis 1995)). Our data tell a different story. Figure 8 shows that on average, homes in low-income parts of the West receive larger implicit subsidies than in high-income areas (probably because expected protection costs are highest in rural and semi-rural areas). Panel B considers the 
transaction value of the home, which is a strong predictor of total wealth for most American homeowners. Again, lower-value homes have higher protection costs on average. $^{27}$

\section{Discussion}

This section considers the economic implications of our estimated WUI subsidies. Section 6.1 considers efficiency costs and Section 6.2 discusses policies that could reduce these distortions.

\subsection{Economic Efficiency}

Following the logic of Section 2, we separately consider the costs of expanding the WUI footprint into undeveloped areas, adding additional homes in developed areas, and crowding out of private protective investments.

\subsubsection{Expansion into New High-Risk Areas}

The trend of WUI expansion in high fire-risk zones is predicted to continue throughout the West (Gude, Rasker, and Noort 2008; Mann et al. 2014). Our results imply that the total costs of such expansions can be well above the costs felt by local decisionmakers. Table 3 shows average expected protection costs as a share of transaction values for various levels of fire risk and housing density. Panel A shows detailed estimates for wildfire hazard classes 1 to 5 . The estimates for the highest-cost categories are strikingly high, topping out at a subsidy rate of $36 \%$ for 11,000 homeowners in the highest fire risk, lowest-density parts of the West. The logic of Section 2 means that private willingness-to-pay (WTP) for homes in such areas would have to be substantially above private cost for this type of development to improve welfare. The later rows of Panel A show that new development at higher-densities can be justified by lower private WTP. Finally, Panel B separately summarizes subsidy rates for WUI homes in the lowest fire-risk areas (WHP class 0 ), which average about $0.8 \%$ of home value.

The final column of Table 3 uses these subsidy rates to conduct a counterfactual

27. In this sense, fire protection differs from some other federal environmental programs. The National Flood Insurance Program, the Superfund program, and clean energy tax credits have all been shown to favor higher-income households (Kahn and Smith 2017; Sigman 2001; Borenstein and Davis 2016). 
thought exercise. This simplified back-of-the-envelope calculation supposes that a local decisionmaker in each area makes a one-shot decision about the level of development, starting from a base of no WUI homes. Given our estimates and elasticity values from the literature, we can calculate the deviation from the counterfactual home quantity $q_{0}$ that would have been chosen if homeowners or local governments were required to pay the expected protection cost for each WUI home.

Define $\tau$ as the expected protection cost; $p$ as the observed transaction value, which is assumed to equal the constant marginal cost of supplying housing; and counterfactual user cost $p_{0}=p+\tau$. The assumption of perfectly elastic WUI supply reflects abundant land for development and few regulatory constraints in the ex-urban and rural areas where we are focused. The demand elasticity is $\epsilon$, which we set at -1.0 based on existing evidence. ${ }^{28}$ The percentage increase in the decisionmaker's chosen housing quantity in a given area due to the subsidy is $\frac{\Delta q}{q_{0}}=\epsilon \frac{\tau}{p_{0}}$. Table 3 shows that the implied effects on historical expansion of the WUI are large in high-cost places, reaching up to $27 \%$. The subtotal row for Panel A shows that the cumulative effect across groups is a $2.3 \%$ increase in WUI footprint, which represents about 84,000 additional high-risk WUI homes caused by the subsidy. The estimates in Panel B imply an additional increase of about 37,000 homes.

This calculation ignores many important complications of housing markets and urban development, and the resulting values should thus be interpreted with caution. We leave more detailed calibrations for future work but note two reasons that this approximation may understate the future economic costs of subsidized WUI fire protection. First, our estimates are based on historical averages and thus underestimate future protection costs due to the worsening wildfire problem. Second, this distortion may interact with other distortions such as the favorable tax treatment of home mortgage

28. The demand elasticity reflects adjustments in both long-distance migration and within-city location choice. Polinsky and Ellwood (1979) finds that the price elasticity of demand for new, detached single family housing is about -1.0. In a somewhat related setting to ours, Gregory (2017) argues that the long-run population elasticity may be as large as -2.0 based on post-hurricane resettlement decisions for young people and on Kennan and Walker (2011). Anas and Chu (1984) find a within-city location choice elasticity of between -0.27 and -0.87 . On the supply side, Saiz (2010) reports elasticities of -1.53, -1.67, and -2.27 for the Denver, Colorado Springs, and Albuquerque areas. These parameters reflect both urban centers and WUI areas and thus likely understate the WUI elasticity. Topel and Rosen (1988) finds a U.S.-wide supply elasticity for new housing starts of -3.0. Moreover, the prices we observe are near the minimum profitable construction costs presented in Glaeser and Gyourko (2018). 
interest and zoning restrictions in urban areas that encourage development outside of cities.

\subsubsection{Already-Developed Areas and Private Protective Investments}

The protection costs that we measure are not high enough to justify abandonment of already-constructed homes, which represent large sunk investments. The efficiency implications of additional construction in developed areas depend on marginal protection cost, as discussed in Section 2.3. We find that once development passes a low threshold, these marginal costs are small even in high-risk areas. Beyond net densities of roughly 0.16 homes per acre, the cost of protecting homes during a fire increases very little with additional development. One way of interpreting these surprisingly large economies of density is that aggressive techniques such as bulldozing firelines and deploying aircraft include a fixed cost component. Once the number of homes in the path of the blaze is large enough to justify such expenditures, additional threatened homes introduce little additional cost.

This result implies that pricing fire protection for new homes at its expected marginal cost would incentivize shifting construction towards already-developed WUI areas, away from un- or sparsely-developed locations. If such densification is independently desirable because of other market failures around land use ("sprawl"), such a policy may have additional benefits.

Freely-provided wildland firefighting may also reduce the attractiveness of other riskreducing investments. A number of private actions can reduce a home's vulnerability during a wildfire, at some cost. Homes can be built with fire-resistant roofs, windows, and other materials. Residents can maintain vegetation to create "defensible space" around the home. Existing studies have documented low take-up of such investments despite widespread outreach efforts (Champ, Donovan, and Barth 2013; Dickinson et al. 2015). This underinvestment is usually attributed to imperfect information or behavioral failures, but the substantial externalities that we identify in this paper are another possible reason for low take-up. Moreover, these externalities also rationalize

limited effort by local and state governments to mandate such investments through building codes and inspections. We see private and municipal decision-making as an important area for additional empirical research. 


\subsubsection{Other Market Failures}

Large wildfires can impose costs on downwind populations via smoke exposure. If protecting homes also reduced smoke, there would be additional external benefits to WUI firefighting. The effects of WUI firefighting on smoke are unknown, but there is reason to believe they may be limited. The focus is often on "point protection" of homes instead of on reducing the overall burned area, which is what determines smoke production (National Wildfire Coordinating Group 2014; Wei et al. 2018).

Another potential factor is the organizational incentives of federal agencies. If fire managers face imperfect incentives to minimize incident costs, reforms that improve the efficiency of firefighting would reduce protection costs. Arguably, one might expect greater local or individual accountability for firefighting costs to increase pressure to discipline these costs.

\subsection{Policies to Internalize Protection Costs}

One candidate policy to mitigate these distortions would be to require home-builders to pay a fee equal to the net present value of expected protection costs when building a new home in an undeveloped or sparsely developed area. The empirical analysis in this study provides a road map for calculating this spatially specific corrective $\operatorname{tax}^{29}$

In 2014, California began requiring homeowners in the Cal Fire protection area to pay an equal annual fee of about $\$ 150$ per year. The fee proved unpopular among homeowners and was suspended in 2017. This study shows that such a fee would need to be much more geographically differentiated in order to correct incentives (as opposed to simply raising revenue). Another lesson from this study is that exempting owners of existing homes could increase the political acceptability of such a policy without reducing its effectiveness, since the protection costs we estimate are not generally high enough to justify abandonment of existing homes.

An alternative would be to assign firefighting costs to local governments, which would recover them through property taxes or other measures. This approach would incentivize cities and counties to consider fire protection costs in zoning, land use, and

29. Importantly, the effect of such a policy does not depend on the accuracy of individuals' beliefs about wildfire risk. A tax computed by the government and paid at the time of construction would presumably make the external costs of fire protection highly salient. 
building codes. Firefighting could continue to be supplied via the current system of west-wide dispatch with local governments reimbursing federal agencies for a larger share of costs. A third option, if legally and politically feasible, would be to recover firefighting costs from insurance companies holding homeowner's policies near the ignition point of the fire. Such a rule would increase insurance premiums according to expected firefighting costs.

\section{Conclusion}

Unlike other natural hazards, a large share of the total costs of wildfires are due to costly efforts to prevent property damage. We find that protection of private homes accounts for most of the billions of dollars spent by the federal and state governments to combat wildfires each year. Decisions by homeowners and local governments about construction and maintenance of homes in the wildland-urban interface therefore generate large cost externalities. We also find that beyond low levels of development, the marginal effect of additional homes on firefighting expenditures is surprisingly small.

We use our results to calculate spatially differentiated implicit subsidies for homeowners throughout the western United States. Wildfire protection represents a large transfer of federal and state revenues to homeowners in high-cost places, making it an important mechanism for redistribution to rural and ex-urban areas that has not been fully appreciated by economists. Our back-of-the-envelope calculations suggest that free federal fire protection may have increased development in high fire risk areas by $2.5 \%$ overall, and by substantially more than that in the highest-risk areas. The estimated protection costs call into question the net social benefits of converting undeveloped and sparsely developed wildland areas to low-density housing use, a type of new development that is predicted to be widespread in coming decades. At the same time, the low marginal protection costs that we measure in already-developed areas imply substantial benefits from clustered development. The effect of free federal fire protection on individual and municipal incentives for fire-resistant construction and maintenance is an important area for future empirical research.

This study also provides a road map for calculating a spatially differentiated "fire protection fee" for new construction that reflects the expected future costs that would be incurred to protect the home. Such a policy applied to individuals or local gov- 
ernments would change incentives for development in high-risk areas.

More broadly, this study underscores the importance of institutions in adapting to climate change. The costs of inefficient policies will increase as the climate warms. For wildfires, as for many other impacts of climate change, the ultimate costs of a warmer planet will be determined not only by the degree of physical change but also by the mediating influence of public policy.

\section{References}

Abatzoglou, John T., and A. Park Williams. 2016. "Impact of Anthropogenic Climate Change on Wildfire Across Western US Forests." Proceedings of the National Academy of Sciences 113 (42): 11770-11775.

Anas, Alex, and Chaushie Chu. 1984. "Discrete Choice Models and the Housing Price and Travel to Work Elasticities of Location Demand." Journal of Urban Economics 15:107-123.

Arno, Stephen F., and Steven Allison-Bunnell. 2002. Flames in Our Forest: Disaster or Renewal? Island Press.

Auffhammer, Maximilian. 2018. "Climate Adaptive Response Estimation: Short And Long Run Impacts Of Climate Change On Residential Electricity and Natural Gas Consumption Using Big Data." NBER Working Paper 24397.

Balch, Jennifer, Bethany Bradley, John Abatzoglou, R. Chelsea Nagy, Emily Fusco, and Adam Mahood. 2017. "Human-Started Wildfires Expand the Fire Niche Across the United States." Proceedings of the National Academy of Sciences 114 (11): 2946-2951.

Barreca, Alan, Karen Clay, Olivier Deschenes, Michael Greenstone, and Joseph S. Shapiro. 2016. "Adapting to Climate Change: The Remarkable Decline in the US Temperature-Mortality Relationship over the Twentieth Century." Journal of Political Economy 124 (1): 105-159.

Borenstein, Severin, and Lucas Davis. 2016. "The Distributional Effects of US Clean Energy Tax Credits." Tax Policy and the Economy 30 (1): 191-234.

Boustan, Leah Platt, Matthew E. Kahn, and Paul W. Rhode. 2012. "Moving to Higher Ground: Migration Response to Natural Disasters in the Early Twentieth Century." American Economic Review 102 (3): 238-244.

Brueckner, Jan K. 1997. "Infrastructure Financing and Urban Development: The Economics of Impact Fees." Journal of Public Economics 66 (3): 383-407. 
Burke, Marshall, and Kyle Emerick. 2016. "Adaptation to Climate Change: Evidence from US Agriculture." American Economic Journal: Economic Policy 8 (3): 10640 .

Champ, Patricia A., Geoffrey H. Donovan, and Christopher M. Barth. 2013. "Living in a Tinderbox: Wildfire Risk Perceptions and Mitigating Behaviours." International Journal of Wildland Fire 22 (6): 832-840.

Davis, Mike. 1995. "The Case for Letting Malibu Burn." Environmental History Review 19 (2): 1-36.

Deryugina, Tatyana. 2017. "The Fiscal Cost of Hurricanes: Disaster Aid versus Social Insurance." American Economic Journal: Economic Policy 9 (3): 168-198.

Dickinson, Katherine, Hannah Brenkert-Smith, Patricia A. Champ, and Nicholas Flores. 2015. "Catching Fire? Social Interactions, Beliefs, and Wildfire Risk Mitigation Behaviors." Society \&3 Natural Resources 28 (8): 807-824.

Dillon, Gregory K. 2015. Wildfire Hazard Potential for the Coterminous United States. Forest Service Research Data Archive.

Donovan, Geoffrey, Patricia Champ, and David Butry. 2007. "Wildfire Risk and Housing Prices: A Case Study from Colorado Springs." Land Economics 83 (2): 217233.

Faivre, Nicolas, Yufang Jin, Michael L. Goulden, and James T. Randerson. 2014. "Controls on the Spatial Pattern of Wildfire Ignitions in Southern California." International Journal of Wildland Fire 23 (6): 799-811.

Gebert, Krista M, David E Calkin, and Jonathan Yoder. 2007. "Estimating Suppression Expenditures for Individual Large Wildland Fires." Western Journal of Applied Forestry 22 (3): 188-196.

Glaeser, Edward L., and Joseph Gyourko. 2018. "The Economic Implications of Housing Supply." Journal of Economic Perspectives 32 (1): 3-30.

Gregory, Jesse. 2017. "The Impact of Post-Katrina Rebuilding Grants on the Resettlement Choices of New Orleans Homeowners." Working Paper.

Gude, Patricia H., Kingsford Jones, Ray Rasker, and Mark C. Greenwood. 2013. "Evidence for the Effect of Homes on Wildfire Suppression Costs." International Journal of Wildland Fire 22.

Gude, Patricia, Ray Rasker, and Jeff van den Noort. 2008. "Potential for Future Development on Fire-Prone Lands." Journal of Forestry 106 (4): 198-205.

Halvorsen, Robert, and Raymond Palmquist. 1980. "The Interpretation of Dummy Variables in Semilogarithmic Equations." American Economic Review 70 (3): 474-75. 
Hammer, Roger, Susan Stewart, and Volker Radeloff. 2009. "Demographic Trends, the Wildland-Urban Interface, and Wildfire Management." Society and Natural Resources 22 (8): 777-782.

Hoover, Katie, and Bruce R. Lindsay. 2017. "Wildfire Suppression Spending: Background, Issues, and Legislation in the 115th Congress." Congressional Research Service Report R44966, October.

Kahn, Matthew E, and V Kerry Smith. 2017. "The Affordability Goal and Prices in the National Flood Insurance Program." NBER Working Paper.

Kennan, John, and James R. Walker. 2011. "The Effect of Expected Income on Individual Migration Decisions." Econometrica 79 (1): 211-251.

Kennedy, Peter. 1981. "Estimation with Correctly Interpreted Dummy Variables in Semilogarithmic Equations." American Economic Review 71 (4): 801.

Kousky, Carolyn, Erzo F. P. Luttmer, and Richard J. Zeckhauser. 2006. "Private Investment and Government Protection." Journal of Risk and Uncertainty 33 (1): $73-100$.

Kousky, Carolyn, and Sheila Olmstead. 2012. "Induced Development in Risky Locations: Fire Suppression and Land Use in the American West." Working Paper.

Liang, Jingjing, Dave E. Calkin, Krista M. Gebert, Tyron J. Venn, and Robin P. Silverstein. 2008. "Factors Influencing Large Wildland Fire Suppression Expenditures." International Journal of Wildland Fire 17 (5): 650-659.

Loomis, John. 2004. "Do Nearby Forest Fires Cause a Reduction in Residential Property Values?" Journal of Forest Economics 10 (3): 149-157.

Lueck, Dean, and Jonathan Yoder. 2016. Clearing the Smoke from Wildfire Policy: An Economic Perspective. PERC Policy Series 56.

Mann, Michael, Peter Berck, Max Moritz, Enric Batllori, James Baldwin, Conor Gately, and D. Richard Cameron. 2014. "Modeling Residential Development in California from 2000 to 2050: Integrating Wildfire Risk, Wildland and Agricultural Encroachment." Land Use Policy 41:438-452.

Martinuzzi, Sebastián, Susan Stewart, David Helmers, Miranda Mockrin, Roger Hammer, and Volker Radeloff. 2015. The 2010 Wildland-Urban Interface of the Conterminous United States. Research Map NRS-8. U.S. Department of Agriculture, Forest Service, Northern Research Station.

Massada, Avi Bar, Alexandra D. Syphard, Susan I. Stewart, and Volker C. Radeloff. 2012. "Wildfire Ignition-distribution Modelling: A Comparative Study in the Huron-manistee National Forest, Michigan, USA." International Journal of Wildland Fire 22 (2): 174-183. 
McCoy, Shawn J., and Randall P. Walsh. 2018. "Wildfire Risk, Salience and Housing Demand." Journal of Environmental Economics and Management 91:203-228.

National Wildfire Coordinating Group. 2014. Wildland Fire Incident Management Field Guide. Technical report PMS 210 NFES 002943.

Oster, Emily. 2019. "Unobservable Selection and Coefficient Stability: Theory and Evidence." Journal of Business 86 Economic Statistics 37 (2): 187-204.

Polinsky, A. Mitchell, and David T. Ellwood. 1979. "An Empirical Reconciliation of Micro and Grouped Estimates of the Demand for Housing." Review of Economics and Statistics: 199-205.

Radeloff, Volker, Roger Hammer, Susan Stewart, Jeremy Fried, Sherry Holcomb, and Jason McKeefry. 2005. "The Wildland-Urban Interface in the United States." Ecological Applications 15 (3): 799-805.

Radeloff, Volker, David Helmers, H. Anu Kramer, Miranda Mockrin, Patricia Alexandre, Avi Bar-Massada, Van Butsic, et al. 2018. "Rapid Growth of the US WildlandUrban Interface Raises Wildfire Risk." Proceedings of the National Academy of Sciences 115, no. 13 (March): 3314-3319.

Saiz, Albert. 2010. "The Geographic Determinants of Housing Supply." The Quarterly Journal of Economics 125 (3): 1253-1296.

Sigman, Hilary. 2001. "The Pace of Progress at Superfund sites: Policy Goals and Interest Group Influence." Journal of Law and Economics 44 (1): 315-343.

Simon, Gregory L. 2017. Flame and Fortune in the American West: Urban Development, Environmental Change, and the Great Oakland Hills Fire. 1st ed. University of California Press.

Smith, V Kerry, Jared Carbone, Jaren Pope, Daniel Hallstrom, and Michael Darden. 2006. "Adjusting to Natural Disasters." Journal of Risk and Uncertainty 33 (1): $37-54$.

Stephens, Scott, Brandon Collins, Eric Biber, and Peter Fulé. 2016. "US Federal Fire and Forest Policy: Emphasizing Resilience in Dry Forests." Ecosphere 7 (11).

Stetler, Kyle M., Tyron J. Venn, and David E. Calkin. 2010. "The Effects of Wildfire and Environmental Amenities on Property Values in Northwest Montana, USA." Ecological Economics 69 (11): 2233-2243.

Syphard, Alexandra, Volker Radeloff, Jon Keeley, Todd Hawbaker, Murray Clayton, Susan Stewart, and Roger Hammer. 2007. "Human Influence on California Fire Regimes." Ecological Applications 17 (5): 1388-1402.

Topel, Robert, and Sherwin Rosen. 1988. "Housing Investment in the United States." Journal of Political Economy 96 (4): 718-740. 
USDA (USDA Office of Inspector General). 2006. Forest Service Large Fire Suppression Costs. Audit Report 08601-44-SF.

Wei, Yu, Matthew Thompson, Jessica Haas, Gregory Dillon, and Christopher O'Connor. 2018. "Spatial Optimization of Operationally Relevant Large Fire Confine and Point Protection Strategies: Model Development and Test Cases." Canadian Journal of Forest Research 48 (5): 480-493.

Wibbenmeyer, Matthew. 2017. "Burning Down the House: Wildfire and the Benefits of Responses to Natural Disasters." Working Paper. 
Figure 1: The Market for Housing in a Risky Place

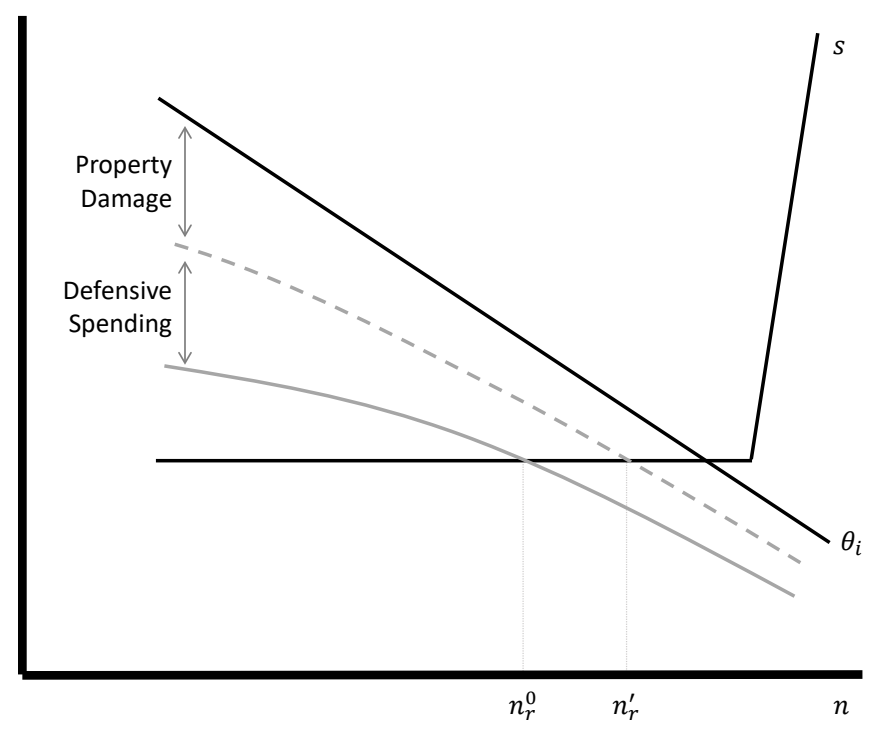

Notes: Illustration of housing demand in the risky place under alternative policies for financing defensive expenditures, as described in Section 2.

Figure 2: Example National Forest Units
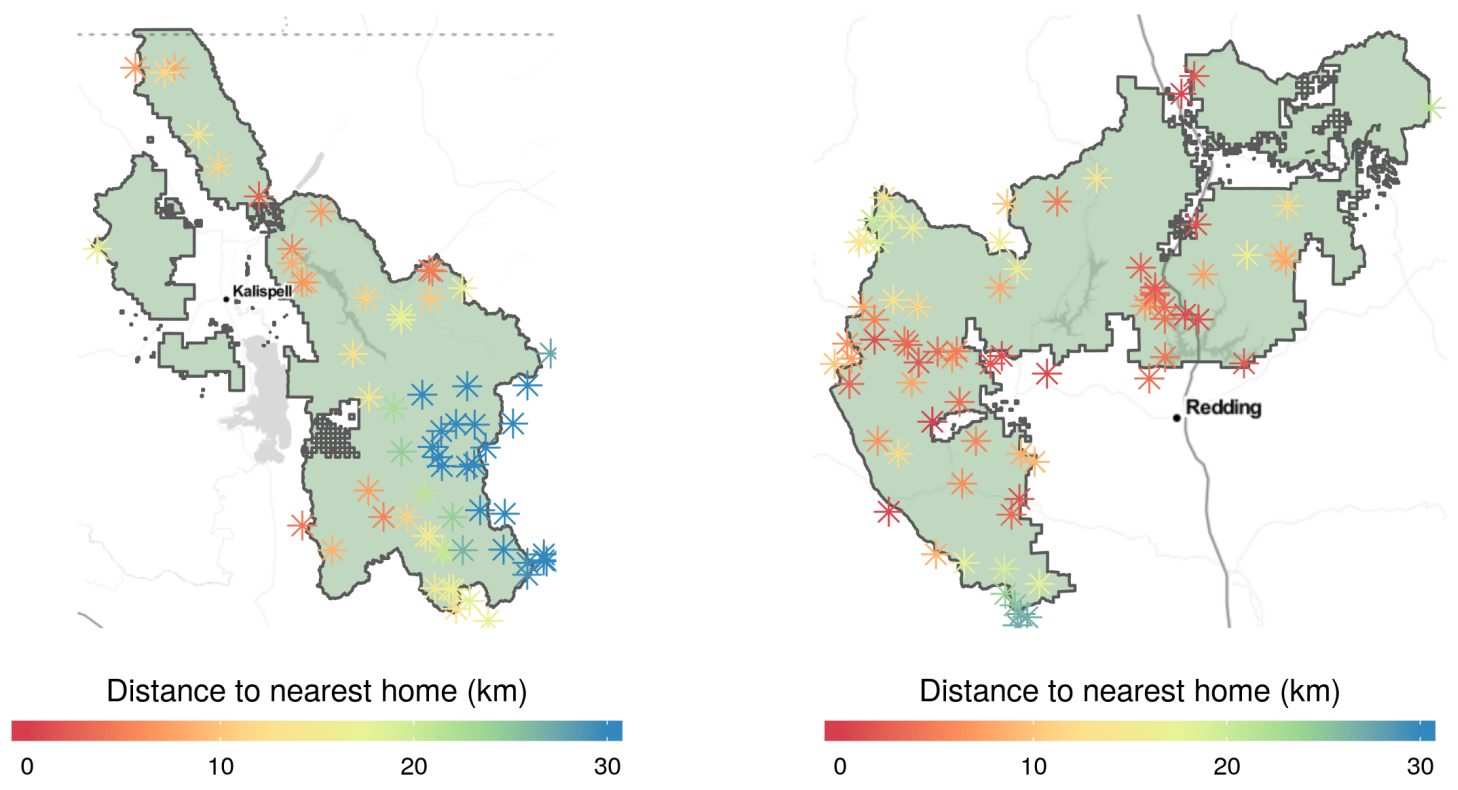

Notes: Each panel shows a single national forest area in green. Stars show individual wildfires colored by distance from ignition point to nearest home (top-coded at $30 \mathrm{~km}$ ). Left map is Flathead National Forest (Montana); right map is Shasta Trinity National Forest (California). 
Figure 3: The Effect of Homes on Firefighting Costs

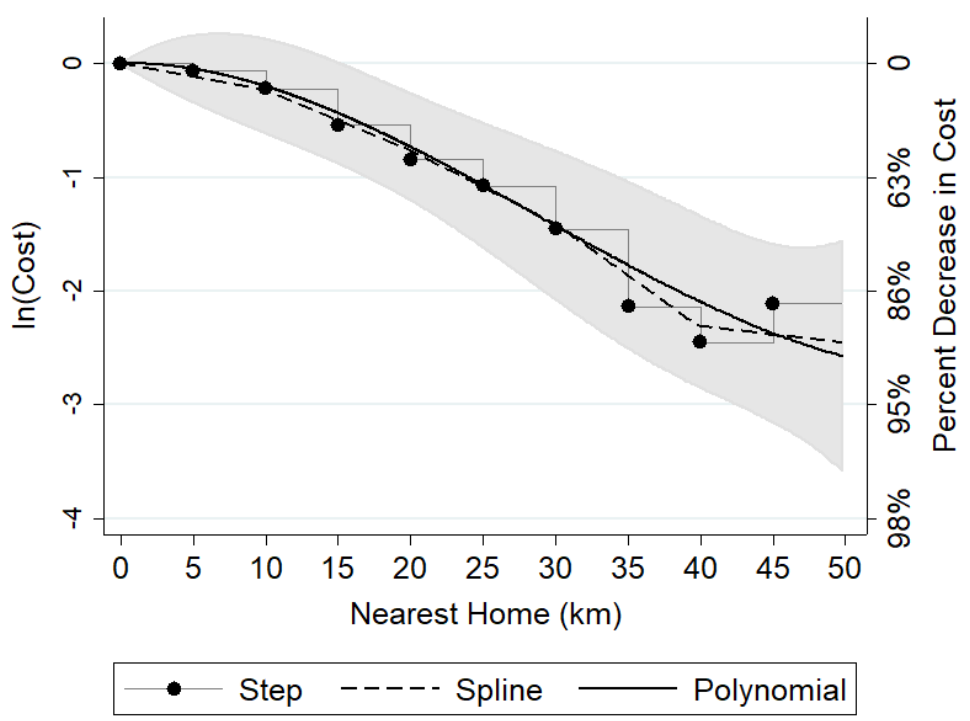

Notes: Figure shows three separate regressions of log firefighting cost on distance from ignition point to the nearest home. The step function shows coefficients on indicators for $5 \mathrm{~km}$ distance bins. Linear spline is a piecewise linear regression with knots every $10 \mathrm{~km}$. The gray shaded area around the cubic polynomial is the $95 \%$ confidence interval. Each regression includes national forest fixed effects, state by month-of-year fixed effects, and state by year fixed effects. Standard errors are clustered by national forest. The right-hand vertical scale shows approximate percentage decrease in cost relative to a fire less than $5 \mathrm{~km}$ from homes, calculated as $\exp (\beta)-1$ for a coefficient $\beta$ in the binned regression.

Figure 4: Non-linear Effects of the Number of Nearby Homes

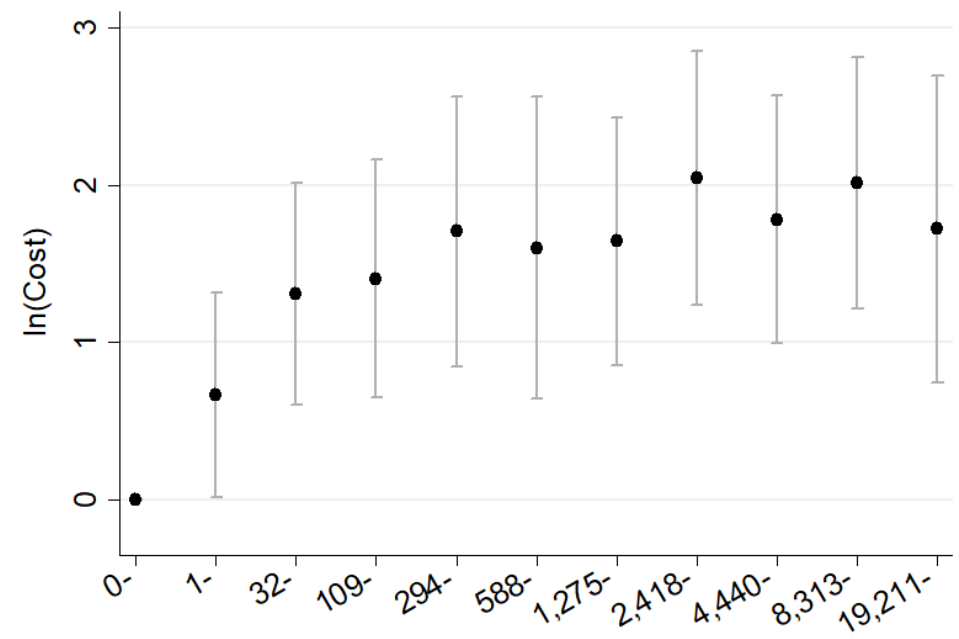

Number of Homes within 30 kilometers

Notes: Figure shows point estimates and 95\% confidence intervals from a regression of log firefighting cost on deciles of home counts within 30 kilometers of the fire's ignition point. The regression includes national forest fixed effects, state by month-of-year fixed effects, and state by year fixed effects. Standard errors are clustered by national forest. 
Figure 5: Average Historical Protection Costs for 8.6 Million W.U.I. Homes

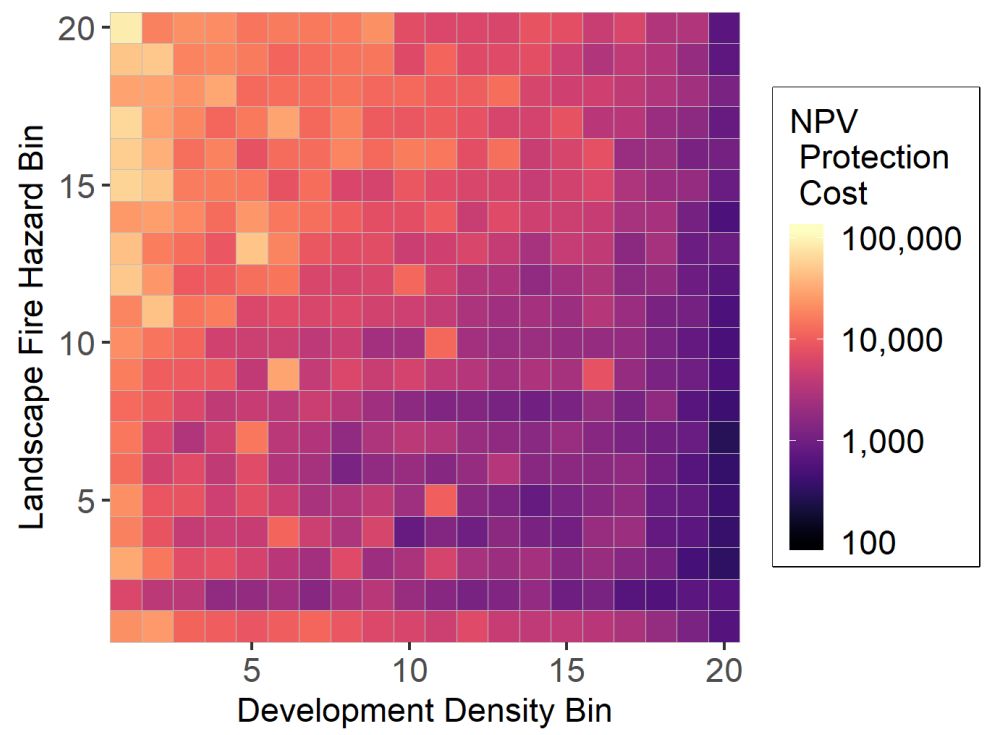

Notes: Figure shows average NPV of historical protection costs in each cell. The 20 horizontal-axis bins are defined by the grid cell-level distribution of population density. The 20 vertical-axis bins are defined by wildfire hazard potential (Dillon 2015). One bin includes homes in areas with zero WHP; the remaining 19 bins follow the distribution of non-zero WHP scores. Cost estimates use the "suppression plus" cost metric and a $5 \%$ discount rate.

Figure 6: Expected Protection Costs (West-wide)
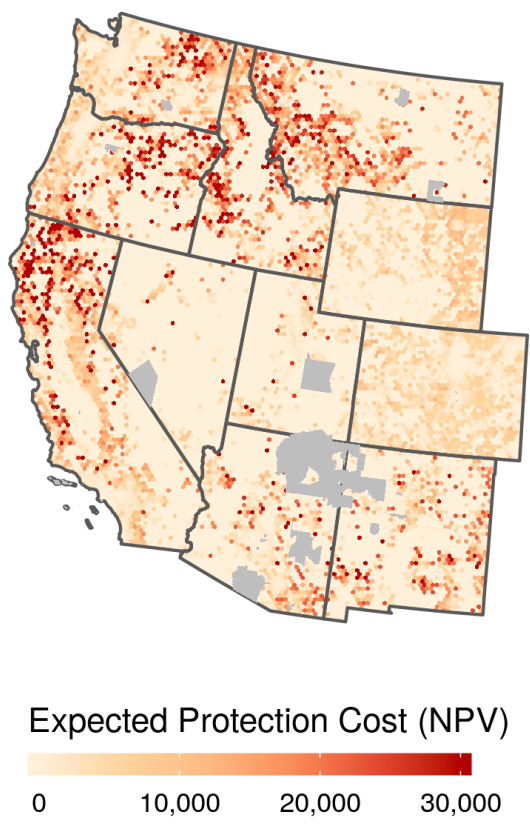

Notes: Actuarial estimates of the NPV of the government's expected cost to protect a home from wildfires, averaged across $15 \mathrm{~km}$ hex cells. Scale is top-coded at $\$ 30,000$ per home; gray is missing data. Sample includes 8.6 million at-risk homes. See Section 5 for details. 
Figure 7: Expected Protection Costs (Local Variation)
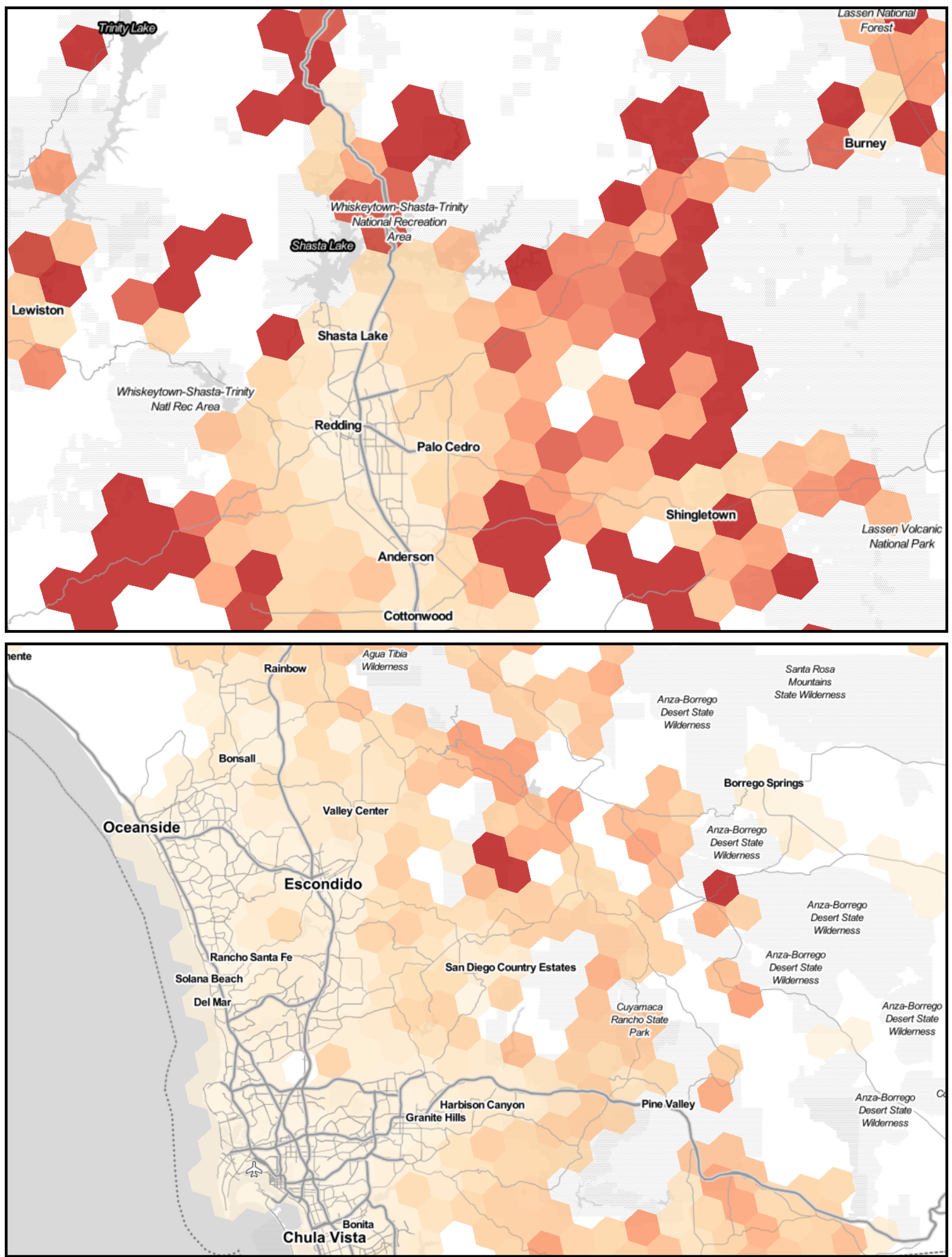

Notes: Best viewed in color. Reproduces Fig. 6 with same color scale and $5 \mathrm{~km}$ cells. White and gray areas are unpopulated or public. Top map is Shasta County, CA; bottom is San Diego County, CA. 
Figure 8: Expected Protection Cost by Income and Home Value

(a) Income

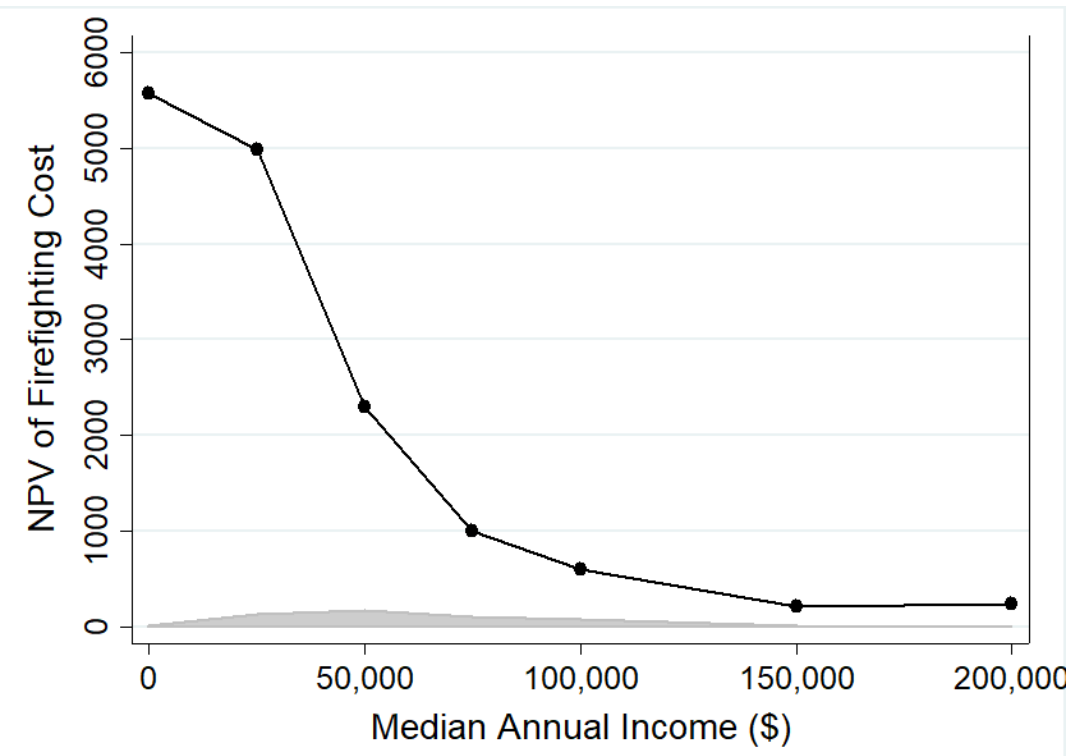

(b) Transaction Value

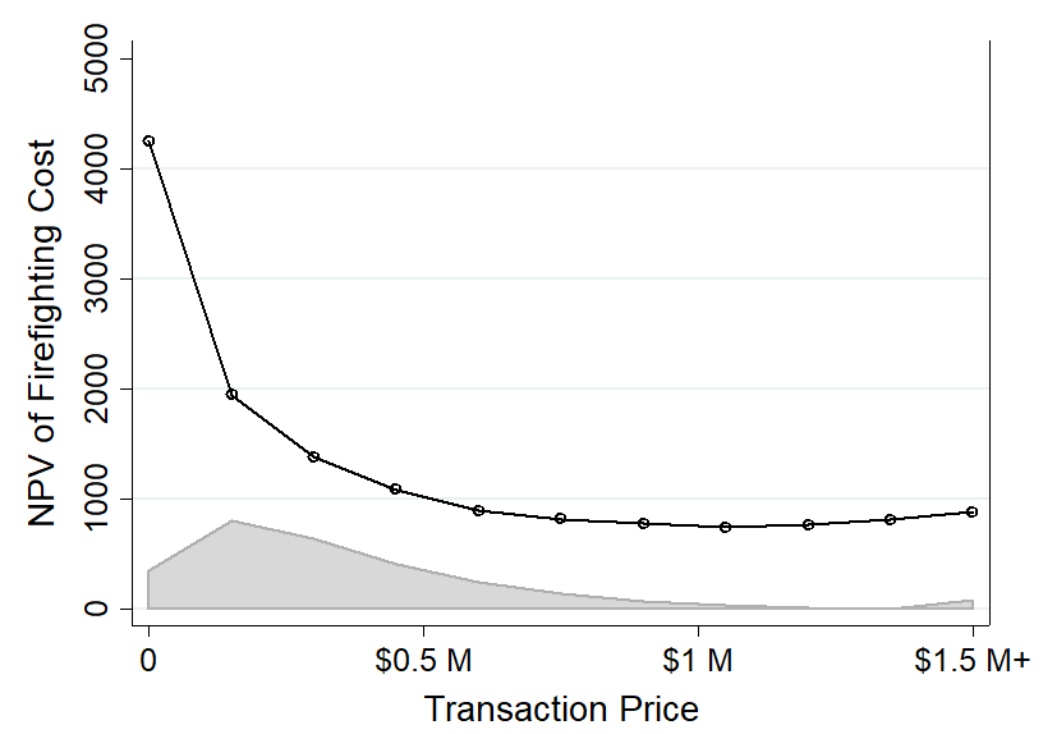

Notes: The black line in each panel shows average expected protection costs. The gray density shows the distribution of homes. Panel (a): Each home is assigned the median annual income for its Census block group from the 2015 American Community Survey. Panel (b): This calculation uses the subset of homes with non-missing transaction values; see data appendix for details. 
Table 1: The Effect of Proximity to Homes on Firefighting Costs

\begin{tabular}{|c|c|c|c|c|c|}
\hline & (1) & $(2)$ & $(3)$ & $(4)$ & $(5)$ \\
\hline \multicolumn{6}{|l|}{ Distance to Homes $(\mathrm{km})$} \\
\hline $10-20$ & $\begin{array}{l}-0.34 \\
(0.15)\end{array}$ & $\begin{array}{l}-0.34 \\
(0.15)\end{array}$ & $\begin{array}{l}-0.42 \\
(0.19)\end{array}$ & $\begin{array}{l}-0.38 \\
(0.21)\end{array}$ & $\begin{array}{l}-0.46 \\
(0.32)\end{array}$ \\
\hline $20-30$ & $\begin{array}{l}-0.97 \\
(0.28)\end{array}$ & $\begin{array}{l}-0.90 \\
(0.27)\end{array}$ & $\begin{array}{l}-1.00 \\
(0.37)\end{array}$ & $\begin{array}{l}-0.97 \\
(0.34)\end{array}$ & $\begin{array}{l}-1.52 \\
(0.57)\end{array}$ \\
\hline $30-40$ & $\begin{array}{l}-1.73 \\
(0.46)\end{array}$ & $\begin{array}{l}-1.66 \\
(0.45)\end{array}$ & $\begin{array}{l}-1.67 \\
(0.51)\end{array}$ & $\begin{array}{l}-1.72 \\
(0.50)\end{array}$ & $\begin{array}{l}-2.50 \\
(0.73)\end{array}$ \\
\hline $40+$ & $\begin{array}{l}-2.09 \\
(0.41)\end{array}$ & $\begin{array}{l}-2.03 \\
(0.38)\end{array}$ & $\begin{array}{l}-1.93 \\
(0.46)\end{array}$ & $\begin{array}{l}-2.11 \\
(0.45)\end{array}$ & $\begin{array}{l}-2.21 \\
(0.91)\end{array}$ \\
\hline $\begin{array}{l}\text { Controls for Weather, } \\
\text { Topography, and Vegetation }\end{array}$ & & $\mathrm{X}$ & $\mathrm{X}$ & $\mathrm{X}$ & $\mathrm{X}$ \\
\hline National Forest FE & $\mathrm{X}$ & $\mathrm{X}$ & $\mathrm{X}$ & $\mathrm{X}$ & $\mathrm{X}$ \\
\hline Year by State FE & $\mathrm{X}$ & $\mathrm{X}$ & & $\mathrm{X}$ & $\mathrm{X}$ \\
\hline Month-of-Year by State FE & $\mathrm{X}$ & $\mathrm{X}$ & & $\mathrm{X}$ & $\mathrm{X}$ \\
\hline Month-of-Sample by State FE & & & $\mathrm{X}$ & & \\
\hline Lightning fires only & & & & $\mathrm{X}$ & \\
\hline Timber Fuels only & & & & & $\mathrm{X}$ \\
\hline Fires & 2,089 & 2,089 & 2,089 & 1,470 & 772 \\
\hline $\mathrm{R}^{2}$ & 0.42 & 0.43 & 0.54 & 0.45 & 0.58 \\
\hline
\end{tabular}

Notes: Table reports the results of five separate OLS regressions. The sample includes western US fires managed by the Forest Service during 1995-2014. In each regression the dependent variable is the natural log of suppression cost. The table rows report coefficients and standard errors on dummy variables corresponding to distance to the nearest home. The omitted category is $0-$ 10 kilometers. Controls for weather, topography, and vegetation include wind speed, wind speed squared, terrain slope, slope squared, vapor pressure deficit (VPD), VPD squared, precipitation, precipitation squared, an indicator for south/southwest facing, and indicators for fuel models (vegetation types) from LANDFIRE. Weather variables are measured on the day of ignition and topographic variables are measured at the ignition site. See online appendix for regression coefficients for these controls. National forest fixed effects include 86 national forests in the western US. Standard errors are clustered at the national forest level. 
Table 2: Expected Protection Costs for 8.6 Million Western Homes

\begin{tabular}{lrrrr}
\hline \hline & $(1)$ & $(2)$ & $(3)$ & $(4)$ \\
& $\begin{array}{r}\text { Federal } \\
\text { Suppression } \\
\text { Only (\$) }\end{array}$ & $\begin{array}{r}\text { Suppression } \\
\text { Plus } \\
(\$)\end{array}$ & $\begin{array}{r}\text { California } \\
\text { Only } \\
(\$)\end{array}$ & $\begin{array}{r}\text { Share of } \\
\text { Property } \\
\text { Value (\%) }\end{array}$ \\
\hline Mean & 1,077 & 2,408 & 2,712 & 1.6 \\
p50 & 500 & 1,200 & 1,300 & 0.6 \\
p90 & 2,100 & 5,200 & 6,600 & 3.6 \\
p95 & 3,800 & 8,400 & 9,000 & 5.5 \\
p99 & 12,700 & 22,700 & 18,200 & 19.6 \\
\hline $\mathrm{N}$ & $8,633,554$ & $8,633,554$ & $3,483,715$ & $8,633,554$ \\
\hline
\end{tabular}

Notes: This table describes the distribution of expected firefighting costs for homes in the western United States. These costs represent the additional costs incurred by the federal government to protect each home, and are calculated using 210 actuarial groups based on six categories of landscape fire risk, five categories of housing density, and seven wildland firefighting dispatch regions (GACC regions). Costs are present values using a 5\% discount rate. The first three columns report expected costs using three different metrics defined in the text. The final column reports the "suppression plus" cost measure divided by the transaction value of the property. Values are in 2017 dollars. Percentile cutoffs are rounded to the nearest $\$ 100$. See text for details. 
Table 3: Implied Changes in Housing Quantity

\begin{tabular}{|c|c|c|c|c|}
\hline $\begin{array}{l}\text { Wildfire } \\
\text { Hazard } \\
\text { Class }\end{array}$ & $\begin{array}{c}\text { Density } \\
\text { Group }\end{array}$ & $\begin{array}{r}\text { Subsidy as \% } \\
\text { of Observed } \\
\text { Price }\end{array}$ & $\begin{array}{r}\text { Observed } \\
\text { Number of } \\
\text { of Homes }\end{array}$ & $\begin{array}{r}\% \text { Increase in } \\
\text { Quantity Due } \\
\text { to Subsidy }\end{array}$ \\
\hline \multicolumn{5}{|c|}{ Panel A. Highest Risk Areas } \\
\hline 5 & 0 & 36.2 & 11,331 & 26.6 \\
\hline 4 & 0 & 21.9 & 28,118 & 18.0 \\
\hline $1-3$ & 0 & 15.9 & 111,713 & 13.7 \\
\hline 5 & 1 & 13.5 & 15,019 & 11.9 \\
\hline 4 & 1 & 11.0 & 31,968 & 9.9 \\
\hline $1-3$ & 1 & 6.1 & 154,463 & 5.7 \\
\hline 5 & 2 & 5.8 & 26,010 & 5.5 \\
\hline 4 & 2 & 7.0 & 60,453 & 6.5 \\
\hline $1-3$ & 2 & 4.0 & 265,348 & 3.8 \\
\hline 5 & 3 & 4.8 & 52,708 & 4.6 \\
\hline 4 & 3 & 3.6 & 143,169 & 3.5 \\
\hline $1-3$ & 3 & 2.3 & 581,670 & 2.3 \\
\hline 5 & 4 & 2.4 & 72,763 & 2.3 \\
\hline 4 & 4 & 1.2 & 334,607 & 1.2 \\
\hline $1-3$ & 4 & 0.6 & $1,777,361$ & 0.6 \\
\hline \multicolumn{2}{|c|}{ Panel A Total } & 2.6 & $3,666,701$ & 2.3 \\
\hline \multicolumn{5}{|c|}{ Panel B. All Other WUI Homes } \\
\hline 0 & $0-4$ & 0.8 & $4,966,853$ & 0.7 \\
\hline
\end{tabular}

Notes: This table summarizes subsidy rates and back-of-envelope quantity changes using the fire hazard and density categories described in the text. The subsidy rates in Column 3 are number-of-homes-weighted average subsidy rates across geographic regions. 
A Additional Results and Robustness Checks $\quad$ A2

A.1 Effect of Homes on Fire Costs . . . . . . . . . . . . . . . . A2

A.1.1 Robustness Checks . . . . . . . . . . . . . . . A2

A.1.2 Non-USFS Agencies . . . . . . . . . . . . . . . . A9

A.1.3 Effect of Homes on the Number of Fires . . . . . . . . . . A12

A.2 Expected Protection Costs . . . . . . . . . . . . . . A14

A.2.1 Variables Used to Define Actuarial Groups . . . . . . . . . . . A14

A.2.2 Maps of Suppression-Only and California Measures . . . . . A15

A.2.3 Alternative Measures Based on Interview Evidence . . . . . . A15

A.2.4 Machine Learning to Define Actuarial Groups . . . . . . . . A16

A.3 Theory Appendix . . . . . . . . . . . . . . . . A18

B Construction of the dataset $\quad$ A20

B.1 Wildland Firefighting Expenditures . . . . . . . . . . . A20

B.1.1 US Forest Service . . . . . . . . . . . . . . . . . A20

B.1.2 Department of Interior Agencies . . . . . . . . . . . . . A22

B.1.3 California Department of Forestry and Fire Protection . . . . A22

B.1.4 Federal Emergency Management Agency . . . . . . . . . . . . A23

B.1.5 Harmonization of Fire Suppression Cost Data . . . . . . . . A24

B.1.6 Ignition Point Characteristics and Weather Data . . . . . . A24

B.2 Parcel Data . . . . . . . . . . . . . . . . . . . . . . . A A28

B.2.1 Comparison to Census Aggregate Data . . . . . . . . . . A A29

B.3 Calculating Counterfactual Costs With No Nearby Homes . . . . . . A33

B.3.1 Main Approach . . . . . . . . . . . . . . . . . . . . . A33

B.3.2 Alternative Approaches: GLM and Retransformation ..... A33

C Comparison to Forest Service Accounting Data 


\section{A Additional Results and Robustness Checks}

\section{A.1 Effect of Homes on Fire Costs}

\section{A.1.1 Robustness Checks}

Appendix Table 1 shows the results from Table 1 in the main text, including coefficients on the control variables as well as an additional "no controls" specification. It also shows an additional specification that includes controls for the distance from the ignition point to the nearest primary road. ${ }^{30}$

Appendix Table 2 shows a robustness check proposed by Oster (2019), building on Altonji, Elder, and Taber (2005) and related work. This sensitivity test bounds the potential bias from unobservable confounders under an assumption about $\delta$, the relative degree of selection on observables and unobservables, and an assumption about $R_{\max }$, the $R^{2}$ of a hypothetical regression containing all the observables and unobservables. Oster (2019) shows that for $\delta=1$ (equal selection on onbservables and unobservables), the bias-adjusted treatment effect $\beta^{*}$ is approximately $\tilde{\beta}-[\dot{\beta}-$ $\tilde{\beta}] \frac{R_{\max }-\tilde{R}}{\tilde{R}-\dot{R}}$. Here, $\tilde{\beta}$ and $\tilde{R}$ are the coefficient and $R^{2}$ from a regression with the full set of controls, and $\dot{\beta}$ and $\dot{R}$ come from a restricted specification. This approximate formula provides intuition: results are more robust when including controls produces smaller changes in the coefficient, and larger increases in the $R^{2}$.

We implement the exact version of the calculation provided in Oster (2019) and the software package psacalc. Because Oster's test is limited to a scalar treatment, we implement the regression test for a linear version of Equation 3, where $g$ (Homes) is the distance from the ignition point to the nearest home (this is a mild restriction given the near-linearity apparent in Figure 3). The restricted specification includes only national forest fixed effects. The controlled specification is Column (3) from Table 1, the richest set of controls that we discuss. It includes the weather, topography, and vegetation variables described in Table 1 and Appendix Table 1. It also includes yearmonth by state (i.e., month of sample by state) dummies that proxy for unobservable changes in fire risk due to factors such as fuel dryness. We follow Oster (2019) and assume that $R_{\max }=1.3 \tilde{R}$. The final column of Appendix Table 2 reports Oster's recommended quantity, an "identified set" for the effect of distance to homes on fire costs. The lower bound is the bias-adjusted treatment effect assuming $\delta=1$, and the upper bound is $\tilde{\beta}$. In Oster's framework, results are considered robust when this set excludes zero. This condition holds in our case. Furthermore, the lower bound on the treatment effect of -0.042 is similar to the fully-controlled regression coefficient of -0.050 .

Appendix Table 3 shows additional robustness checks for the effects of the number of

30. Road data come from the US Census TIGER/Line shapefile for primary roads for 2016. Primary roads roughly correspond to interstate highways. 
nearby homes on fire costs. Columns (1) through (5) show the same checks that we showed for the effect of the nearest home in Table 1. Our results are robust to these various tests. Column (6) shows an additional specification that measures the stock of nearby homes by total transaction value, instead of number of homes. Results are again similar.

Appendix Figure 1 shows results using different radii around the ignition point to count threatened homes. The omitted category in each regression is fires with zero homes within the radius. The other bins in each regression are defined by deciles of number of homes, conditional on any homes within the radius. For all three radii, there is a clear pattern of quick increases across the first two bins, and then roughly constant costs at higher numbers of homes. Note that direct comparisons of these coefficients across bins are difficult, since the comparison group of fires with zero threatened homes is systematically different across columns (e.g., for $40 \mathrm{~km}$, all fires with zero homes are very remote by construction). Several other effects also presumably occur simultaneously as we widen the radius: since further-away homes have less effect on costs, these measures attenuate somewhat; however, because calculating density over a wider area may reduce noise in our assessment of the number of threatened homes, there may be another factor making these measurements more precise. Finally, note that the actual bin endpoints vary across models. Importantly, however, the obvious non-linear pattern of costs by number of homes exists for any radius.

Appendix Figure 2 plots covariate overlap for the covariates included in the regressions. 
Appendix Table 1: The Effect of Proximity to Homes: Full Results

\begin{tabular}{|c|c|c|c|}
\hline & $(1)$ & $(2)$ & $(3)$ \\
\hline $10-20 \mathrm{~km}$ & $\begin{array}{l}-0.5232 \\
(0.1709)\end{array}$ & $\begin{array}{c}-0.3436 \\
(0.1491)\end{array}$ & $\begin{array}{l}-0.4099 \\
(0.1586)\end{array}$ \\
\hline $20-30 \mathrm{~km}$ & $\begin{array}{l}-1.1075 \\
(0.3261)\end{array}$ & $\begin{array}{c}-0.9018 \\
(0.2676)\end{array}$ & $\begin{array}{c}-0.9957 \\
(0.2861)\end{array}$ \\
\hline $30-40 \mathrm{~km}$ & $\begin{array}{l}-2.4784 \\
(0.3796)\end{array}$ & $\begin{array}{c}-1.6605 \\
(0.4528)\end{array}$ & $\begin{array}{l}-1.7601 \\
(0.5275)\end{array}$ \\
\hline $40+\mathrm{km}$ & $\begin{array}{l}-2.7290 \\
(0.3631)\end{array}$ & $\begin{array}{c}-2.0257 \\
(0.3774)\end{array}$ & $\begin{array}{l}-2.1063 \\
(0.4511)\end{array}$ \\
\hline WindSpeed & & $\begin{array}{c}0.0642 \\
(0.0347)\end{array}$ & $\begin{array}{c}0.0691 \\
(0.0347)\end{array}$ \\
\hline WindSpeed $^{2}$ & & $\begin{array}{c}-0.0017 \\
(0.0013)\end{array}$ & $\begin{array}{l}-0.0019 \\
(0.0013)\end{array}$ \\
\hline TerrainSlope & & $\begin{array}{c}0.0413 \\
(0.0181)\end{array}$ & $\begin{array}{c}0.0420 \\
(0.0185)\end{array}$ \\
\hline TerrainSlope $^{2}$ & & $\begin{array}{c}-0.0007 \\
(0.0004)\end{array}$ & $\begin{array}{c}-0.0007 \\
(0.0004)\end{array}$ \\
\hline VaporPressureDeficit & & $\begin{array}{c}0.0681 \\
(0.0371)\end{array}$ & $\begin{array}{c}0.0661 \\
(0.0351)\end{array}$ \\
\hline VaporPressureDeficit ${ }^{2}$ & & $\begin{array}{c}-0.0015 \\
(0.0007)\end{array}$ & $\begin{array}{l}-0.0014 \\
(0.0007)\end{array}$ \\
\hline Precipitation & & $\begin{array}{c}-0.0513 \\
(0.0440)\end{array}$ & $\begin{array}{l}-0.0446 \\
(0.0432)\end{array}$ \\
\hline Precipitation $^{2}$ & & $\begin{array}{c}0.0010 \\
(0.0010)\end{array}$ & $\begin{array}{c}0.0010 \\
(0.0010)\end{array}$ \\
\hline South/SW Aspect & & $\begin{array}{c}0.2361 \\
(0.1356)\end{array}$ & $\begin{array}{c}0.2322 \\
(0.1362)\end{array}$ \\
\hline Shrub Fuel Model & & $\begin{array}{c}-0.1266 \\
(0.1926)\end{array}$ & $\begin{array}{c}-0.1482 \\
(0.1921)\end{array}$ \\
\hline Timber Fuel Model & & $\begin{array}{c}-0.0829 \\
(0.1545)\end{array}$ & $\begin{array}{l}-0.0900 \\
(0.1527)\end{array}$ \\
\hline Slash Fuel Model & & $\begin{array}{c}0.5048 \\
(0.3638)\end{array}$ & $\begin{array}{c}0.4466 \\
(0.3730)\end{array}$ \\
\hline Urban/Barren Fuel Model & & $\begin{array}{c}-0.1804 \\
(0.2460)\end{array}$ & $\begin{array}{c}-0.1837 \\
(0.2476)\end{array}$ \\
\hline Distance to Primary Road & & & $\begin{array}{c}0.0109 \\
(0.0064)\end{array}$ \\
\hline (Distance to Primary Road) $^{2}$ & & & $\begin{array}{l}-0.0000 \\
(0.0000)\end{array}$ \\
\hline Constant & $\begin{array}{l}13.5168 \\
(0.1873)\end{array}$ & $\begin{array}{l}10.8345 \\
(1.6243)\end{array}$ & $\begin{array}{l}10.1655 \\
(1.6171)\end{array}$ \\
\hline National Forest FE & & $\mathrm{X}$ & $\mathrm{X}$ \\
\hline Year by State FE & & $\mathrm{X}$ & $\mathrm{X}$ \\
\hline Month-of-Year by State FE & & $\mathrm{X}$ & $\mathrm{X}$ \\
\hline Fires & 2,089 & 2,089 & 2,089 \\
\hline $\mathrm{R}^{2}$ & 0.09 & 0.43 & 0.43 \\
\hline
\end{tabular}

Notes: Column (2) reproduces Column (2) of Table 1, showing coefficients for the controls. Column (1) shows a no-controls specification for comparison. Terrain slope is the linear slope of the ground surface. Wind speed is average speed on the day of ignition at the reference weather station listed in FAMWEB (in miles per hour). Vapor pressure deficit is for the ignition location and day, from PRISM, and measured in hectopascals (millibars). Precipitation is the amount of precipitation on the ignition day in mm, from PRISM. Fuel model fixed effects include four categories corresponding to LANDFIRE fuel models for brush, grass, timber, and barren/urban/other. The omitted fuel model category is grass. Forest unit fixed effects include 86 national forests in the western US Standard errors are clustered at the national forest level. 
Appendix Table 2: Oster's (2019) Coefficient Stability Test

\begin{tabular}{lccc}
\hline \hline & $\begin{array}{c}\text { Restricted } \\
\text { Specification }\end{array}$ & $\begin{array}{c}\text { Controlled } \\
\text { Specification }\end{array}$ & $\begin{array}{c}\text { Identified } \\
\text { Set }\end{array}$ \\
\hline Coefficient & -0.054 & -0.050 & $(-0.042,-0.050)$ \\
Standard Error & 0.005 & 0.007 & \\
$\mathrm{R}^{2}$ & 0.27 & 0.54 \\
\hline Included Controls & National Forest FEs & $\begin{array}{c}\text { National Forest FEs, } \\
\text { Weather, Topography, } \\
\end{array}$ & $\begin{array}{c}\text { Vegetation, Month-of-sample } \\
\text { by state dummies }\end{array}$ \\
\hline
\end{tabular}

Notes: This table implements a procedure proposed by Oster (2019) to bound selection bias due to unobservable confounders. See the text of Appendix A.1.1 for details. 
Appendix Table 3: The Effect of Number or Value of Homes, Robustness Checks

\begin{tabular}{|c|c|c|c|c|c|c|}
\hline & \multicolumn{5}{|c|}{ Number } & \multirow{2}{*}{$\frac{\text { Value }}{(6)}$} \\
\hline & (1) & $(2)$ & $(3)$ & $(4)$ & (5) & \\
\hline \multicolumn{7}{|l|}{ Quintile Bins } \\
\hline 1 & $\begin{array}{c}0.97 \\
(0.31)\end{array}$ & $\begin{array}{c}0.94 \\
(0.31)\end{array}$ & $\begin{array}{c}0.91 \\
(0.36)\end{array}$ & $\begin{array}{c}1.00 \\
(0.34)\end{array}$ & $\begin{array}{l}1.15 \\
(0.69)\end{array}$ & $\begin{array}{c}0.89 \\
(0.32)\end{array}$ \\
\hline 2 & $\begin{array}{c}1.52 \\
(0.38)\end{array}$ & $\begin{array}{l}1.46 \\
(0.37)\end{array}$ & $\begin{array}{l}1.38 \\
(0.40)\end{array}$ & $\begin{array}{c}1.46 \\
(0.39)\end{array}$ & $\begin{array}{l}1.41 \\
(0.54)\end{array}$ & $\begin{array}{c}1.43 \\
(0.42)\end{array}$ \\
\hline 3 & $\begin{array}{c}1.61 \\
(0.45)\end{array}$ & $\begin{array}{l}1.57 \\
(0.43)\end{array}$ & $\begin{array}{c}1.37 \\
(0.48)\end{array}$ & $\begin{array}{l}1.45 \\
(0.45)\end{array}$ & $\begin{array}{l}1.91 \\
(0.66)\end{array}$ & $\begin{array}{c}1.64 \\
(0.40)\end{array}$ \\
\hline 4 & $\begin{array}{c}1.85 \\
(0.39)\end{array}$ & $\begin{array}{l}1.78 \\
(0.37)\end{array}$ & $\begin{array}{l}1.75 \\
(0.44)\end{array}$ & $\begin{array}{c}1.71 \\
(0.43)\end{array}$ & $\begin{array}{c}2.31 \\
(0.65)\end{array}$ & $\begin{array}{c}1.86 \\
(0.37)\end{array}$ \\
\hline 5 & $\begin{array}{c}1.87 \\
(0.43)\end{array}$ & $\begin{array}{c}1.81 \\
(0.41)\end{array}$ & $\begin{array}{c}1.54 \\
(0.47)\end{array}$ & $\begin{array}{c}1.75 \\
(0.49)\end{array}$ & $\begin{array}{l}1.98 \\
(0.70)\end{array}$ & $\begin{array}{c}1.83 \\
(0.41)\end{array}$ \\
\hline $\begin{array}{l}\text { Controls for Weather, } \\
\text { Topography, and Vegetation }\end{array}$ & & $\mathrm{X}$ & $\mathrm{X}$ & $\mathrm{X}$ & $\mathrm{X}$ & $\mathrm{X}$ \\
\hline National Forest FE & $\mathrm{X}$ & $\mathrm{X}$ & $\mathrm{X}$ & $\mathrm{X}$ & $\mathrm{X}$ & $\mathrm{X}$ \\
\hline Month-of-Year by State FE & $\mathrm{X}$ & $\mathrm{X}$ & & $\mathrm{X}$ & $\mathrm{X}$ & $\mathrm{X}$ \\
\hline Year by State FE & $\mathrm{X}$ & $\mathrm{X}$ & & $\mathrm{X}$ & $\mathrm{X}$ & $\mathrm{X}$ \\
\hline Month-of-Sample by State FE & & & $\mathrm{X}$ & & & \\
\hline Lightning fires only & & & & $\mathrm{X}$ & & \\
\hline Timber Fuels only & & & & & $\mathrm{X}$ & \\
\hline $\mathrm{N}$ & 2,089 & 2,089 & 2,089 & 1,470 & 772 & 2,089 \\
\hline $\mathrm{R}^{2}$ & 0.42 & 0.43 & 0.54 & 0.45 & 0.57 & 0.43 \\
\hline
\end{tabular}

Notes: Columns (1) through (5) reproduce estimates from Figure 4 in the main text, using bins of the number of homes within 30 kilometers as the variables of interest. The bins are equal observation bins for fires with at least one nearby home (see Figure 4 for bin ranges). The omitted category is fires with zero nearby homes. Column (6) shows an alternative specification that measures the stock of homes within $30 \mathrm{~km}$ by total transaction value. Again, bins are equal observation bins for fires with at least one nearby home, and the excluded category is fires with zero nearby homes. Homes with unusable transaction values, as defined in Section B.2, are assigned the average transaction value of other homes withing $30 \mathrm{~km}$ of the ignition point. See Table 1 for details on controls for weather, topography, and vegetation. Standard errors are clustered by national forest. 
Appendix Figure 1: Costs by Number of Homes: Alternative Radii

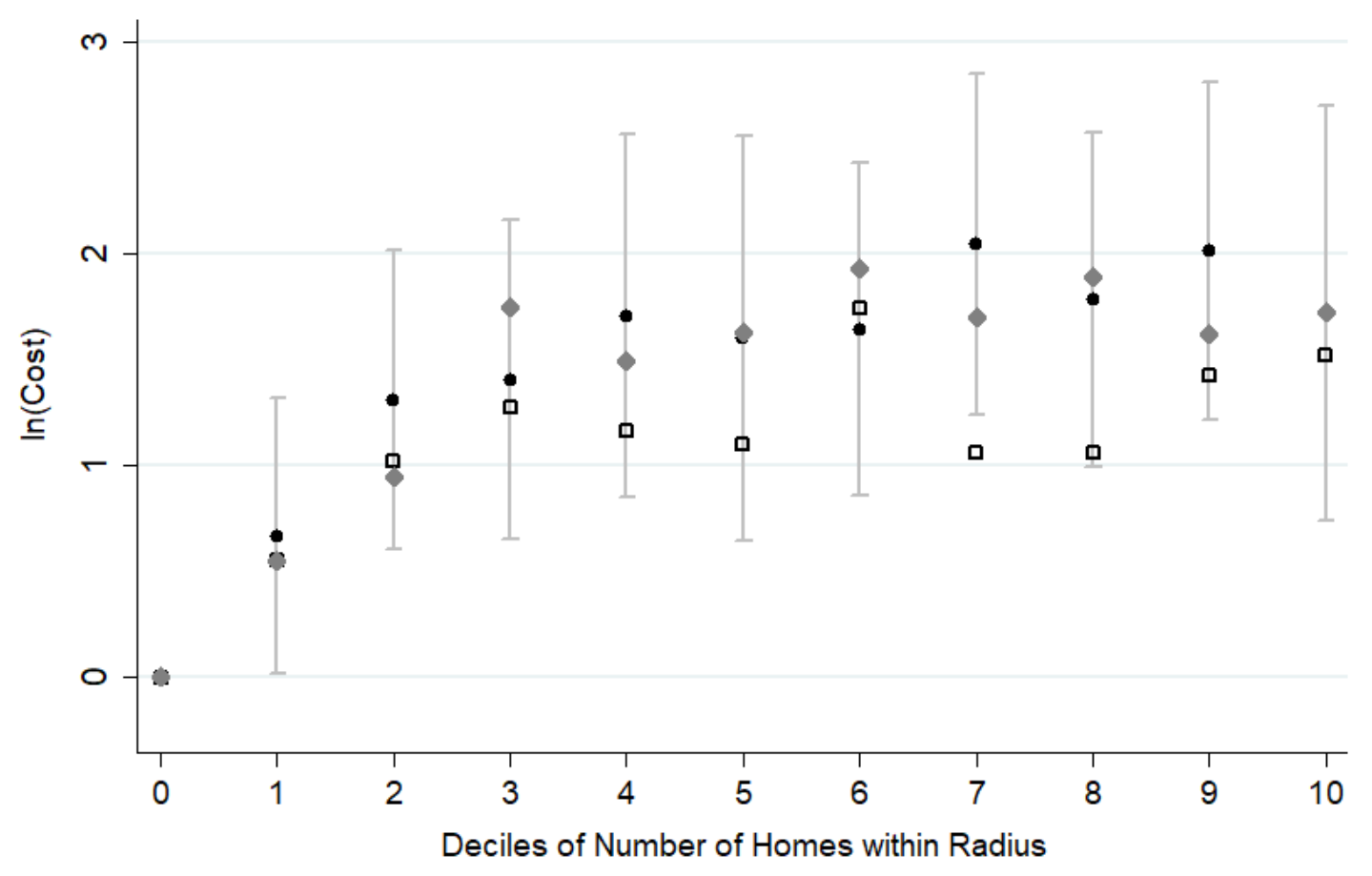

口 $20 \mathrm{~km} \cdot 30 \mathrm{~km} \quad 40 \mathrm{~km}$

Notes: This figure reproduces Figure 4 from the main text using alternative radii. Each set of markers shows coefficients from a single regression using a different radius around the ignition point of the fire. The bins correspond to deciles of the distribution of number of homes within the radius, conditional on any homes within the radius. The omitted category in each regression is fires with zero homes within the radius. For all three radii, there is a clear pattern of quick increases across the first three to four bins, and then roughly constant costs at higher numbers of homes. 
Appendix Figure 2: Covariate Overlap by Distance from Ignition Point to Nearest Home

(a) Day of Year (Ignition)

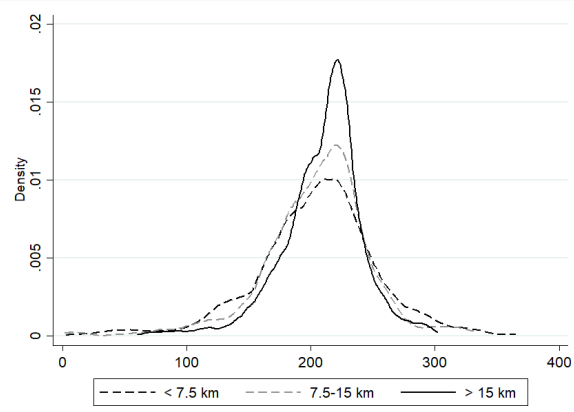

(c) Temperature (F)

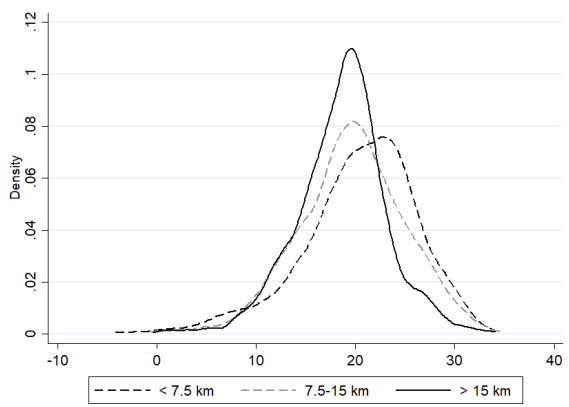

(e) Terrain Slope

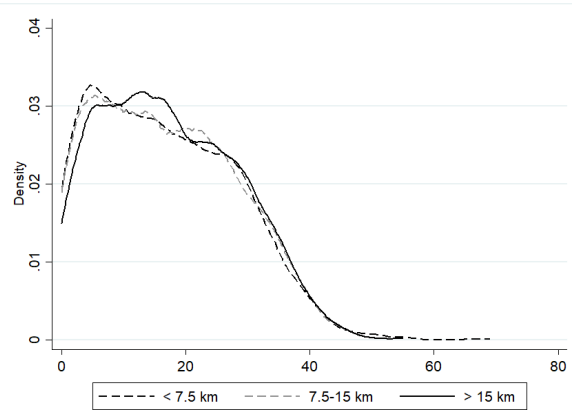

(g) Lightning-caused

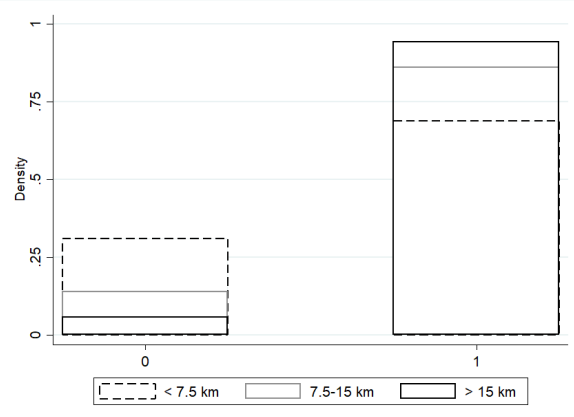

(b) Wind Speed (mph)

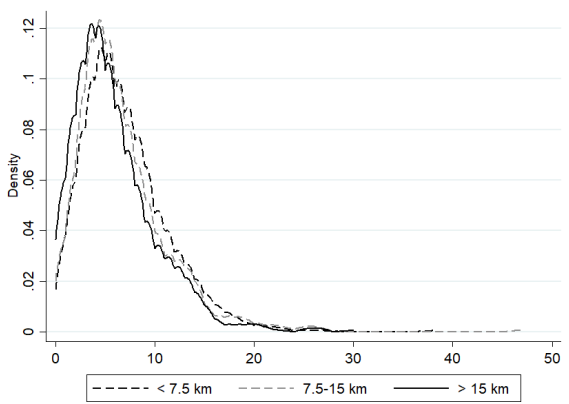

(d) Vapor Pressure Deficit

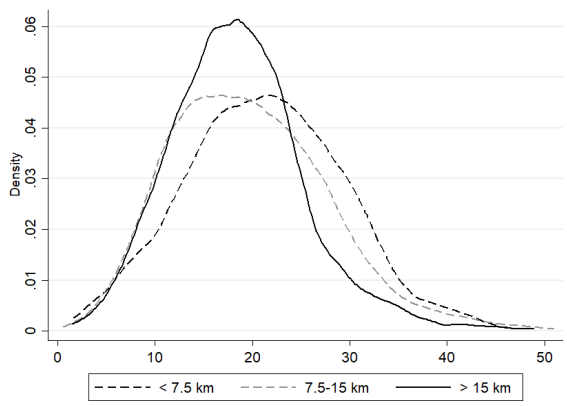

(f) South/southwest-facing

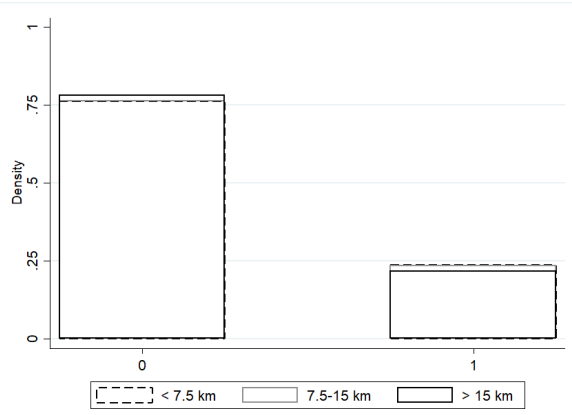

(h) "Timber" fuel model

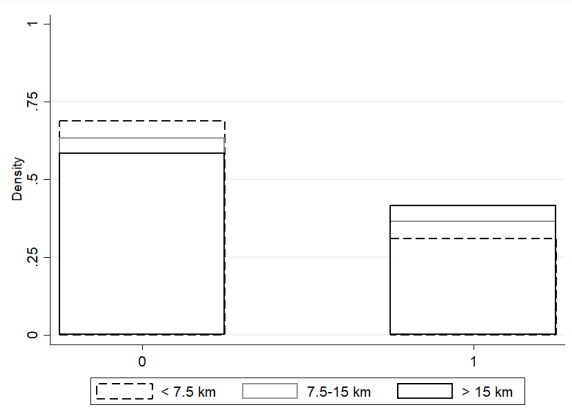

Notes: Figure shows covariate distributions for the US Forest Service fires analyzed in Table 1 and Figures 3 and 4. Panels (b), (c), and (d) report weather on the day of ignition. Wind speed is average wind speed from the reference weather station reported in FAMWEB. Temperature and vapor pressure deficit are mean daily values from PRISM. Terrain slope is the slope percentage, where 100 corresponds to a slope of 1 (i.e, a 45-degree line). "Timber" fuel models follow the Anderson Fire Behavior Fuel Models. 


\section{A.1.2 Non-USFS Agencies}

The analysis of the effect of home construction on firefighting costs in Section 4 focuses on fires managed by the US Forest Service. Forest Service fires represent the largest group of expenditures and longest time series in our dataset. The national forests also provide a useful source of identifying variation, in that each national forest represents a mostly-contiguous area of public land with broadly similar landscapes and vegetation. This contiguity allows us to take advantage of variation in ignition locations within each of these 86 units using a fixed effects strategy. In comparison, Bureau of Land Management lands are less likely to consist of large contiguous units of land (instead, patches of BLM land in each state are managed by a system of district offices). Similarly, Cal Fire incidents take place on diffuse private and state lands throughout California.

For completeness, this section shows the relationship between homes and ignition costs for each of the agencies from which we were able to obtain data. Given that the empirical design used in the main text is not available for these other agencies, we focus on raw correlations. Appendix Figure 3 plots log firefighting costs against the distance from the ignition point to the nearest home. Across agencies, costs decline for fires located further from homes. Given that the data represent independent administrative databases compiled separately by each agency, the broad similarities across agencies are notable. For the US Forest Service, Cal Fire, the Bureau of Indian Affairs, and the National Park Service, there is a clear downward relationship with a linear slope between -0.036 and -0.073 . Bureau of Land Management incidents show a different relationship, with a slope near zero and a lower intercept. One possible explanation for this difference is that it may reflect the characteristics of fires managed by BLM. Compared to USFS fires, the fires managed by BLM are more likely to occur in easier-to-manage grass areas, and less likely to occur in timber fuels. Notwithstanding this pattern for BLM, the broad agreement across the other four agencies is reassuring. This is particularly true given the relatively small size of BLM expenditures relative to USFS and Cal Fire, both overall and in per-incident terms (see Appendix Table 7).

Appendix Figure 4 plots log firefighting costs against the total number of nearby homes. Across agencies, these ln-ln plots imply small or near-zero increases in firefighting costs as the number of nearby homes grows large. 
Appendix Figure 3: Cost vs. Distance to Nearest Home, by Agency
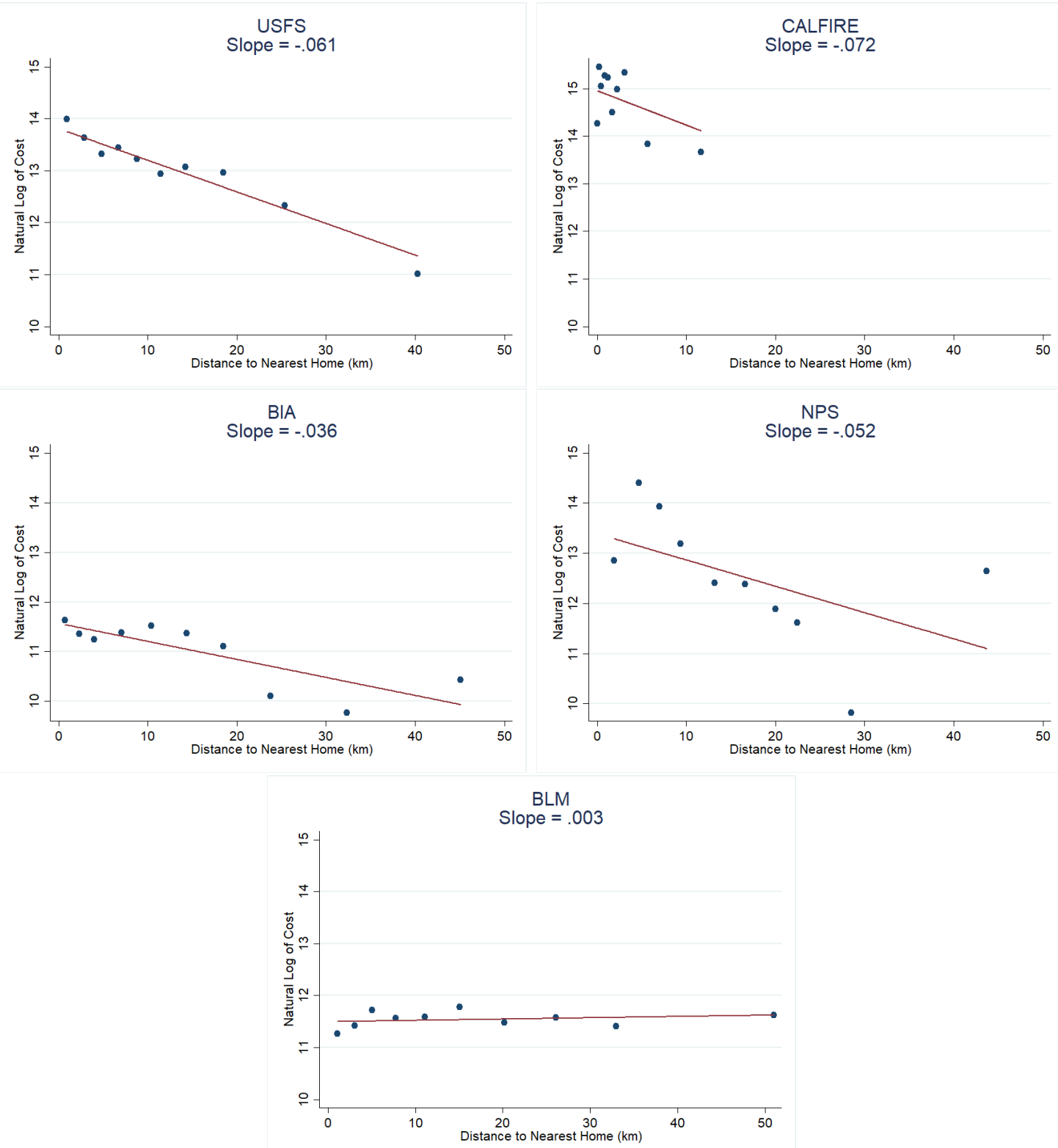

Notes: Figure shows binned scatterplots for each agency from which we obtained incident expenditure data. The dots show average log incident costs for each decile of distance to nearest home. The red lines show a linear fit. Cal Fire is the California Department of Forestry and Fire Protection; BIA is the Bureau of Indian Affairs; BLM is the Bureau of Land Management; and NPS is the National Park Service. 
Appendix Figure 4: Cost vs. Number of Nearby Homes, by Agency
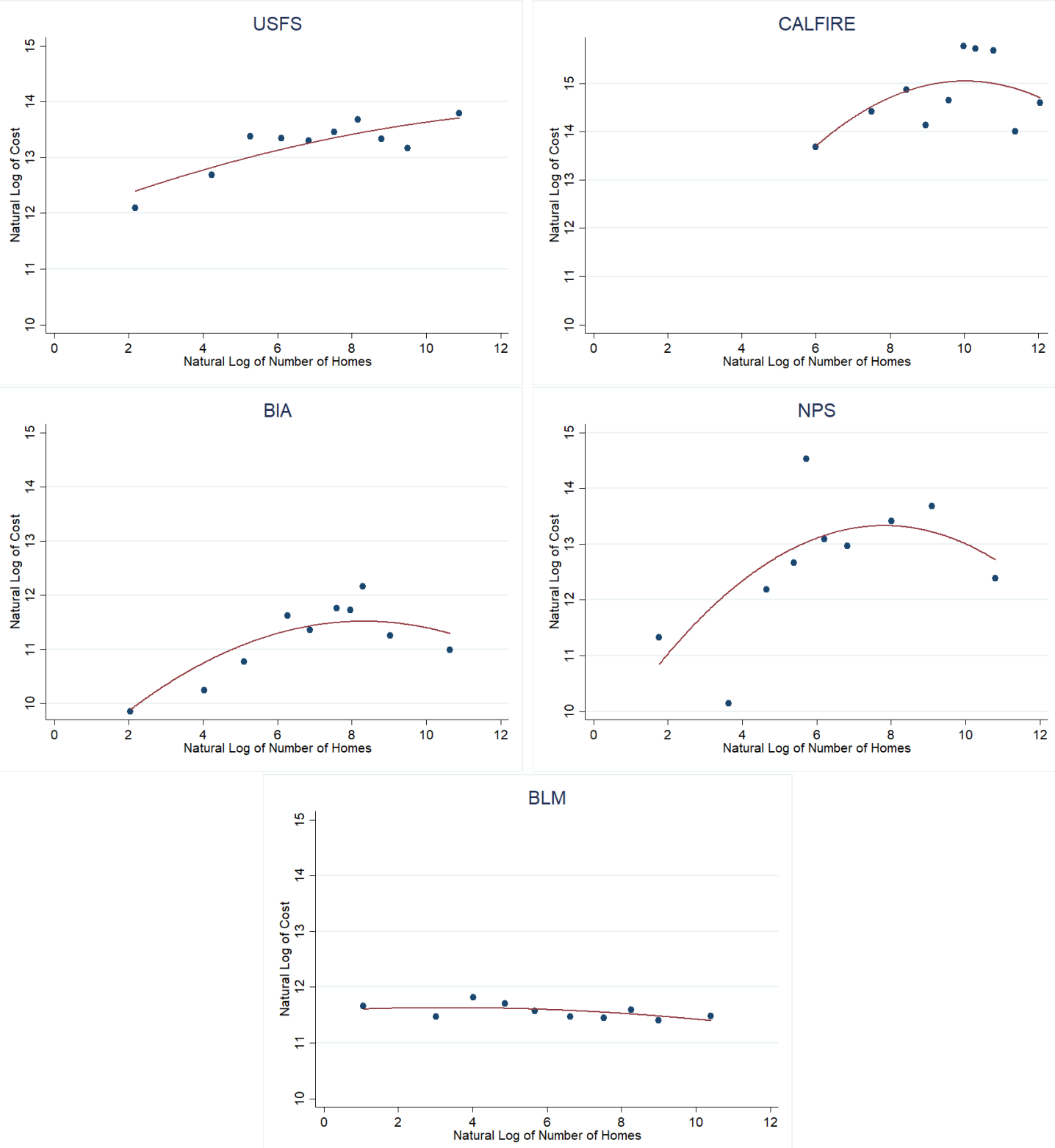

Notes: Figure shows binned scatterplots for each agency from which we obtained incident expenditure data. The dots show average log incident costs for each decile of log number of nearby homes (fires with zero nearby homes are not plotted). The red lines show a quadratic fit. Cal Fire is the California Department of Forestry and Fire Protection; BIA is the Bureau of Indian Affairs; BLM is the Bureau of Land Management; and NPS is the National Park Service. 


\section{A.1.3 Effect of Homes on the Number of Fires}

To evaluate whether adding homes increases the number of fires (in addition to increasing expenses on each fire), we use panel variation in home construction near national forests in our dataset. We construct a year-by-national forest panel including 76 national forests and 20 years. Because new homes are most likely to affect the number of ignitions in places with relatively low levels of existing development, we exclude national forests with more than 100,000 homes within 30 kilometers of the national forest boundary in 1995 (this excludes $20 \%$ of national forest areas with the highest 1995 populations).

We implement a range of panel regression specifications. The outcome variable is the number of fires larger than 300 acres in each forest-year. Our preferred statistical approach is a Poisson regression, since the number of large fires is a count variable. ${ }^{31}$ The key identification challenge in this setting is to separate the effect of new home construction from other time-varying determinants of fire probability. Because homes are durable, the number of homes near each national forest increases monotonically across the sample. We adopt a variety of time trends and year fixed effects specifications to control as flexibly as possible for potential secular trends in the number of fires in each national forest caused by factors like climate change or annual drought cycles. Our results in this section should be interpreted with caution, since they rest on the assumption that, conditional on these controls, the trend in new home construction near each national forest is uncorrelated with other trends in fire occurrence.

Appendix Table 4 shows the results. All of these regressions include national forest fixed effects to account for time-invariant determinants of fire risk, such as local topography. Across specifications, new home development has a small positive effect on the number of large fires each year. In Column (1), the estimated coefficient in the Poisson regression is 0.042 . This implies that adding 1,000 new homes increases the annual number of fires in this national forest by about $4.3 \%$. The mean number of large fires in each national forest-year is 1.48 , so this implies that an additional 1,000 homes lead to 0.06 additional large fires per year. Columns (2)-(5) include alternative polynomial time trends and find similar results. Column (6) instead includes year fixed effects, which allows for arbitrary annual trends at the West-wide level. Column (7) shows the same fixed effects specification in an OLS regression.

31. We use a cluster-robust variance estimator to eliminate the typical limitation of classical Poisson regression, which is that that the mean and variance of the estimates must be equal. 
Appendix Table 4: The Effect of Homes on the Number of Fires

\begin{tabular}{|c|c|c|c|c|c|c|c|}
\hline & (1) & $(2)$ & (3) & $(4)$ & (5) & (6) & $(7)$ \\
\hline & Poisson & Poisson & Poisson & Poisson & Poisson & Poisson & OLS \\
\hline Thousands of Homes & $\begin{array}{c}0.042 \\
(0.008)\end{array}$ & $\begin{array}{c}0.050 \\
(0.011)\end{array}$ & $\begin{array}{c}0.040 \\
(0.013)\end{array}$ & $\begin{array}{c}0.051 \\
(0.011)\end{array}$ & $\begin{array}{c}0.043 \\
(0.012)\end{array}$ & $\begin{array}{c}0.040 \\
(0.013)\end{array}$ & $\begin{array}{c}0.033 \\
(0.018)\end{array}$ \\
\hline National Forest FE & $\mathrm{X}$ & $\mathrm{X}$ & $\mathrm{X}$ & $\mathrm{X}$ & $\mathrm{X}$ & $\mathrm{X}$ & $\mathrm{X}$ \\
\hline Linear Time Trend & & $\mathrm{X}$ & & & & & \\
\hline Quadratic Time Trend & & & $\mathrm{X}$ & & & & \\
\hline Regional Linear Trends & & & & $\mathrm{X}$ & & & \\
\hline Regional Quadratic Trends & & & & & $\mathrm{X}$ & & \\
\hline Year Fixed Effects & & & & & & $\mathrm{X}$ & $\mathrm{X}$ \\
\hline $\mathrm{N}$ & 1,180 & 1,180 & 1,180 & 1,180 & 1,180 & 1,180 & 1,180 \\
\hline
\end{tabular}

Notes: Table reports the results of seven separate regressions. In each regression the dependent variable is the number of fires larger than 300 acres in each national forest-year. Columns (1)-(6) show results for several Poisson regression specifications, and Column (7) shows an OLS specification for comparison. The variable of interest is the number homes within 30 kilometers of the national forest boundary, in thousands. The table reports regression coefficients and standard errors, which are calculated using a cluster robust variance estimator at the national forest level. For the Poisson specifications, the coefficients can be converted to expected percentage changes in the number of large fires using calculation $e^{\beta}-1$. See text for details. The mean number of fires in each national forest-year is 1.5. "Regional Linear Trends" and "Regional Quadratic Trends" indicate that the regression includes separate polynomial time trends for each of the five forest service regions included in the sample area. 


\section{A.2 Expected Protection Costs}

\section{A.2.1 Variables Used to Define Actuarial Groups}

Appendix Figure 5: Variables Used to Define Actuarial Groups

(a) Wildfire Hazard Potential

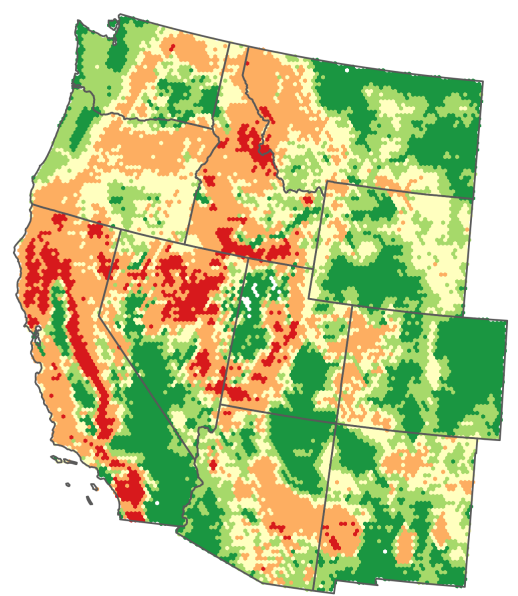

Wildfire Hazard Potential

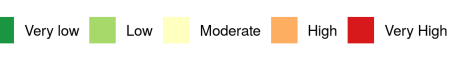

(b) Population Density

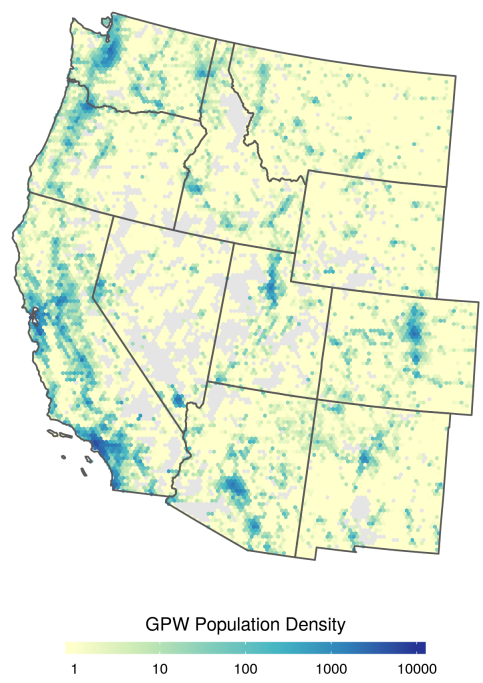

(c) Region

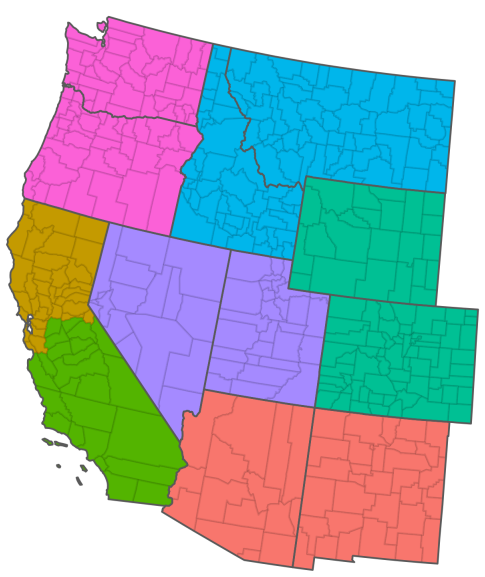

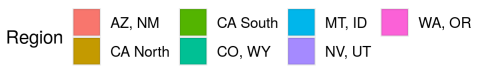

Notes: Wildfire hazard potential: Dillon (2015). Population density: CIESIN (2017). 


\section{A.2.2 Maps of Suppression-Only and California Measures}

Appendix Figure 6 reproduces the map in Figure 6 using the alternative measures of expected protection cost described in Section 5.1.3 of the main text. Panel A uses the Suppression Only cost measure and Panel B uses the California-specific cost measure. The California measure is displayed as zero for all areas outside California.

Appendix Figure 6: Expected Protection Cost, Alternative Measures

(a) "Suppression Only"

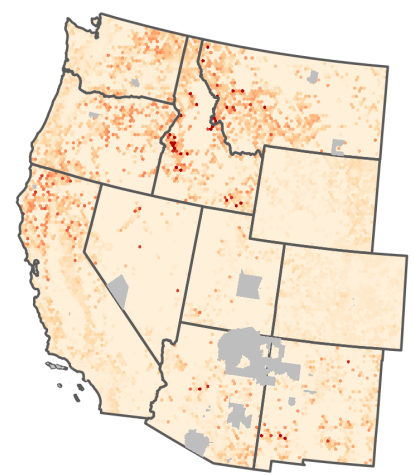

Expected Protection Cost (NPV)

$0 \quad 10,000 \quad 20,000 \quad 30,000$ (b) California-specific

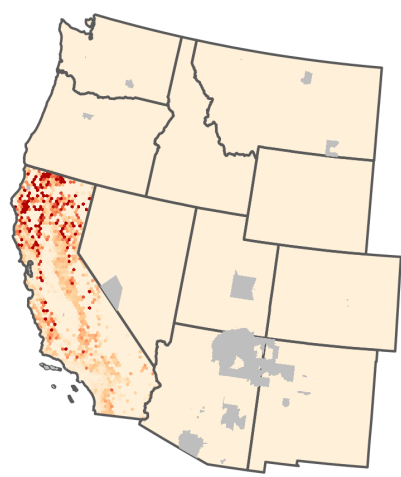

Expected Protection Cost (NPV)

$0 \quad 10,000 \quad 20,000 \quad 30,000$

Notes: This figure reproduces Figure 6 showing alternative measures of expected protection cost. See Section 5 for a detailed description of the construction of these measures. Units for the color scale are 2017 dollars per home. The California-specific measure in Panel (b) is displayed as zero for areas outside California.

\section{A.2.3 Alternative Measures Based on Interview Evidence}

Table 5 compares implicit subsidy estimates using different methods to measure the share of expenditures devoted to protecting homes. Columns 1A, 2A, and 3A show the main estimates from Table 2. Spending on home protection for each incident is the difference between observed costs and predicted costs for that fire in the absence of nearby homes, using the regression model in Section 4. Columns 1B, 2B, and 3B compute analogous subsidy estimates under the alternative assumption that $72.5 \%$ of all fire costs are attributable to protecting homes, based on USDA (2006). Comparing $1 \mathrm{~A}$ to $1 \mathrm{~B}, 2 \mathrm{~A}$ to $2 \mathrm{~B}$, and $3 \mathrm{~A}$ to $3 \mathrm{~B}$ shows relatively small differences. 
Appendix Table 5: Expected Parcel Protection Costs, Alternative Estimates

\begin{tabular}{|c|c|c|c|c|c|c|}
\hline & \multicolumn{2}{|c|}{$\begin{array}{c}\text { Federal } \\
\text { Suppression } \\
\text { Only (\$) }\end{array}$} & \multicolumn{2}{|c|}{$\begin{array}{l}\text { Suppression } \\
\text { Plus } \\
(\$)\end{array}$} & \multicolumn{2}{|c|}{$\begin{array}{l}\text { California } \\
\text { Only } \\
(\$)\end{array}$} \\
\hline & $(1 \mathrm{~A})$ & $(1 \mathrm{~B})$ & $(2 \mathrm{~A})$ & $(2 \mathrm{~B})$ & $(3 \mathrm{~A})$ & (3B) \\
\hline Mean & 1,077 & 932 & 2,408 & 2,1 & 2,712 & 2,315 \\
\hline p50 & 500 & 400 & 1,200 & 1,100 & 1,300 & 1,100 \\
\hline p90 & 2,100 & 1,800 & 5,200 & 4,500 & 6,600 & 5,500 \\
\hline p95 & 3,800 & 3,400 & 8,400 & 7,300 & 9,000 & 7,800 \\
\hline p99 & 12,700 & 11,100 & 22,700 & 20,900 & 18,200 & 15,700 \\
\hline & $8,633,554$ & $8,633,554$ & $8,633,554$ & $8,633,554$ & $3,483,715$ & $3,483,715$ \\
\hline
\end{tabular}

Notes: Columns 1A, 2A, and 3A are identical to Table 2. Columns 1B, 2B, and $3 \mathrm{~B}$ assume that $72.5 \%$ of all fire costs are attributable to homes. The method used to divide protection expenditures across individual homes is the same as in the main analysis.

\section{A.2.4 Machine Learning to Define Actuarial Groups}

The main analysis assigns homes to actuarial groups and then averages historical costs for homes in each group to yield expected protection costs. Instead of having the researcher define these actuarial groups, it is possible to use a machine learning technique to define groups. To evaluate the robustness of the actuarial groups used in the main text, we implemented such an approach using a regression tree. Using righthand-side variables supplied by the researcher, the regression tree algorithm groups homes in order to minimize the prediction error for historical firefighting costs in each group. The number of groups is governed by a complexity parameter that specifies the minimum required improvement in prediction accuracy to justify additional splits. Appendix Figure 7 illustrates the approach. For this figure, we use a high value for the complexity parameter so that there are relatively few splits in the tree. The right-hand-side variables are 10 bins of wildfire hazard potential (WHP) and 10 bins of development density as predictors.

To compare results using this approach to those displayed in Table 2 in the main text, Appendix Table 6 shows the distribution of expected protection costs with a more complex tree using 10 bins of WHP, 10 bins of development density, and the 7 firefighting dispatch regions. This tree generates 79 actuarial groups. The overall distribution of expected protection costs with the regression tree (column 2) is similar to the distribution of expected protection costs in the main analysis (column 1), and 
Appendix Figure 7: Illustrative Regression Tree for Defining Actuarial Groups

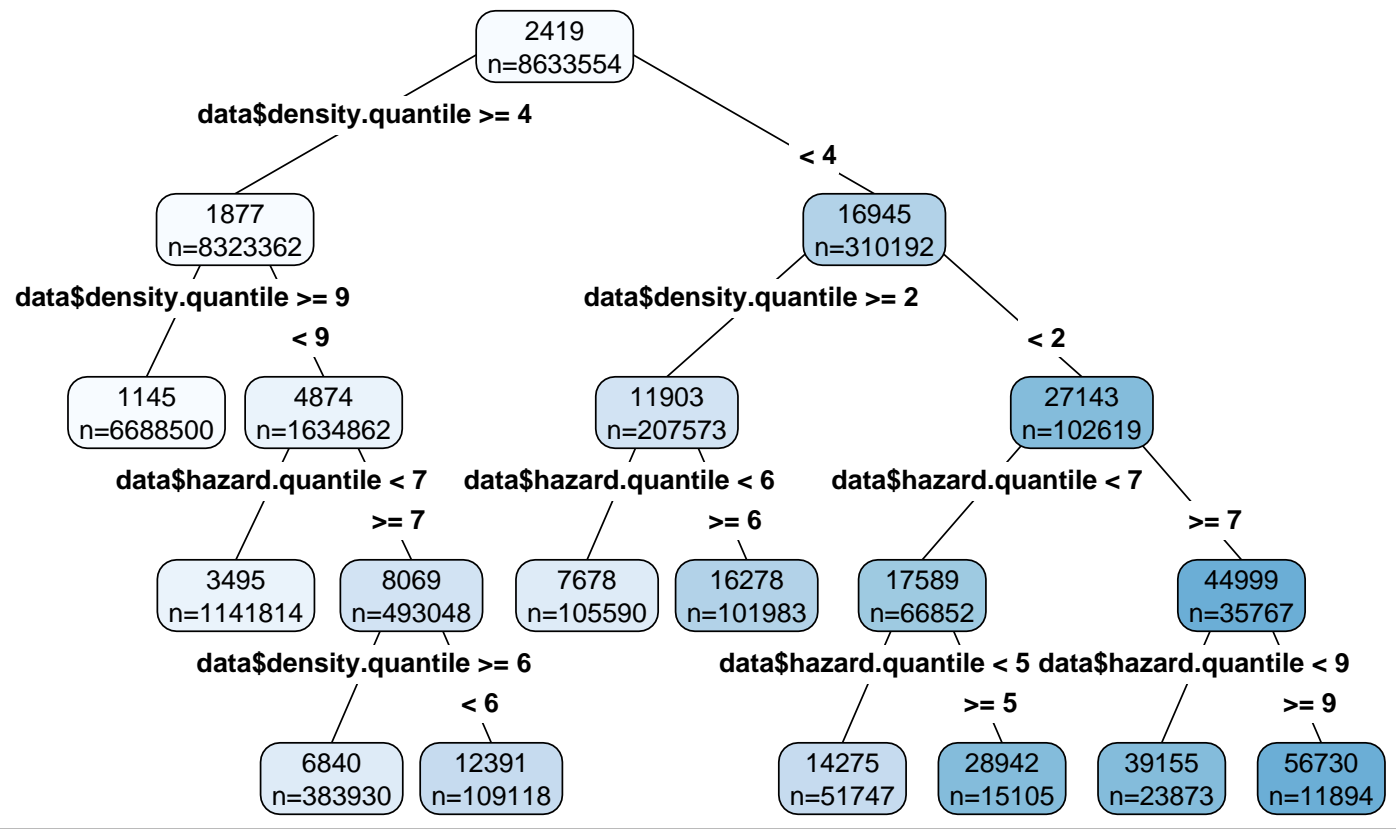

Notes: This figure illustrates the regression tree approach to defining actuarial groups using a restricted set of predictors and a limited complexity parameter. The top number in each node is the predicted protection cost. The number of homes in each group is given as " $\mathrm{n}$ ".

the correlation of individual protection costs between the two approaches is 0.8 .

Appendix Table 6: Expected Protection Costs using Regression Trees

\begin{tabular}{lrr}
\hline \hline & $(1)$ & $(2)$ \\
\hline Mean & 2,408 & 2,416 \\
p50 & 1,200 & 1,300 \\
p90 & 5,200 & 4,700 \\
p95 & 8,400 & 8,000 \\
p99 & 22,700 & 22,300 \\
N & $8,633,554$ & $8,633,554$ \\
\hline
\end{tabular}

Notes: This table shows expected protection costs for the Suppression Plus cost metric. Column 1 is identical to Table 2. Column 2 shows the distribution of costs when actuarial groups are selected using a regression tree algorithm. Percentile cutoffs are rounded to the nearest $\$ 100$. 


\section{A.3 Theory Appendix}

\section{Proof that Per-Capita Disaster Costs Decrease with Population}

Claim: Per-capita disaster-related $\operatorname{costs} \frac{f\left(n_{r}\right)}{n_{r}}+H\left(f\left(n_{r}\right)\right)$ decrease with $n_{r}$. Proof: Take the derivative with respect to $n_{r}$ and re-arrange.

$$
\frac{f^{\prime}\left(n_{r}\right)}{n_{r}}\left(1+n_{r} H^{\prime}(f)\right)-\frac{f\left(n_{r}\right)}{n_{r}^{2}}
$$

Recall $f$ is chosen to minimize $f+n_{r} H(f)$, so that the derivative $1+n_{r} H^{\prime}(f)$ equals zero. Expression 4 reduces to $-\frac{f\left(n_{r}\right)}{n_{r}^{2}}$, which is negative.

\section{Intensive margin changes in risky place population}

This section considers the marginal protection cost and the marginal welfare impact of changes in the risky place population. Differentiating Expression 1 with respect to $n_{r}$ yields the change in net benefits,

$$
\theta_{n_{r}}-s\left(n_{r}\right)-\phi f^{\prime}\left(n_{r}\right)-\phi\left[H\left(f\left(n_{r}\right)\right)+\frac{\partial H}{\partial f\left(n_{r}\right)} f^{\prime}\left(n_{r}\right) n_{r}\right]
$$

The first term is WTP of the marginal risky place resident. The second is the marginal cost of supplying housing. The third is the expected marginal increase in defensive expenditures. The final term in brackets is the change in expected property damages, which includes expected damages for one more home and decreased expected losses for all inframarginal homes due to increased defensive expenditures during a disaster.

The assumptions in this model allow us to apply the envelope theorem to further simplify Expression 5 to $\theta_{n_{r}}-s\left(n_{r}\right)-\phi H\left(f\left(n_{r}\right)\right) .{ }^{32}$ Compare this expression for social marginal benefit to the private marginal benefit for risky place residents, $\theta_{n_{r}}-$ $s\left(n_{r}\right)-\phi H\left(f\left(n_{r}\right)\right)-\phi \frac{\partial H}{\partial f\left(n_{r}\right)} f^{\prime}\left(n_{r}\right) n_{r}$. The latter expression includes an additional term equalling the benefit to inframarginal residents. Thus, private marginal benefit in the risky place exceeds social marginal benefit (recall that $\frac{\partial H}{\partial f}<0$ ).

Welfare analysis on the intensive margin depends on assumptions about how development is coordinated. If we assume the marginal resident internalizes all costs and benefits of their location decision except central government expenditures, then failure to price marginal defensive expenditures leads to excess development in the risky place. Such an assumption may be justified if a local government manages risky place development to maximize local benefits, or if risky place residents arrange private side payments. If we instead assume that the marginal resident receives no compensation

32. Rewrite $\theta_{n_{r}}-s\left(n_{r}\right)-\phi H\left(f\left(n_{r}\right)\right)-\phi f^{\prime}\left(n_{r}\right)\left[1+\frac{\partial H}{\partial f} n_{r}\right]$. Optimality of $f$ means that $1+\frac{\partial H}{\partial f} n_{r}=0$. 
for benefits to inframarginal households, then the failure to price marginal defensive expenditures is offset by this second externality. If dispatch of defensive expenditures during disasters is exactly optimal and we only consider small changes in population, these externalities offset exactly and providing defensive expenditures for free yields the optimal result on the intensive margin.

Let us step back from this ambiguous result and consider the empirical analysis. We find that $f^{\prime}\left(n_{r}\right)$ is near zero in already-developed areas. This means that any intensive margin distortion due to subsidized marginal protection costs would be small. It also means that spillover benefits to inframarginal residents must be small because there is little actual change in firefighting dispatch. Thus, regardless of what one assumes about how development proceeds in already-developed places, our results imply that any intensive margin distortions are small. What matters for welfare is instead new development in undeveloped and sparsely-developed high-risk places, where the large average protection costs that we measure imply that total benefits may not exceed total social cost.

\section{Extending the Theoretical Model to Private Self-protection}

Let $g$ represent the amount of private risk-reducing investment by each identical homeowner in the risky place. Private damages in the event of a disaster are now $H(f, g)$, with $\frac{\partial H}{\partial g}<0$ and $\frac{\partial^{2} H}{\partial g^{2}}>0$. Assume that the central government takes $g$ and $n_{r}$ as given when choosing $f$ during a disaster (as happens for wildfire and other natural hazards). The optimal emergency defensive expenditure $f$ during a disaster is now given by,

$$
f^{*}\left(n_{r}, g\right)=\underset{f}{\arg \min } f+n_{r} H(f, g)
$$

so that $f^{*}$ is defined by the first order condition $-n_{r} \frac{\partial H(f, g)}{\partial f}=1$.

If $\frac{\partial^{2} H}{\partial f \partial g}=0$, private protection has no effect on the government's choice of emergency defensive expenditures. If $\frac{\partial^{2} H}{\partial f \partial g}>0$, private investments $g$ reduce the rate at which damages decrease with increases in $f$ (the marginal benefit of emergency defensive expenditures), and thus the optimal choice of $f$ during a disaster. For example, increased $g$ may reduce a structure's vulnerability to wildfire, reducing the need for an aggressive firefighting response (the final possibility, $\frac{\partial^{2} H}{\partial f \partial g}<0$, seems unlikely in practice).

Knowing the central government's dispatch rule for aid during a disaster, homeowners in the risky place choose $g$ to minimize their private disaster-related costs. When homeowners must reimburse the central government for their share of per-capita defensive expenditures, they solve

$$
\min _{g} g+\phi \frac{1}{n_{r}} f^{*}\left(n_{r}, g\right)+\phi H\left(f^{*}\left(n_{r}, g\right), g\right)
$$


When homeowners do not pay for defensive expenditures, they solve

$$
\min _{g} g+\phi H\left(f^{*}\left(n_{r}, g\right), g\right)
$$

The first order conditions for these problems are identical except for an additional $\frac{\phi}{n_{r}} \frac{\partial f^{*}\left(n_{r}, g\right)}{\partial g}$ term for the fully accountable household. This term is the marginal reduction in future expected emergency defensive expenditures due to investments in self-protection. Fully accountable households consider this benefit when choosing $g$. When emergency defensive expenditures are provided for free, households do not consider this benefit and thus choose less than the socially optimal investment in self-protection.

\section{B Construction of the dataset}

Our data combine administrative data on firefighting expenditures from multiple agencies, parcel-level assessor data for the universe of western US homes, topographical information, risk assessments, and weather conditions data. This section provides a complete account of the dataset construction; readers should refer to section Section 3 in the main paper for a high-level summary. Table 7 gives descriptive statistics for the dataset and Figure 8 maps all of the large fires in the sample, colored by agency.

\section{B.1 Wildland Firefighting Expenditures}

The fire suppression and preparedness cost data come from six different sources, including five federal agencies and one state firefighting agency. The federal agencies are the United States Forest Service, the National Park Service, the Bureau of Land Management, the Bureau of Indian Affairs, and the Federal Emergency Management Agency. The state agency is California's Department of Forestry and Fire Protection (Cal Fire). We obtained firefighting data at the incident level from each agency through a combination of Freedom of Information Act (FOIA) requests (or similar records requests for state data) and publicly available sources. Our geographical focus is the western United States. We define the "western United States" as the states of Arizona, California, Colorado, Idaho, Montana, New Mexico, Nevada, Oregon, Utah, Washington, and Wyoming. We discuss each source of data in detail below, as well as the process by which we harmonize these datasets.

\section{B.1.1 US Forest Service}

The US Department of Agriculture, Forest Service (USFS) accounts for the largest share of fire suppression expenditures of any federal agency and is primarily responsible for fires that ignite in or near the boundaries of National Forest areas. We obtain historical by-incident suppression costs (primarily wage and equipment costs incurred by USFS) for fires managed by the USDA Forest Service from 1995 to 2014 from the 
National Fire and Aviation Management Web (FAMWEB) Database. Some institutional detail is helpful in understanding the process by which the data are compiled: the FAMWEB database represents a compilation of individual reports on fire occurrence, the conditions in which the fire ignited, and the suppression efforts undertaken by USFS. These reports are entered into the Fire Statistics System (FIRESTAT) application, which is run by the USFS. FAMWEB is the database which contains this information. ${ }^{33}$

Gebert, Calkin, and Yoder (2007) argue that fire suppression costs are captured more accurately by USFS accounting data than in the FAMWEB database. We therefore also obtain separate USFS accounting data on incident level expenditures through a separate Freedom of Information Act request. However, USFS was only able to provide these records for the period 2004-2012. Moreover, because of inconsistencies between agency reporting of incident PCodes, it is not possible to identify the fire characteristics for many fires in the accounting data. In Appendix Section C, we conduct our empirical analysis using both the accounting data and a subset of the FAMWEB data limited to 2004-2012 and find both qualitatively and quantitatively similar results. We conclude that inaccuracies in the FAMWEB database are sufficiently limited within our sampling frame to have limited impact on our empirical questions of interest and therefore conduct the bulk of our analysis with the FAMWEB data because of its greater temporal coverage. ${ }^{34}$

Over the course of our sampling frame, more than 150,000 wildfire incidents are logged in this database. However, since the Forest Service only reports per-fire cost data for fires above 300 acres, we limit this sample to the 2,419 fires in the 11 western states with a size of 300 acres or larger (the smallest size for which suppression expenditures are separately reported) for which the Forest Service was the jurisdictional owner. We also require that each fire have suppression cost, ignition date, and location data available.

Most ignitions are quickly suppressed at low marginal cost by "initial attack" efforts.

33. Previously, these data were compiled using Kansas City Fire Access Software, or KCFAST. Both KFCAST and FAMWEB include data on suppression expenditures and fire locations, but FAMWEB is the more current and complete of the two, with one exception: FAMWEB does not include any data on which agency was responsible for a given ignition or on the wind speed and direction at the nearest weather station at time of ignition. To obtain these additional fields, we also load and merge in the KCFAST dataset.

34. A more subtle difference between this study and Gebert, Calkin, and Yoder (2007) is that the latter authors use the fire cost per acre as the outcome variable when considering the drivers of wildfire suppression costs, arguing that "fire managers are accustomed to thinking in terms of cost per acre," and also include the natural $\log$ of total acres burned as an explanatory variable. We choose to use total cost as the outcome variable in our regression analysis of incident costs. We also do not include a measure of acres burned as an explanatory variable. We prefer this specification for two reasons: the policy-relevant figure is the total cost of suppression; and acreage burned as the denominator and size of fire as an explanatory variable induces a reverse causality problem (since acreage is a function of suppression effort) and a "bad controls" problem (Angrist and Pischke 2009). 
These incidents are not included in our dataset of large fires. We address this in Section 5 by incorporating data on preparedness expenditures for USFS and the DOI agencies: these are expenditures that occur not in direct response to any particular large wildfire, but instead are undertaken to prevent or mitigate future fire risk. To identify these costs, we obtain budget justification reports from the US Forest Service website for the years 2007-2017. From these documents we extract the region-specific spending allocated towards "Fire Preparedness." In total we obtain more than $\$ 6.1$ billion of preparedness spending for the regions that overlap our sampling frame. ${ }^{35}$ These preparedness costs represent the cost of maintaining initial attack readiness and other fixed costs of the wildland firefighting system. Section 5 describes how we allocate these costs over ignitions.

\section{B.1.2 Department of Interior Agencies}

Four separate agencies within the Department of Interior (DOI) engage in significant fire management. They are the Bureau of Land Management (BLM), the Bureau of Indian Affairs (BIA), the National Park Service (NPS), and the US Fish and Wildlife Service (FWS). We successfully obtained firefighting cost data for BLM, BIA, and NPS through FOIA requests. BLM is responsible for fires that ignite on the 248 million acres of public lands they manage. BIA is responsible for fires starting on the 55 million acres of Indian trust lands, and NPS is responsible for fires igniting within its 417 park units across 84 million acres of land. Each agency provided incident-level data from 2003-2016 from its own accounting databases for fires larger than 100-300 acres. To match the data available from the Forest Service, we limit this sample to include only fires that were the jurisdictional responsibility of the given agency and that affect more than 300 acres and apply similar data quality restrictions as those described for the USFS data. Our final DOI suppression dataset includes 1,617 BLM fires, 315 BIA fires, and 126 NPS fires.

As with USFS, we also include DOI preparedness costs in some scenarios in Section 5. The DOI agencies collectively prepare one annual budget justification that covers wildland fire activities across the entire United States. Our data on DOI preparedness costs come from the fiscal year 2012-2018 versions of these documents. In total, we account for $\$ 2.7$ billion of preparedness spending. Because DOI does not provide region-specific figures for these preparedness costs, we allocate them according to the proportion of total US ignitions that occur within our sampling frame on an annual basis. On average, we allocate $54 \%$ of this preparedness spending to our study area to obtain a total of $\$ 1.5$ billion from the DOI agencies.

\section{B.1.3 California Department of Forestry and Fire Protection}

We also collect fire suppression cost data for California, which includes over $50 \%$ of the population in our sample area and some of the most frequent and costly wildfires.

35. The Forest Service regions that overlap our sampling frame are 01, 02, 03, 04, 05, and 06. 
Suppression cost data for California come from a public records request to the California Department of Forestry and Fire Protection (Cal Fire). Cal Fire is responsible for managing wildfires on 31 million acres of State Responsibility Area lands, loosely corresponding to private- and state-owned lands outside of incorporated towns and cities. We merge three sets of administrative records from Cal Fire. The first is a complete listing of all reported wildland fire incidents in the Cal Fire protection area during 2007-2016, regardless of size. This dataset includes the ignition date, acres burned, Cal Fire geographic unit, and, for incidents after mid-2011, the latitude and longitude of the ignition point. ${ }^{36}$ The third dataset is an administrative record of firefighting expenditures at the incident level for 788 incidents during 2011-2016. According to Cal Fire, these expenditure data are carefully tracked because they are the basis of cross-agency reimbursements for mutual aid expenditures - for example, reimbursements to California by the federal government under the FEMA Fire Management Assistance Grant (FMAG) program, or by local governments to Cal Fire for firefighting assistance in incorporated areas.

Beginning with the list of significant fires, we drop those that are not the jurisdictional responsibility of Cal Fire. Limiting our sample to fires for which we are able to obtain precise location and suppression cost data results in 104 large fires (and 318 fires of any size) from 2011-2016.

\section{B.1.4 Federal Emergency Management Agency}

Our final agency source is the Federal Emergency Management Agency (FEMA). FEMA does not directly engage in firefighting efforts. Instead, FEMA reimburses state agencies and local governments for their costs on large firefighting efforts through the Fire Management Assistance Grant (FMAG) program. These grants reimburse $75 \%$ of the firefighting expenses incurred by state and local governments during qualifying incidents. We obtained incident-level data on FEMA reimbursements for wildfire incidents during 2000-2017 through a Freedom of Information Act request. These records contain the incident name, date, state, and amount reimbursed. They do not contain geographic coordinates (or a common identifier that would allow us to merge them to other agency data to recover geographic information). For cost scenarios in Section 5 that include FEMA reimbursements, we allocate these costs, multiplied by 1.33 to include the non-reimbursed portion, over fires in each year-state cell similarly to preparedness costs. In any calculation where we include Cal Fire cost data, we do not include FEMA reimbursements to California, which presumably include costs incurred by Cal Fire.

36. To supplement the location records for earlier fires, we also obtain shapefile data for a subset of Cal Fire incidents from the publicly available Fire and Resource Assessment Program database managed by Cal Fire. 


\section{B.1.5 Harmonization of Fire Suppression Cost Data}

To ensure consistent data quality, we harmonize the data across all agencies from which we source suppression expenditures. Specifically, we ensure that ignition date, ignition location, responsible agency, cause of fire, area burned, and suppression cost data are present for all incidents and that the costs reflect values in 2017 dollars. Federal, state, and local firefighting agencies provide assistance to one another through coordinated dispatch systems and mutual aid agreements. We carefully considered the implications of this aid for our analysis. We confirmed with each agency that its reported costs represent only that agency's costs for a given incident (except for FEMA reimbursements). Thus, we avoid double counting when adding up historical costs across agencies in Section 5. When investigating the effect of homes on costs in Section 4.1, we use only USFS cost data and further limit the sample to incidents where USFS was the primary responsible agency. This restriction is used by Gebert, Calkin, and Yoder (2007), who argue that USFS bears at least $90 \%$ of the costs of these fires. ${ }^{37}$

We have also attempted to ensure that cost concepts are at least broadly comparable across agencies. In general, the firefighting cost data in the final dataset include wages (salaries, overtime, hazard pay) and equipment costs. Usage costs for agencyowned equipment (as opposed to equipment from private contractors) are tracked somewhat differently by different agencies. For example, in direct correspondence BLM indicated that they assign mileage costs for regular vehicles and engine-hour costs for fire engines to each incident, while NPS indicated that they assign only fuel and repair costs. The allocation of salary costs between "preparedness" and "suppression" budget categories may also differ somewhat across agencies.

Finally, we compute the spatial relationship between each fire and potentially valuable resources nearby. Specifically, we measure the distance from the ignition point of each fire to the nearest parcel in the parcels dataset described in Section B.2, the nearest state or federal highway, and the count of homes and their value within $x \mathrm{~km}$ of the ignition point, where $x \in\{5,10, \ldots, 50\}$.

\section{B.1.6 Ignition Point Characteristics and Weather Data}

Using the harmonized location data, we obtain elevation, slope, aspect, and fuel model data for the ignition point of each fire from LANDFIRE. The former three products are derived from the high-resolution National Elevation Dataset; elevation represents the land height above sea level and is given in meters, slope represents the angle of the land and is given in degrees, and aspect represents the direction of the slope and is given in degrees as well. The fuel model data are the 13 Anderson Fire

37. Ideally, we would sum each agencies expenditures on each individual incident. Unfortunately, USFS and the DOI agencies do not reliably use consistent incident identifiers, making such a merge impossible. 
Appendix Table 7: Descriptive statistics

\begin{tabular}{|c|c|c|c|c|c|}
\hline \multicolumn{6}{|c|}{ Panel A: Pooled fire characteristics } \\
\hline & Mean & $\mathrm{P} 10$ & $\mathrm{P} 50$ & P90 & \\
\hline Area burned & 7,873 & 383 & 1,433 & 16,034 & \\
\hline Fire cost & $2,350,820$ & 9,066 & 227,461 & $5,233,689$ & \\
\hline Elevation & 1,554 & 707 & 1,559 & 2,353 & \\
\hline Slope & 12 & 1 & 10 & 29 & \\
\hline Temperature & 20 & 13 & 21 & 27 & \\
\hline Precipitation & 0 & 0 & 0 & 1 & \\
\hline Vapor Pressure Deficit & 21 & 11 & 21 & 32 & \\
\hline Nearest home distance & 14 & 1 & 10 & 33 & \\
\hline Parcels in $5 \mathrm{~km}$ & 160 & 0 & 0 & 109 & \\
\hline Parcels in $10 \mathrm{~km}$ & 757 & 0 & 0 & 1,011 & \\
\hline Parcels in $20 \mathrm{~km}$ & 3,345 & 0 & 90 & 7,093 & \\
\hline Value in $5 \mathrm{~km}$ & 45,633 & 0 & 0 & 18,536 & \\
\hline Value in $10 \mathrm{~km}$ & 210,261 & 0 & 0 & 182,871 & \\
\hline Value in $20 \mathrm{~km}$ & 936,119 & 0 & 13,094 & $1,450,741$ & \\
\hline \multicolumn{6}{|c|}{ Panel B: Fire characteristics by agency } \\
\hline & USFS & BLM & BIA & NPS & Cal Fire \\
\hline Number of fires & 2,419 & 1,617 & 315 & 126 & 104 \\
\hline Acres burned (1000s) & 19,442 & 13,435 & 1,814 & 685 & 690 \\
\hline Suppression cost (m) & 8,799 & 507 & 257 & 94 & 854 \\
\hline
\end{tabular}

Notes: Table reports descriptive statistics for fires with area greater or equal to 300 acres in our sample. P10, P50, and P90 indicate the 10th, 50th (median), and 90th percentile of values. Aspect is given in degrees, elevation is in meters above sea level, fire cost is in 2017 US $\$$, nearest home distance is in kilometers, parcels is the number of parcels within the given distance, precipitation is in $\mathrm{mm}$, slope is in degrees, temperatures is in Celsius, and Vapor Pressure Deficit is in millibars.

Behavior Fuel Models and describe the fire potential of surface fuel components (e.g., the type of foliage in the area). We also obtain ignition-day weather (maximum and minimum temperatures, precipitation, and measure of humidity) from the PRISM daily weather dataset, as well as ignition-day wind direction and speed from the FAMWEB dataset. 
Appendix Figure 8: Federal Wildfires

USFS

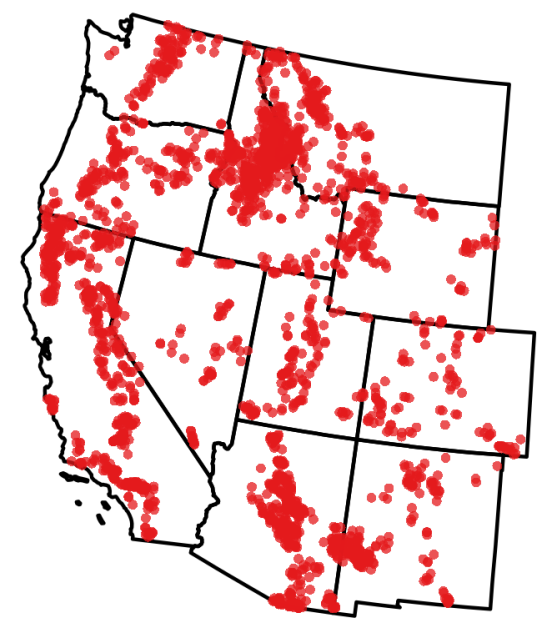

NPS

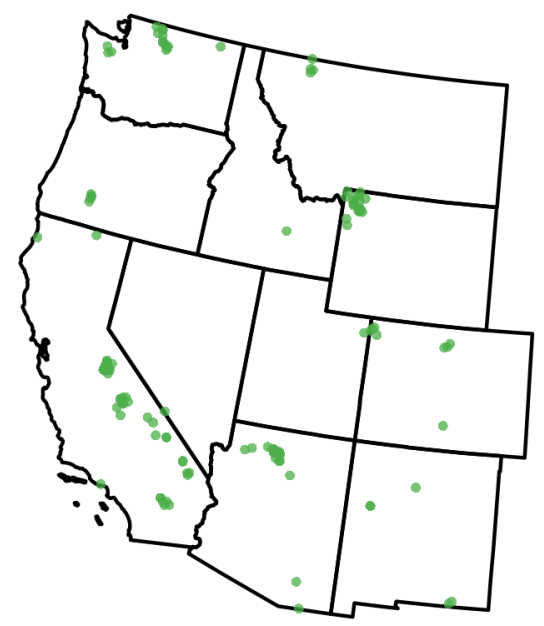

BLM

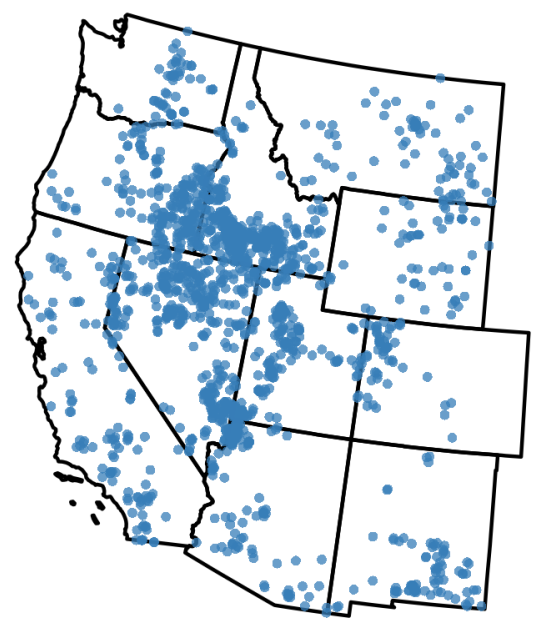

BIA

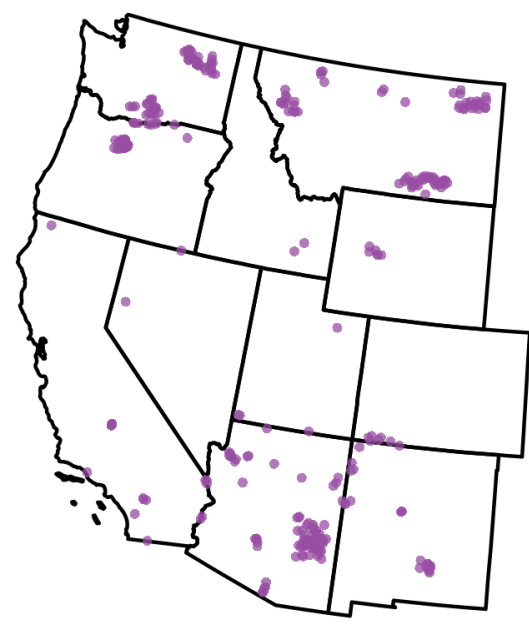

Notes: Map of federally managed fires between 1995 and 2016 larger than 300 acres. 
Appendix Figure 9: Cal Fire Wildfires

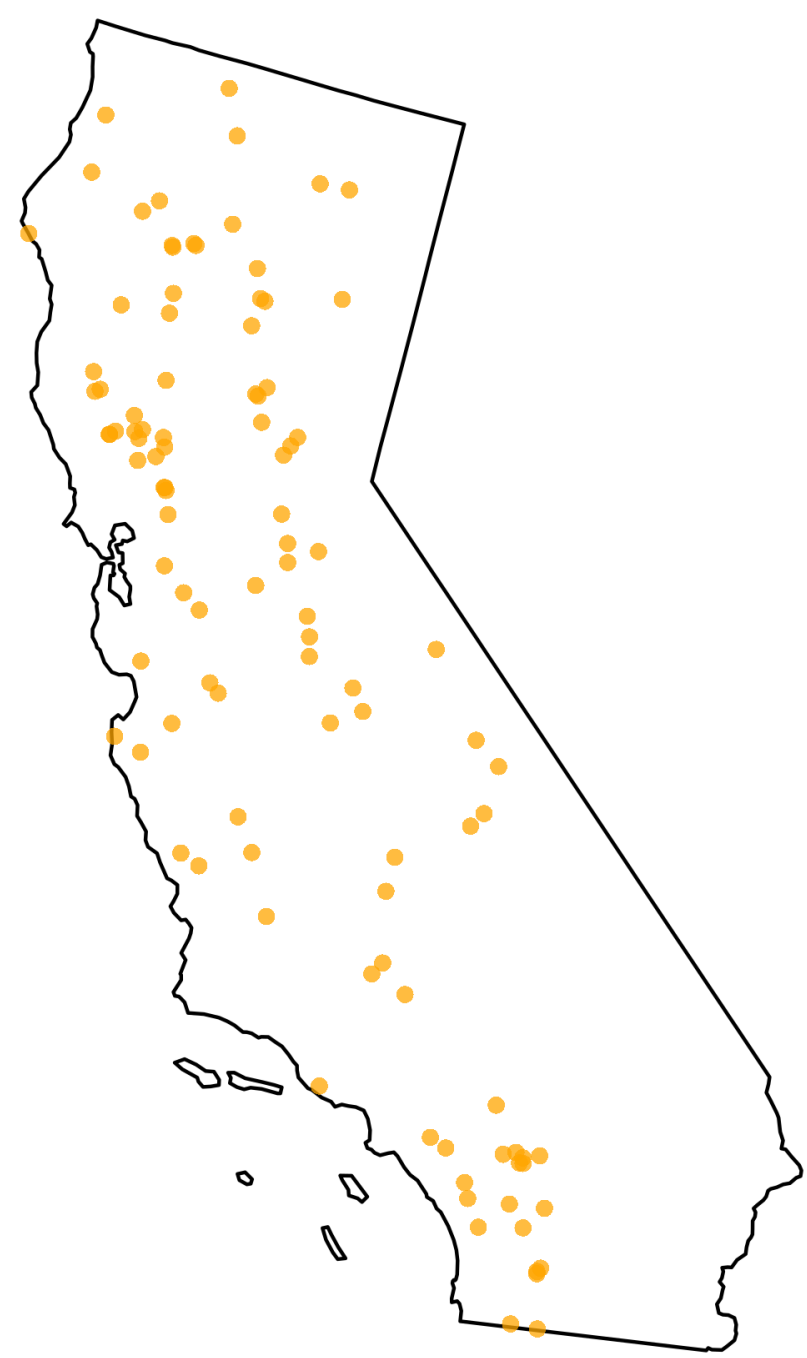

Notes: Map of Cal Fire-managed fires between 2011 and 2016 larger than 300 acres. 


\section{B.2 Parcel Data}

The homes data include information on home locations, values, year built, and other property characteristics for 18.5 million parcels, or nearly all of the homes in the western United States. We also include parcels within $50 \mathrm{~km}$ of these states to accurately capture the nearness and number of parcels for wildfires that occur near the eastern borders of our sample. These data represent a compilation of tax assessor data from individual counties. ${ }^{38}$ A primary advantage of these data is the inclusion of detailed locational information; specifically the data include both latitude and longitude as well as street address for each parcel. While previous studies in this area rely on publicly available data on the number and value of homes in a Census block (Gebert, Calkin, and Yoder 2007; Gude et al. 2013), this confidential dataset enables us to precisely locate homes relative to wildfire ignition points. Because Census blocks can be large in rural areas and particularly when located near national forests, the standard approach using Census block centroids introduces substantial noise into the estimate of distance-to-nearest parcel for each fire. In Section B.2.1 we document the improved locational precision and the data quality benefits produced by this approach.

We limit the sample to include only homes in partially vegetated areas that would be threatened by wildland fires, based on wildland-urban interface (WUI) categories identified in Radeloff et al. (2005). Specifically, we include homes located in the following vegetation categories: high density interface, high density intermix, medium density interface, medium density intermix, low density interface, low density intermix, very low density vegetated, and uninhabited vegetated. ${ }^{39}$ We exclude homes in areas without wildland vegetation, and specifically in areas with the following categories: high density no vegetation, medium density no vegetation, low density no vegetation, very low density no vegetation, and uninhabited no vegetation. Because the federal government controls so much land in the West, and so much residential development is in wildland areas, these sample exclusions are not particularly restrictive. Our analysis dataset includes 9,148,972 homes (about 44\% of all residential parcels including homes, condos, and apartments in the West). ${ }^{40}$ We also link the parcels to the USFS Wildfire Hazard Potential (WHP) ratings to assess physical fire risk (Dillon 2015). These risk scores are designed to "depict the relative potential for wildfire that would be difficult for suppression resources to contain," and combine

38. This proprietary compilation was provided by CoreLogic@ through a data agreement with Stanford University. Our comparisons to publicly-available home counts at the tract level, available upon request, confirm the comprehensiveness of the data.

39. Because the WUI data are built from Census records and our parcel data represent precise locations, occasionally a parcel is located in a so-called "uninhabited vegetated" area. As we rely on the WUI data to identify vegetated areas, we include homes in these areas as well.

40. This sample of 9.1 million homes used to estimate Equation (3) also includes homes near the sampling area but lying in bordering states in order to appropriately account for all nearby homes. In our main results, we report the expected protection cost only for homes in the 11 western states. 
data from a large-scale fire simulator with spatial fuels and vegetation data to produce indicators of WHP. For each parcel, we assign a categorical and a continuous measure of WHP for that location as a measure of the risk faced by that parcel. We also add a measure of population density (population per square meter) from the Gridded Population of the World dataset, which reports density within roughly one $\mathrm{km}$ square grid cells.

The data also include reported transaction values. As is common for real estate data, many reported transactions do not represent true arms-length sales. We use only transaction values determined by CoreLogic to be arms-length transactions, and we further remove transactions indicated as refinancing, foreclosures, or inter-family transfers. We also exclude transaction values below $\$ 10,000$ or above $\$ 100,000,000$ in 2017 dollars, and transactions prior to 1980. After these cleaning steps, we have usable transaction values for $69 \%$ of homes in the raw data.

\section{B.2.1 Comparison to Census Aggregate Data}

Our study uses parcel-level data to assess the locations of homes threatened by wildfire. Previous studies rely on counts of housing units at the Census block scale (Gebert, Calkin, and Yoder 2007; Gude et al. 2013). Appendix Table 8 demonstrates that high-risk regions are systematically likely to have large Census block sizes. The average Census block size for homes in the highest decile of firefighting cost is 7.0 square $\mathrm{km}$, and the 95th percentile is 29.7 square kilometers. This large grid size introduces substantial noise into geographic analyses of aggregate home counts. Our study instead uses parcel-level data to assess home locations. This represents a substantial increase in granularity over existing studies. ${ }^{41}$ The degree of this advantage over aggregate block-level data depends on the accuracy with which parcel locations are reported in the real estate data. The underlying records in this dataset are collected by county tax assessors, and the quality of the data varies across counties. In the following section, we describe the process by which we obtain highly accurate parcel locations for the dataset and the advantages this provides relative to using Census block centroids.

The process of generating geographic coordinates for individual structure locations is called geocoding. This section compares the default geocoding for the homes in our dataset to an alternative geocoding algorithm. We also compare our results using methods to identify homes based on publicly available data that have been used in related work (e.g., Gebert, Calkin, and Yoder 2007; Radeloff et al. 2005; Radeloff et al. 2018).

The housing data used in this project come from a compilation of tax assessor data.

41. A separate advantage of parcel-level data over Census data is that we know the year in which a home was constructed, and thus whether the home was present at the time of each fire in the dataset. Census data report static housing counts every 10 years. 
This dataset includes a field identifying the latitude and longitude of each home in the dataset. Overall, careful investigation of subsamples of the data imply that these coordinates are quite accurate. However, these default locations often locate multiple homes in precisely the same geographic location. To improve the accuracy of parcel locations, we implemented a secure, locally-hosted geocoding algorithm on a local server to calculate coordinates for each home. We used a locally hosted instance of the Nominatim geocoder ${ }^{42}$ to geocode homes in our dataset based on the address field, while maintaining data confidentiality and security.

Overall, the geographic coordinates generated by Nominatim align closely with the default locations in the homes data. The median distance between reported locations is 41 meters. For most homes, we believe that the Nominatim locations represent small shifts that slightly improve location accuracy. The exception is for addresses that include typographical errors. In this case, Nominatim may return locations that are not meaningful - for example, that may be hundreds of kilometers outside of the county containing the home. ${ }^{43}$ To eliminate these errors, we backstop the Nominatim locations with the default locations in the original dataset (which tend to be more accurate but less precise) using the following rule: if the Nominatim location is A) more than one $\mathrm{km}$ outside of the county given in the tax assessor data, B) differs from the tax assessor location by more than $5 \mathrm{~km}$, or C) was not obtained using the street address (e.g., was geolocated by the Nominatim algorithm based only on city and state), we use the tax assessor location instead. Using this backstop method, we re-code $89 \%$ of the addresses in our full dataset using Nominatim, and the remainder with the default locations in the original dataset.

Previous studies of wildland-urban interface issues have used publicly-available Census data to identify approximate home locations. The decennial Census includes counts of population and housing units at the Census block level. Forestry studies frequently use these block-level aggregate data to locate homes (e.g., by average population over the area of the Census block, or assigning population to the centroid). ${ }^{44}$ One challenge with using aggregate Census data is that Census blocks in areas with high fire risk tend to be many square kilometers or more, reducing the accuracy of the approach. Appendix Table 8 shows this. On the other hand, Census block-based approaches do not rely on the accuracy of address-based geocoding.

The figures and tables in this section explore the robustness of our results to three possible methods to locating homes: our geolocation method, a method that follows previous work in using Census block centroids for homes' locations, and a method

42. Nominatim uses Open Street Map data to conduct forward and reverse geocoding and is available at https://github.com/openstreetmap/Nominatim.

43. The County field in the underlying dataset is likely to be particularly reliable, since the dataset is assembled from individual county tax records.

44. Martinuzzi et al. (2015) describes one approach in detail, including how raw Census blocks are processed to remove portions that overlap public land and other steps. 
Appendix Table 8: The Advantage of Parcel-level Data: Census Blocks in High-Cost Areas are Large

\begin{tabular}{lcc}
\hline \hline & \multicolumn{2}{c}{ Area in $\mathrm{km}^{2}$} \\
\cline { 2 - 3 } & $\begin{array}{r}\text { All Populated } \\
\text { Census Blocks }\end{array}$ & $\begin{array}{c}\text { Highest Decile } \\
\text { of Firefighting Cost }\end{array}$ \\
\hline Mean & 1.2 & 6.9 \\
p90 & 0.9 & 14.7 \\
p95 & 3.0 & 29.7 \\
p99 & 22.8 & 101.9 \\
\hline $\mathrm{N}$ & $416,983.0$ & $42,021.0$ \\
\hline
\end{tabular}

Notes: This table shows the distribution of areas for Census blocks, in square kilometers. Column (1) includes all 2010 Census blocks with greater than zero housing units. Column (2) includes the $10 \%$ subset with the highest average expected protection costs as identified in our study. While Census blocks tend to be small overall, the areas of greater interest for understanding firefighting costs are systematically larger. Data on Census block areas, housing counts, and locations are from the US Census Bureau.

using the Census-based list of places (which include both incorporated and unincorporated communities). Appendix Figure 10 reproduces the regression from Figure 3 in the main text. The results are not qualitatively sensitive to the choice of location method. However, both of the Census-based approaches identify few fires with homes more than $40 \mathrm{~km}$ away and the corresponding standard errors for the estimate of the effect of home nearness on fire suppression cost are noisier. In our view, both of these facts reflect that the Census-based approaches systematically underestimate (on average) the distance to nearest home for fires in remote areas for the reasons we describe above. 
Appendix Figure 10: Cost by distance to nearest home

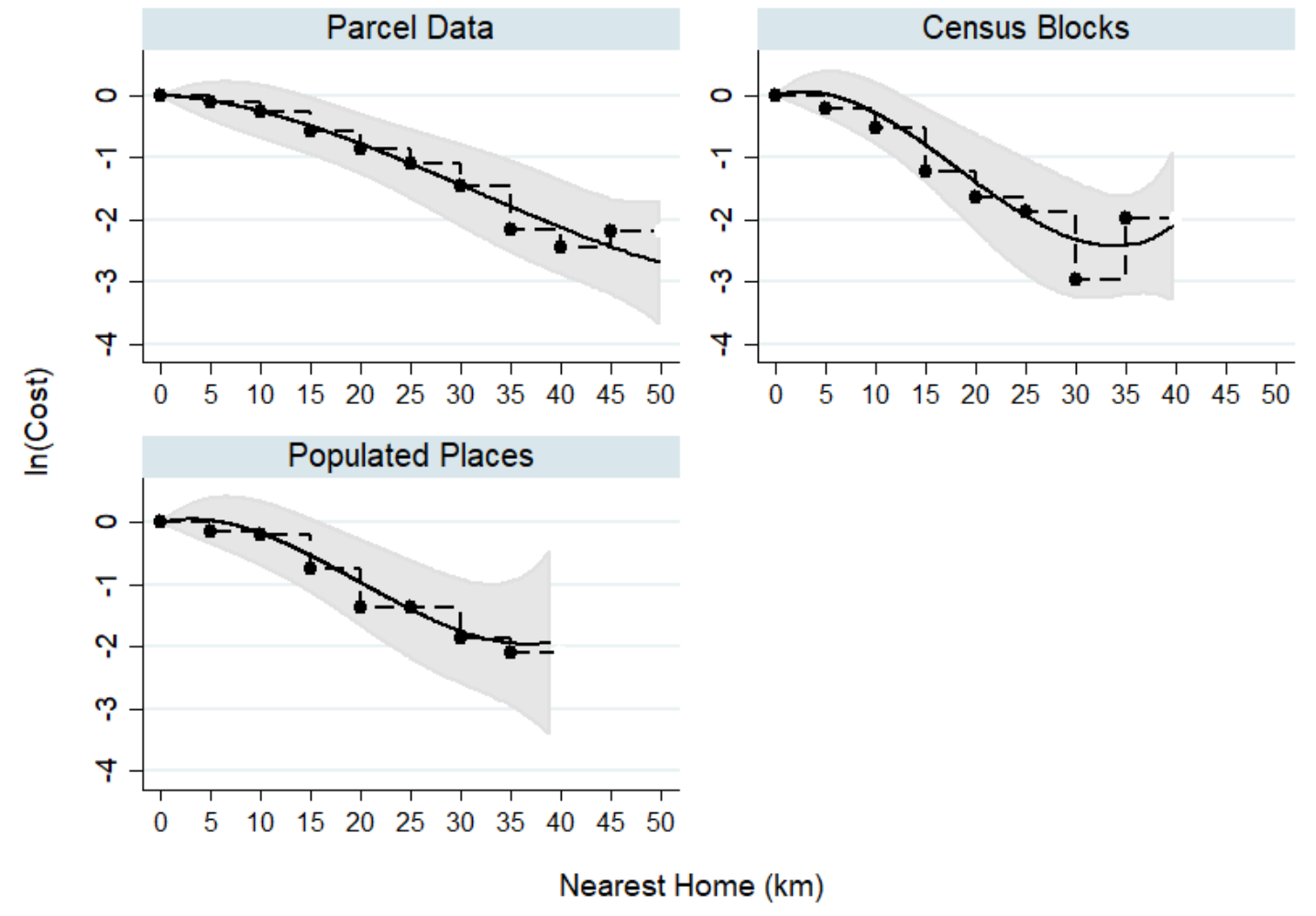

Notes: Each panel estimates the impact of nearest home distance, as measured using three different methods of locating homes, on log suppression cost. "Parcel Data" uses the parcel real estate data with the geocoding and backstop method described in paper. "Census Blocks" uses Census block centroids. "Populated Places" uses the location information given in the Census Populated Places dataset. Each regression includes national forest fixed effects, state by month-of-year fixed effects, and state by year fixed effects. Standard errors are clustered by national forest. 


\section{B.3 Calculating Counterfactual Costs With No Nearby Homes}

For each fire $i$, we use the regression results from Section 4 to calculate $\Delta_{i}$, the increase in firefighting costs relative to what would have been spent on the incident if there were no nearby homes. This section describes that calculation and compares it to an alternative calculation based on a generalized linear model (GLM) approach.

\section{B.3.1 Main Approach}

Our main approach computes $\Delta_{i}$ using the binned model in Section 4.1. Consider a specification with 5 bins, corresponding to $0,10,20,30$, and $40+$ kilometers distance to nearest home, where the omitted category is the $40+$ kilometer bin. Let $\beta_{d}$ represent the regression coefficient on the dummy variable for bin $d$. These coefficients give the increase in log firefighting costs when the nearest home is located $d$ $\mathrm{km}$ away, relative to $40+\mathrm{km}$. The percentage increase in firefighting costs in raw dollars can be calculated as $e^{\beta_{d}-0.5 s}-1$, where $s$ is the sample analog of the variance of $\beta_{d}$ (Halvorsen and Palmquist 1980; Kennedy 1981). In other words, the regression provides an estimate of the average effect of distance to nearest home on firefighting costs. We use these average effect estimates to calculate counterfactual costs in the absence of any homes within $40 \mathrm{~km}$. For homes in bin $d$, letting $c_{i}$ be the observed cost and $\tilde{c_{i}}$ the counterfactual cost, we calculate $\tilde{c_{i}}=\frac{c_{i}}{e^{\beta} d^{-0.5 s}}$. Then $\Delta_{i}$ is $c_{i}-\tilde{c}_{i}$.

\section{B.3.2 Alternative Approaches: GLM and Retransformation}

These counterfactual costs could be computed in other ways. A similar approach with the same OLS semi-log regression is to use the regression coefficients to generate predicted log costs under the counterfactual, and then "re-transform" these predicted values to predictions in dollar units (Duan 1983; Manning et al. 1987; Manning 1998). These counterfactual predicted costs can then be subtracted from predicted costs given the observed distance to home, $\hat{c}_{i}$. In practice, the various retransformation estimators are vulnerable to specification error, especially in the presence of heteroskedasticity (Manning and Mullahy 2001).

A potentially more attractive approach is to use a statistical model that does not require retransformation. Instead of semilog OLS, Manning and Mullahy (2001) recommends the use of a generalized linear model (GLM) with a log link function. Among other advantages, the GLM model generates predicted values in raw dollar units. We implement the GLM approach as a check on the robustness of our main estimates. Following the results of the selection algorithm in Manning and Mullahy (2001), we use a GLM model with a gamma distribution and a log link. ${ }^{45}$ With the GLM approach, $\Delta_{i}$ can be calculated either by using the implied average change in costs in each distance bin (as we did for the OLS estimates), or by directly generating predicted costs given the observed and counterfactual x's. We show results

45. See page 471 in Manning and Mullahy (2001). The resulting value of $\lambda$ is about 2.3. 
for both approaches. Table 9 shows that the average predicted cost differences are similar across approaches. The approach using OLS generates slightly smaller predicted cost differences, implying that the cost differences we use in the main text are conservative.

Appendix Table 9: Counterfactual cost differences

\begin{tabular}{lccc}
\hline \hline \multirow{2}{*}{ Observed distance } & $(1)$ & $(2)$ & $(3)$ \\
& OLS & GLM & GLM \\
\hline \multirow{2}{*}{ Panel A. Average } & Percentage Change in Costs & \\
$10-10$ & 86 & 88 & 88 \\
$20-30$ & 80 & 86 & 86 \\
$30-40$ & 66 & 77 & 77 \\
$40+$ & 30 & 45 & 45 \\
& 0 & 0 & 0 \\
$0-10$ & Panel B. Average Dollar Difference (thousands) & \\
$10-20$ & 4,113 & 4,207 & 4,662 \\
$20-30$ & 2,874 & 3,070 & 3,170 \\
$30-40$ & 1,351 & 1,573 & 1,669 \\
$40+$ & 397 & 599 & 299 \\
& 0 & 0 & 0 \\
\hline
\end{tabular}

Notes: Panel A shows the average percentage decrease in cost for an otherwiseidentical fire with no homes within $40 \mathrm{~km}$. Panel B shows the average difference in expenditures for an otherwise-identical fire with no homes within $40 \mathrm{~km}$ (in thousands of dollars). Column (1) uses the percentage changes implied by the semilog OLS regression coefficients to scale the observed costs. Column (2) uses the percentage changes implied by the GLM regression coefficients to scale the observed costs. Column (3) also uses GLM, but reports the difference in predicted costs using the observed values of the covariates and predicted costs with no homes within $40 \mathrm{~km}$.

\section{Comparison to Forest Service Accounting Data}

Our main analysis makes use of publicly available data on suppression expenditures for US Forest Service Fires. However, Gebert, Calkin, and Yoder (2007) write that the publicly available data on costs are less accurate than official expenditure data recorded in the USFS accounting system. Since the time of their writing, the addition of an accounting code (known as a "P-code") to the FAMWEB data has made this match somewhat more straightforward. 
To check whether the results of our empirical exercise in Section 4.1 are altered by the use of the more accurate accounting data, we submitted a Freedom of Information Act Request to the US Forest Service for the accounting dataset. The dataset we obtained as a result of this processing includes suppression expenditures from 2003-2013 with a limited set of fields. Specifically, it includes the P-code, the amount of suppression expenditures for that code, and the year that those expenditures were billed. The following table summarizes yearly cost for 2004-2012 (2003 and 2013 are partially missing in the accounting dataset) for the FAMWEB data and the accounting dataset we obtain.

Appendix Table 10: Annual costs by suppression cost dataset

\begin{tabular}{lllll} 
Year & FAMWEB & FAMWEB West & WFSU valid & WFSU all \\
\hline 2004 & 247 & 236 & 471 & 679 \\
2005 & 271 & 262 & 440 & 768 \\
2006 & 828 & 799 & 1,142 & 1,355 \\
2007 & 978 & 923 & 977 & 1,263 \\
2008 & 708 & 694 & 1,070 & 1,464 \\
2009 & 401 & 394 & 682 & 840 \\
2010 & 239 & 224 & 373 & 662 \\
2011 & 475 & 436 & 623 & 1,251 \\
2012 & 975 & 952 & 917 & 1,161 \\
\hline Total & 5,122 & 4,920 & 6,695 & 9,442 \\
\hline
\end{tabular}

Notes: All values in millions of dollars. First column includes all incidents in FAMWEB, second column includes only incidents in regions 01-06, third column includes only WFSU incidents with P-codes used for wildfire suppression-related costs. Specifically, the incident code begins with $\mathrm{P}^{*}$, where ${ }^{*}$ is a number for the USFS region, and is followed by a 4 character alphanumeric code beginning with a letter, per USFS specification.

Next, we match the costs in the accounting dataset to the FAMWEB data using the P-code to identify whether the relationship between suppression costs and distance from homes is stable across the use of either source of cost data. We match from the Pcode and year to the suppression expenditure data from FAMWEB. This match is not entirely straightforward: the guidelines over the issuance of P-codes and the proper accounting procedures have changed over the years, and many fires are submitted under the same P-code. In particular, large complex fires are often accounted for using the same P-code. ${ }^{46}$ For the 997 fires in our FAMWEB dataset from 2004-2012,

46. So-called "ABCD" fires, which are small, are also accounted for using a single P-code for each forest-year, but for our purposes this is not an issue since our focus is on incidents with more than 300 burned acres. 
Appendix Figure 11: Comparison of FAMWEB and accounting data: mean suppression costs and distance to nearest home

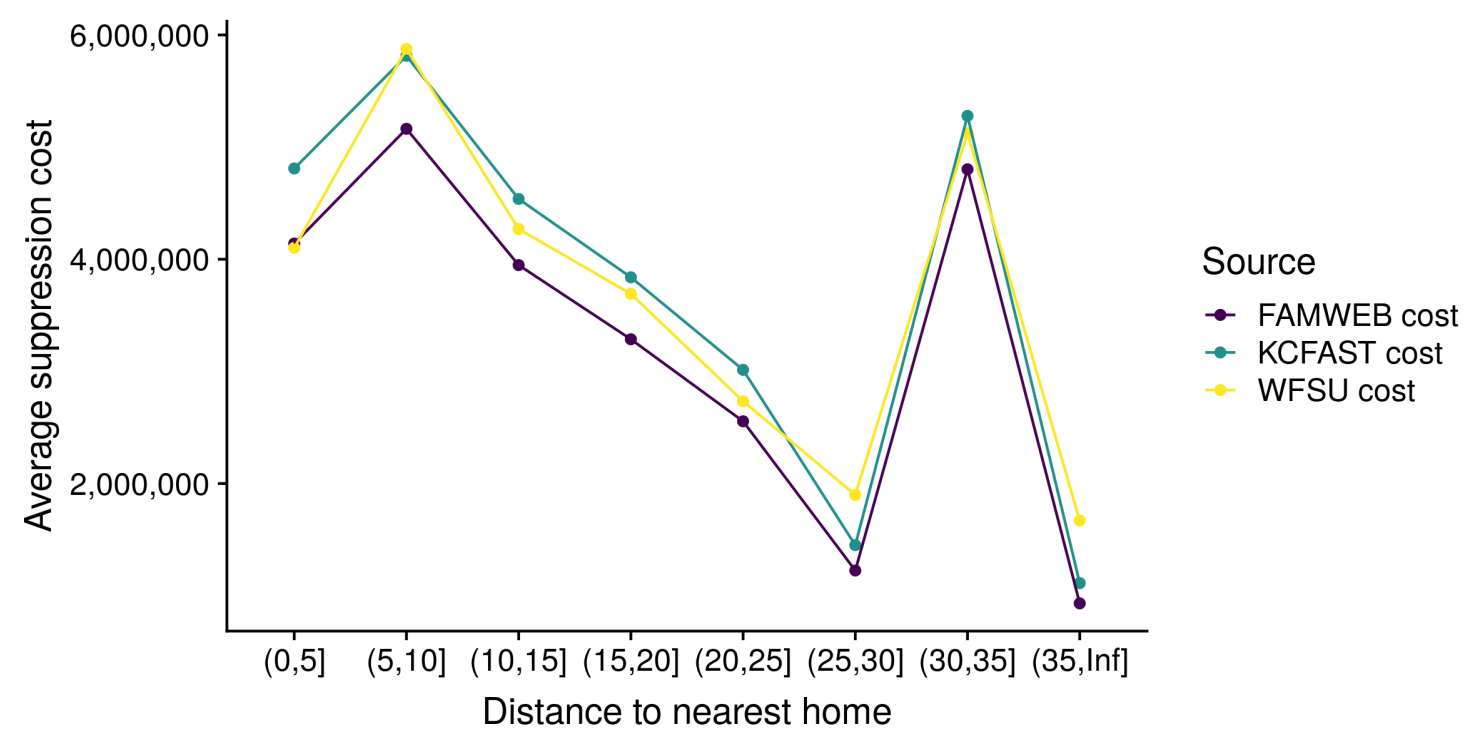

we are able to match 799 of these to the accounting dataset.

We estimate the relationship between fire cost and nearby homes for four sets of costs: A) FAMWEB costs for all fires in FAMWEB, B) FAMWEB costs for all 2004-2012 fires in FAMWEB, C) FAMWEB costs for fires that match to the accounting data, and D) accounting data costs for all fires that match to FAMWEB data. Figures 11 to 14 plot binned averages and sums of costs for each dataset on distance from nearest home and on number of homes within $30 \mathrm{~km}$. Although the sums differ due to the difference in the number of fires included for each set of data, the means have similar patterns. Our conclusions about the usefulness of the FAMWEB data are similar to those of Schuster, Cleaves, and Bell (1997), who wrote at the time that, "One of the purposes for our analysis of per-acre fire expenditures was to assess the quality of suppression expenditure estimates contained in the NIFMID database. These estimates are widely regarded as unreliable. However, the correlation between uncorrected, NIFMID-based expenditures and those from the accounting system is 0.85 , a surprisingly high level." 
Appendix Figure 12: Comparison of FAMWEB and accounting data: mean log suppression costs and distance to nearest home

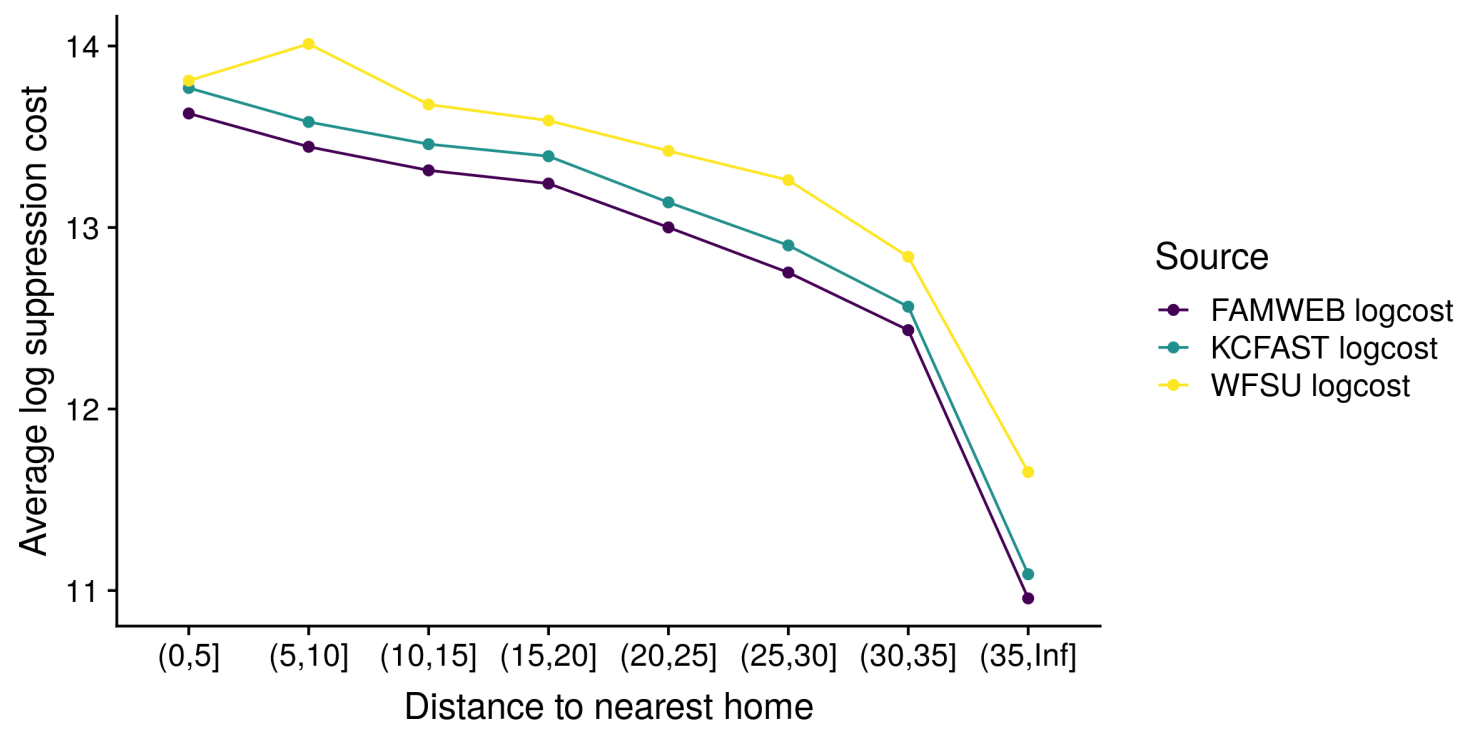

Appendix Figure 13: Comparison of FAMWEB and accounting data: mean suppression costs and number of homes in $30 \mathrm{~km}$

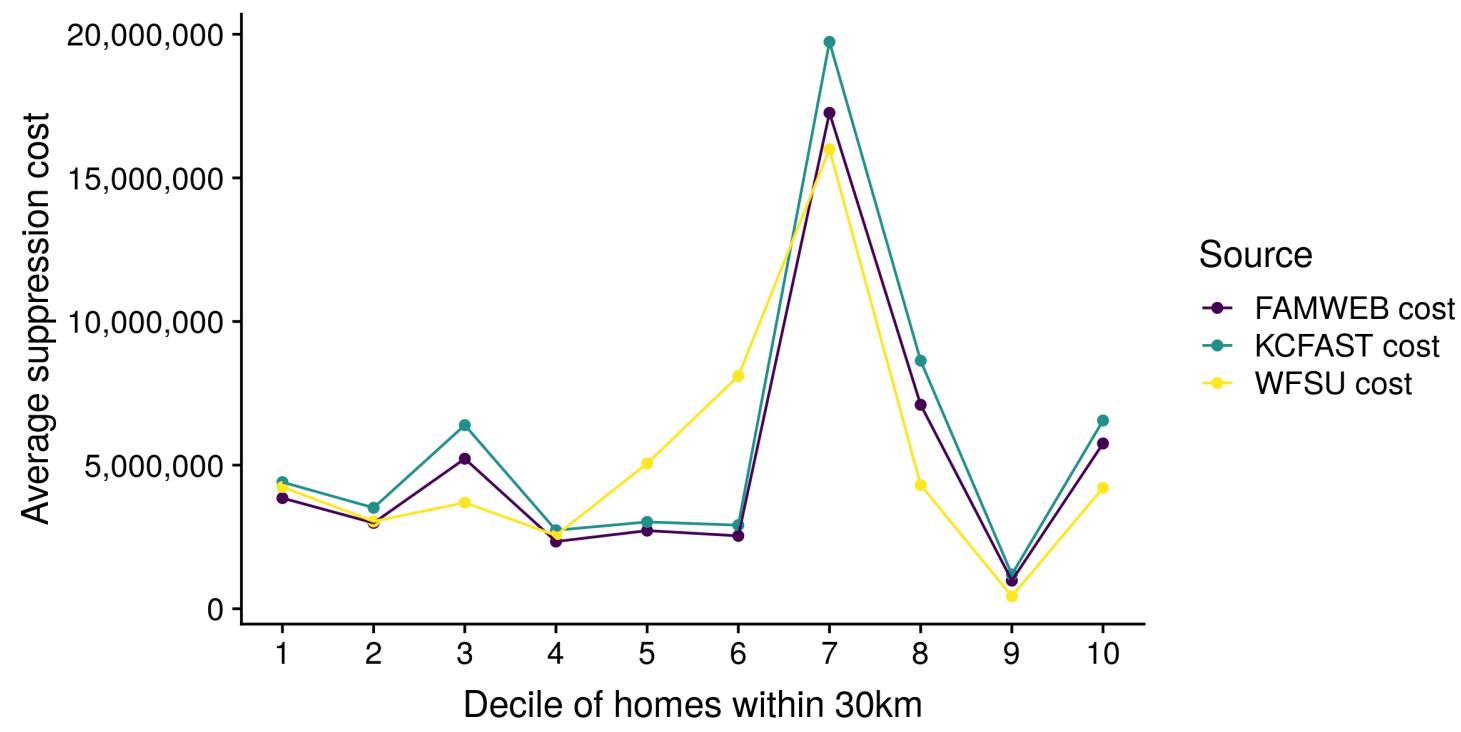


Appendix Figure 14: Comparison of FAMWEB and accounting data: mean log suppression costs and number of homes in $30 \mathrm{~km}$

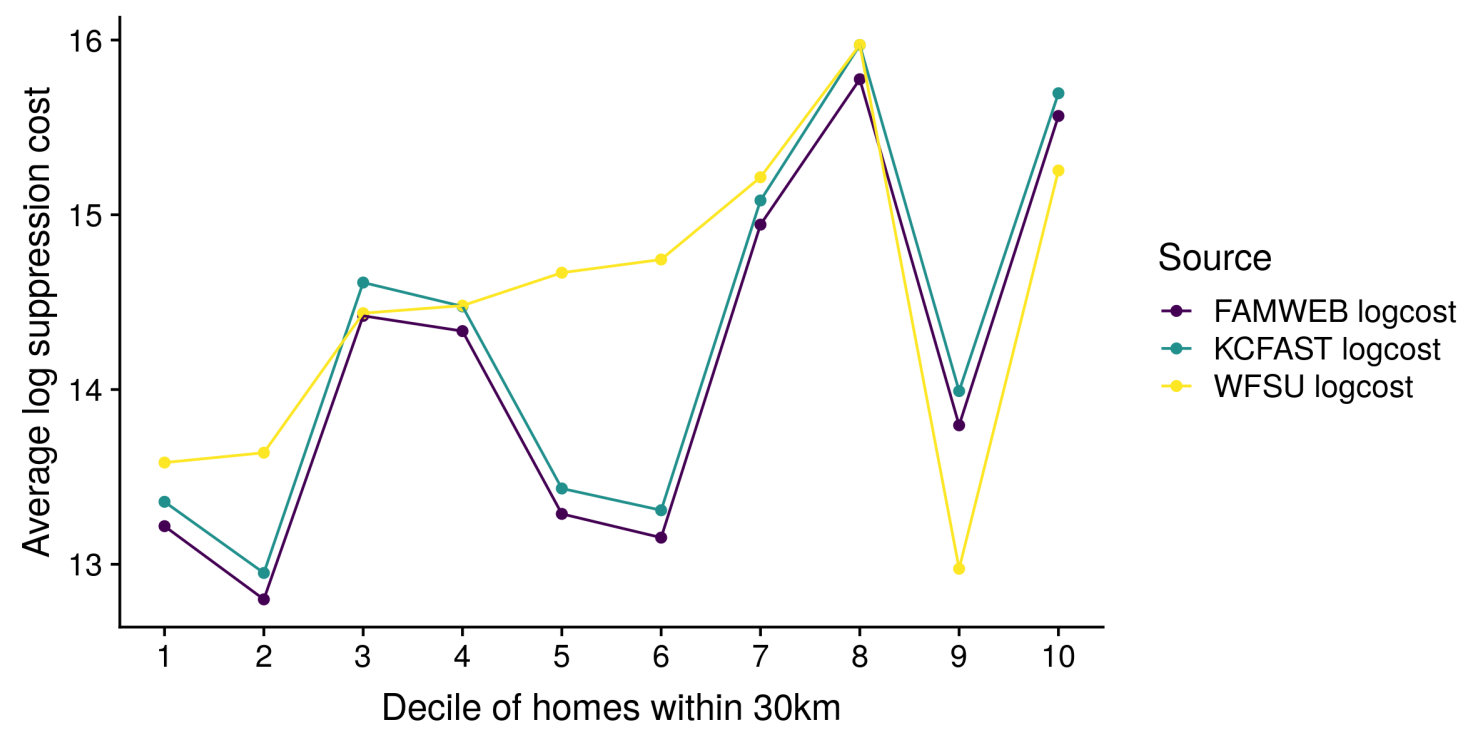

\section{Appendix References}

Altonji, Joseph G., Todd E. Elder, and Christopher R. Taber. 2005. "An Evaluation of Instrumental Variable Strategies for Estimating the Effects of Catholic Schooling." The Journal of Human Resources 40 (4): 791-821.

Angrist, Joshua, and Jorn-Steffen Pischke. 2009. Mostly Harmless Econometrics: An Empiricist's Companion. 1st ed. Princeton University Press.

CIESIN. 2017. Gridded Population of the World, Version 4 (GPWv4): Population Density, Revision 10. Palisades, NY.

Dillon, Gregory K. 2015. Wildfire Hazard Potential for the Coterminous United States. Forest Service Research Data Archive.

Duan, Naihua. 1983. "Smearing Estimate: A Nonparametric Retransformation Method." Journal of the American Statistical Association 78 (383): 605-610.

Gebert, Krista M, David E Calkin, and Jonathan Yoder. 2007. "Estimating Suppression Expenditures for Individual Large Wildland Fires." Western Journal of Applied Forestry 22 (3): 188-196.

Gude, Patricia H., Kingsford Jones, Ray Rasker, and Mark C. Greenwood. 2013. "Evidence for the Effect of Homes on Wildfire Suppression Costs." International Journal of Wildland Fire 22. 
Halvorsen, Robert, and Raymond Palmquist. 1980. "The Interpretation of Dummy Variables in Semilogarithmic Equations." American Economic Review 70 (3): $474-75$.

Kennedy, Peter. 1981. "Estimation with Correctly Interpreted Dummy Variables in Semilogarithmic Equations." American Economic Review 71 (4): 801.

Manning, Willard G. 1998. "The Logged Dependent Variable, Heteroscedasticity, and the Retransformation Problem." Journal of Health Economics 17 (3): 283-295.

Manning, Willard G, and John Mullahy. 2001. "Estimating Log Models: To Transform or Not to Transform?" Journal of Health Economics 20 (4): 461-494.

Manning, Willard G., Joseph P. Newhouse, Naihua Duan, Emmett B. Keeler, and Arleen Leibowitz. 1987. "Health Insurance and the Demand for Medical Care: Evidence from a Randomized Experiment." The American Economic Review 77 (3): $251-277$.

Martinuzzi, Sebastián, Susan Stewart, David Helmers, Miranda Mockrin, Roger Hammer, and Volker Radeloff. 2015. The 2010 Wildland-Urban Interface of the Conterminous United States. Research Map NRS-8. U.S. Department of Agriculture, Forest Service, Northern Research Station.

Oster, Emily. 2019. "Unobservable Selection and Coefficient Stability: Theory and Evidence." Journal of Business $\&$ Economic Statistics 37 (2): 187-204.

Radeloff, Volker, Roger Hammer, Susan Stewart, Jeremy Fried, Sherry Holcomb, and Jason McKeefry. 2005. "The Wildland-Urban Interface in the United States." Ecological Applications 15 (3): 799-805.

Radeloff, Volker, David Helmers, H. Anu Kramer, Miranda Mockrin, Patricia Alexandre, Avi Bar-Massada, Van Butsic, et al. 2018. "Rapid Growth of the US WildlandUrban Interface Raises Wildfire Risk." Proceedings of the National Academy of Sciences 115, no. 13 (March): 3314-3319.

Schuster, Ervin, David Cleaves, and Enoch Bell. 1997. Analysis of USDA Forest Service Fire-Related Expenditures 1970 - 1995. Research Paper PSW-RP-230. USDA Forest Service Pacific Southwest Research Station, March.

USDA (USDA Office of Inspector General). 2006. Forest Service Large Fire Suppression Costs. Audit Report 08601-44-SF. 